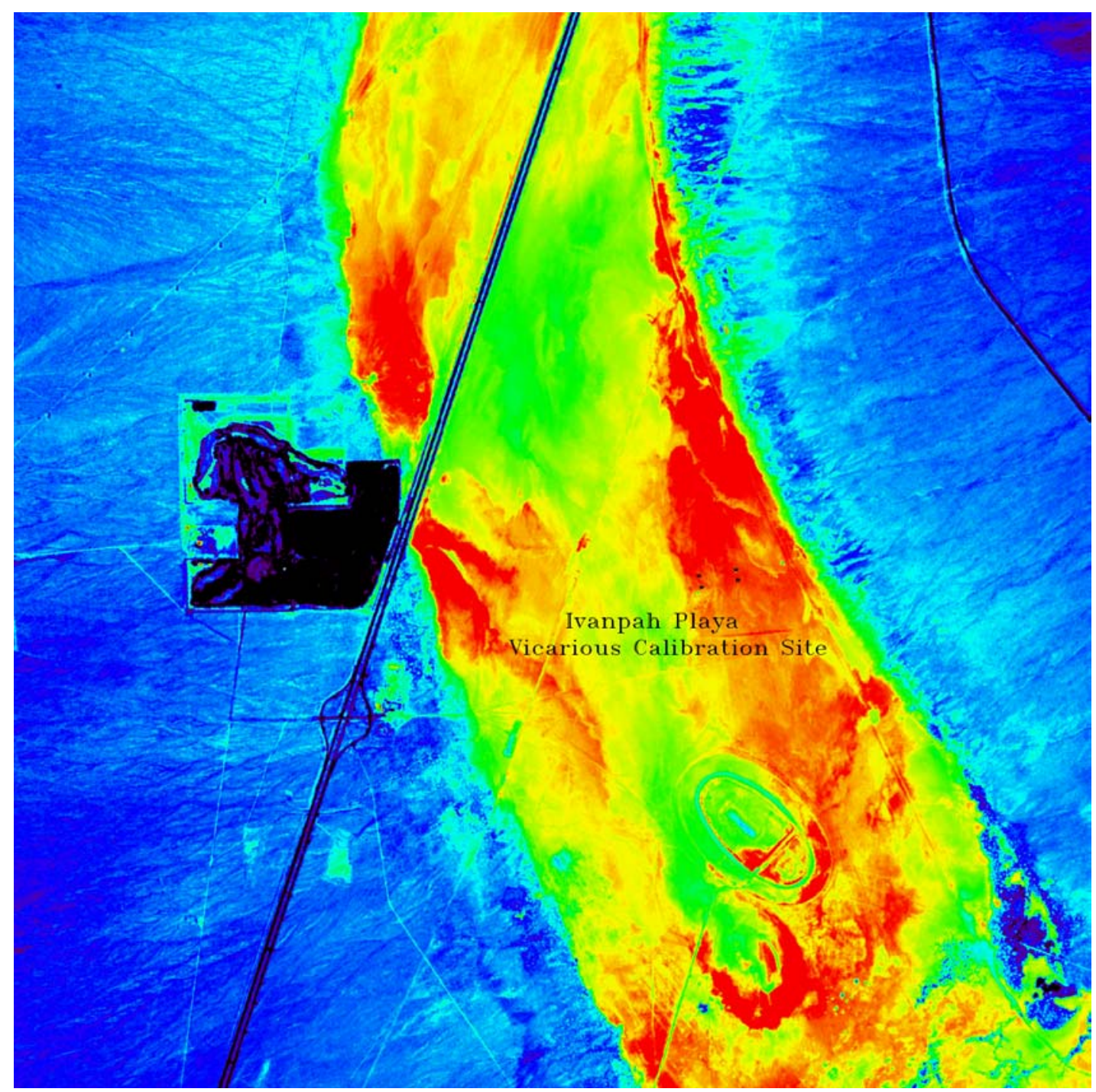

\title{
Final MTI Data Report: Ivanpah Playa (U)
}

Westinghouse Savannah River Company

September 2002 Savannah River Site Aiken, SC 29808 
This document was prepared in conjunction with work accomplished under Contract No. DE-AC09-96SR18500 with the U. S. Department of Energy.

\section{DISCLAIMER}

This report was prepared as an account of work sponsored by an agency of the United States Government. Neither the United States Government nor any agency thereof, nor any of their employees, makes any warranty, express or implied, or assumes any legal liability or responsibility for the accuracy, completeness, or usefulness of any information, apparatus, product or process disclosed, or represents that its use would not infringe privately owned rights. Reference herein to any specific commercial product, process or service by trade name, trademark, manufacturer, or otherwise does not necessarily constitute or imply its endorsement, recommendation, or favoring by the United States Government or any agency thereof. The views and opinions of authors expressed herein do not necessarily state or reflect those of the United States Government or any agency thereof.

This report has been reproduced directly from the best available copy.

Available for sale to the public, in paper, from: U.S. Department of Commerce, National Technical Information Service, 5285 Port Royal Road, Springfield, VA 22161, phone: (800) 553-6847, fax: (703) 605-6900

email: orders@ntis.fedworld.gov

online ordering: http://www.ntis.gov/help/index.asp

Available electronically at http://www.osti.gov/bridge

Available for a processing fee to U.S. Department of Energy and its contractors, in paper, from: U.S. Department of Energy, Office of Scientific and Technical Information, P.O. Box 62, Oak Ridge, TN 37831-0062,

phone: (865)576-8401,

fax: (865)576-5728

email: $\underline{\text { reports@ adonis.osti.gov }}$ 


\title{
Final MTI Data Report: Ivanpah Playa (U)
}

\author{
Prepared by \\ Eliel Villa-Aleman \\ Nonproliferation Technologies Section \\ Savannah River Technology Center \\ Aiken, South Carolina, 29808
}

September 2002 


\section{Table of Contents}

Introduction to Vicarious Calibration of the Multispectral Thermal Imager Satellite at Ivanpah Playa, California

Visible and Near-Infrared Vicarious Calibration Campaign at Ivanpah Playa

Thermal Vicarious Calibration Campaign at Ivanpah Playa

References 


\section{$\underline{\text { List of Figures }}$}

Figure 1.1 Reflectance measurements at Ivanpah Playa with an Analytical

Spectral Devices spectroradiometer.

Figure 1.2 Shows from left to the right a Reagan sun radiometer, an Eppley

Precision Spectro Pyranometer with a shadow band for diffuse solar measurements and Eppley Precision Pyranometer for global solar measurements.

Figure 1.3 Release of helium-filled balloon equipped with a radiosonde for atmospheric measurement (pressure, temperature, and humidity).

Figure 1.4 Preparations of the mobile FTIR prior to the calibration site walk around.

Figure 1.5 Experimental setup for soil surface apparent temperature, air temperature, wind speed and humidity.

Figure 1.6 Best Planck curve fit to the soil surface radiance to calculate soil surface temperature.

Figure 1.7 Emissivity curves at Ivanpah Playa.

Figure 1.8 Typical soil surface picture on the left and typical infrared image on 8 the right side.

Figure 1.9 Camera holder assembly and the Bell helicopter used during our aerial 9 campaigns.

Figure 1.10 Landsat image of White Sands Missile Range test site in New Mexico. 10

Figure 1.11 Reflectance spectra at White Sands and Ivanpah Playa calibration 11 sites.

Figure 1.12 MTI image of Ivanpah Playa with the band C (red, 0.62-0.68 $\mu \mathrm{m}$ ). Highway 15 and golf course to the left is visible in the image.

Figure 2.1 MTI image of Ivanpah Playa. The corners of the calibration site are marked with stars for easier identification.

Figure 2.2 Amplified image of the calibration site.

Figure 2.3 Atmospheric transmission at 440nm during the overpass of the satellite. 
Figure 2.4 Atmospheric transmission at 870nm during the overpass of the satellite.

Figure 2.5 Non-molecular optical depth at the one-hour period about the MTI overpass.

Figure 2.6 Aerosol optical depth at 550nm derived from inversion for theonehour period about the MTI overpass.

Figure 2.7 Derived Junge parameter from aerosol inversion for the one-hour period about the MTI overpass.

Figure 2.8 Columnar water vapor for the one-hour period about the MTI overpass.

Figure 2.9 Columnar ozone for the one-hour period about the MTI overpass.

Figure 2.10 Surface reflectance retrieved for the test site. Shown on second axis with dotted line is percent standard deviation of average.

Figure 2.11 Percent difference between nadier-viewing reflectance of westernmost 24 pixels on September 15 and September 16.

Figure 2.12 A comparison of nadir-viewing reflectance retrieved on September 16. 22 Solid line indicates percent difference between results from RSG ASDs 687 and 614. Dotted line indicated percent difference between RSG 687 and the results from the SRTC ASD.

Figure 2.13 A comparison of nadir and off-nadir measurements with ASD 687 on September 15.

Figure 2.14 The percent difference between nadir-viewing reflectance for full site to those of the westernmost 24 pixels as measured by the ASD 614 on September 16.

Figure 2.15 A mosaic image of the reflectance distribution at the September calibration site $(280 \mathrm{~m} \times 80 \mathrm{~m})$.

Figure 2.16 The satellite image of the September calibration site $(280 \mathrm{~m} \times 80 \mathrm{~m})$.

Figure 2.17 Reflectance variability along the calibration site. 
Figure 2.18 The corresponding reflectance data transect obtained from the MTI 24 satellite image.

Figure 2.19 The at-sensor radiances predicted for the nadir-view of MTI on September 15.

Figure 2.20 The at-sensor radiances for off-nadir view of MTI as well as percent difference between nadir and off-nadir views.

Figure 2.21 The close agreement between the ground reflectance measurements and the MTI calculated reflectance at the bottom of the atmosphere.

Figure 2.22 One of the experimental areas at Ivanpah Playa. Tarps for the MTI 28 resolution studies are shown in the image, next to a variety of instruments for atmospheric measurements.

Figure 2.23 MTI image of the blue tarps separated by 5, 10, and 25 meters. The 5- 29 meter separation is difficult to distinguish from the image.

Figure 3.1 MTI image (band C) of Ivanpah Playa. The corners of the calibration 31 site are marked with stars for easier identification.

Figure 3.2 The mobile FTIR cart for surface temperature and emissivity measurements.

Figure 3.3 Path taken with the mobile FTIR over the calibration site with $280 \mathrm{~m} \mathrm{x}$ 80m dimensions.

Figure 3.4a Planckian curves for two blackbodies at 329.7 and 316.4K, respectively, the sky radiance and the soil radiance.

Figure 3.4b Best blackbody fit to the experimental soil radiance and the temperatures calculated by using only part of the experimental curve.

Figure 3.5 The average calculated emissivity of Ivanpah Playa soil with and without the sky correction in the September 2000 campaign.

Figure 3.6a The best blackbody Planckian fit to the experimental soil curve and the temperatures calculated by using only part of the experimental curve.

Figure 3.6b The minimum, maximum, and average emissivity at Ivanpah Playa on May 2001 with emissivity spectrum from September 16, 2000. 
Figure 3.6c The emissivity calculated for the nadir and 8.6, 18.6, 28.8 and 39.2 38 degrees off nadir angles.

Figure 3.7a Time-dependent soil surface and air temperatures. The top curve 38 shows the air temperature. The soil temperature is represented by the lower changing curve.

Figure 3.7b Cooling of the soil surface with the wind.

Figure 3.7c Close relashionship between the air temperature and wind speed.

Figure 3.7d The interdependence between the soil and air temperatures.

Figure 3.8 Up-close infrared image of Ivanpah Playa surface (1 meter distance).

Figure 3.9 Up-close infrared image of Ivanpah Playa surface (1 meter distance) with an aluminum cone.

Figure 3.10 An infrared image of the calibration site with a tarp located in the southeast location form a 600-meter elevation.

Figure 3.11 The apparent temperature distribution in selected area marked in Figure 3.10.

Figure 3.12a The thermal imprint left behind on the ground after the removal of a 5' x 3' aluminized Mylar tarp.

Figure 3.12b The time dependence temperature of the soil after the removal of the aluminized Mylar tarp.

Figure 3.13 Visible picture of the 50m x 50m aluminized Mylar tarp.

Figure 3.14 An aerial overview of a 25m x 25m aluminized Mylar tarp deployed on September 16, 2000.

Figure 3.15 Twenty-meter ground resolution distance (GRD) thermal MTI satellite image of Ivanpah Playa (band N). From left to the right direction are magnifications of the calibration site at the playa. The position of the $25 \mathrm{~m}$ x $25 \mathrm{~m}$ "cold" aluminized Mylar tarp in the image is evident.

Figure 3.16 Band C TOA radiance of Ivanpah Playa. 
Figure 3.18 Band M TOA radiance of Ivanpah Playa. 46

Figure 3.19 Band L TOA radiance of Ivanpah Playa. 46

Figure 3.20 Band K TOA radiance of Ivanpah Playa. $\quad 47$

Figure 3.21 Band J TOA radiance of Ivanpah Playa. 47

Figure 3.22 Ivanpah Playa and the selected region for analysis using 2-d scatter 47 region analysis tool. The area of the rectangle is $1.7 \mathrm{~km}$ wide by $1.9 \mathrm{~km}$ height.

Figure 3.23 A scatter plot of band N TOA radiance versus band C reflectance. 47

Figure 3.24 A scatter plot of band M TOA radiance versus band C reflectance. $\quad 48$

Figure 3.25 A scatter plot of band L TOA radiance versus band C reflectance. 48

Figure 3.26 A scatter plot of band K TOA radiance versus band C reflectance. 49

Figure 3.27 A scatter plot of band J TOA radiance versus band C reflectance. 49

Figure 3.28 Band M versus band L 2-d scatter plot. 49

Figure 3.29 Band N versus band K 2-d scatter plot. 50

Figure 3.30 Band N versus band K 2-d scatter plot. $\quad 50$

Figure 3.31 The multi-year location of the calibration sites at Ivanpah Playa on 50 the September image.

Figure 3.32 Different emissivities measured at Ivanpah Playa during our campaigns.

Figure 3.33 The emissivities measured on July 2000 and May 2001 campaigns.

The locations of the N, M, and L bands are shown for clarification. The shape of the bands was selected as a better indicator of the location.

Figure 3.34 The emissivities measured during our July 2000 and May 2001 campaigns, the location of the MTI bands and the quartz-like spectral feature. 
Figure 3.35 The quartz emissivity spectrum acquired at Ivanpah Playa from the removal of the May 2001 emissivity from the July 2000 emissivity. The quartz relative emissivity spectrum from a commercially available library is shown in the figure for comparison.

Figure 3.36 The location of the calibration site during the September 2000 campaign. The image is a temperature image calculated using band $\mathrm{N}$ with an emissivity of 0.93 .

Figure 3.37 September 2000 campaign band K emissivity image.

Figure 3.38 September 2000 campaign band L emissivity image.

Figure 3.39 September 2000 campaign band M emissivity image.

Figure 3.40 September 2000 campaign band K emissivity image of the calibration 54 site.

Figure 3.41 September 2000 campaign band L emissivity image of the calibration 54 site.

Figure 3.42 September 2000 campaign band M emissivity image of the calibration site.

Figure 3.43 May 2001 campaign band K emissivity image.

Figure 3.44 May 2001 campaign band L emissivity image.

Figure 3.45 May 2001 campaign band M emissivity image.

Figure 3.46 May 2001 campaign band K emissivity image of the calibration site. 56

Figure 3.47 May 2001 campaign band L emissivity image of the calibration site. 56

Figure 3.48 May 2001 campaign band M emissivity image of the calibration site. 56

Figure 3.49 March 2002 campaign band K emissivity image. 57

Figure 3.50 March 2002 campaign band L emissivity image. 57

Figure 3.51 March 2002 campaign band M emissivity image. 57 


\section{List of Tables}

Table 1.1 Band and wavelength designations 5

Table 1.2 Reflectance-based method error sources, with reference to solar exo- 12 atmospheric irradiance. The values are quoted as one-sigma percentages.

Table 2.1 Non-molecular optical depths for all nine non-absorbing bands of automated solar radiometer.

Table 2.2 Estimates of at-sensor radiance uncertainties due to uncertainties in parameters given.

Table 3.1 Emissivity values in the scatter region analysis in figure 3.22 for the 55 September campaign. An emissivity of 0.93 was selected for band N.

Table 3.2 Emissivity values in the scatter region analysis in figure 3.22 for the 56 May campaign. An emissivity of 0.93 was selected for band $\mathrm{N}$. 


\section{Introduction to Vicarious Calibration of the Multispectral Thermal Imager Satellite at Ivanpah Playa, California}




\begin{abstract}
The Savannah River Technology Center (SRTC) conducted four reflectance and thermal vicarious calibrations for the MTI satellite at Ivanpah Playa, California since July 2000. The vicarious reflectance campaigns held on July and September 2000 were a joint effort between SRTC and the Remote Sensing Group (RSG) of the University of Arizona. The campaign conducted on May 2001 at Ivanpah Playa and Roach Lake was a joint effort between SRTC and Los Alamos National Laboratory (LANL). An additional campaign was conducted on March 2002. The results presented here are a summary of our reflectance and thermal campaigns and interpretation of the satellite imagery. Particular attention was given to the in-depth September 2000 campaign. Analysis of the September 2000 MTI imagery shows close agreement between the ground truth data measured at Ivanpah Playa by SRTC and RSG and the reflectance measured by the MTI satellite.
\end{abstract}

Key Words: MTI Satellite, Ivanpah Playa, Vicarious Calibration 


\section{Introduction}

SRTC conducted vicarious calibration of the MTI satellite at Ivanpah Playa, CA. The primary activities and emphasis of the ground truth work at the playa was to measure surface reflectance, optical atmospheric transmission, global and diffuse solar radiation, and atmospheric profiles of temperature, humidity, pressure for subsequent use in the vicarious calibration of the satellite. Additional experiments were conducted at Ivanpah Playa to support ground spatial resolution, surface emissivity and temperature. Several methods for satellite vicarious calibration were considered to determine top of the atmosphere radiances (TOA). The information presented in this report provides a look at the activities and some of the results obtained from these campaigns. A summary of the work conducted by Kurt Thome from the University of Arizona in support of the MTI vicarious calibration program is included in this work.

Vicarious calibration of the MTI satellite can be accomplished using 1) reflectance-based, 2) irradiance based, and 3) radiance-based methods. These methods can be used to predict the incident radiances at the MTI sensor by applying a radiative transfer code to the results obtained on ground-based data collection of a selected test site that is imaged by MTI. The reflectance-based method was the method of choice for the vicarious calibrations of the visible and near-infrared bands of the MTI satellite.

\section{Reflectance-based method}

The reflectance-based approach relies on ground-based surface reflectance measurements of a selected target at the time of sensor overpass. The reflectance method can be used to calibrate the visible through the near-infrared bands of the MTI satellite. The surface reflectance of a small area at the playa is found by comparing radiometer measurements of the calibration site surface to those from a diffusely reflecting panel of known calibrated reflectance. The calibration reference is a directional-to-hemispheric reflectance standard provided by NIST. Polynomial fits are made to the measured data to calculate the reflectance of the field standard for the sun-view geometry and wavelengths for a given set of field measurements.

The upwelling radiance across the spectral range between 350 and $2500 \mathrm{~nm}$ is measured by a spectroradiometer transported across the calibration site. The primary instrument for the surfacereflectance collection is the Analytical Spectral Devices FieldSpec FR (Figure 1.1) that gives a 1.4-nm spectral resolution from 350 to $1000 \mathrm{~nm}$ and $10-\mathrm{nm}$ resolution for the $1000 \mathrm{~nm}$ to $2500 \mathrm{~nm}$ spectral range.

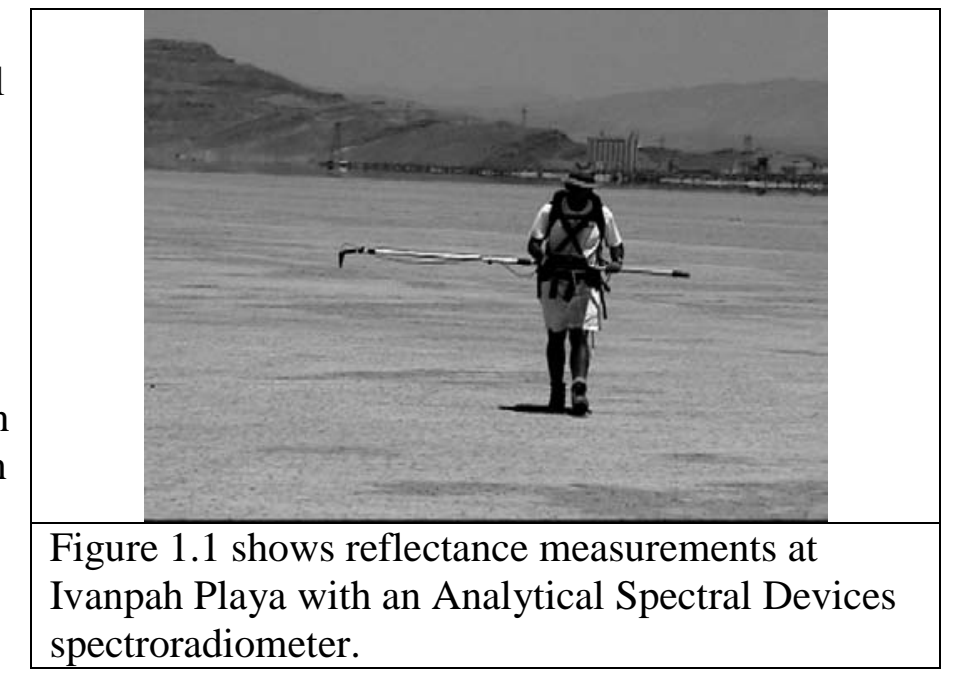

The spectroradiometer collects a number of samples along a straight-line path within some fraction of the area representing an MTI pixel. Reflectance of the site is determined 
in each spectral channel by comparing measurements of the site to those of the calibrated panel and averaging all of the measurements. Sun-angle changes and the bi-directional reflectance of the reflectance panel are taken into account when determining the reflectance. Global irradiance data are used to determine the significance of changes in diffuse skylight illumination.

The primary instrument used to characterize the atmosphere over the site is the solar radiometer. The solar radiometers are relatively calibrated immediately prior to, during, or after each field campaign. Data are used in a Langley method retrieval scheme to determine spectral-atmospheric optical depths. The optical depth results are used as part of an inversion scheme to determine ozone optical depth and a Junge aerosol size distribution parameter. The size distribution and columnar ozone are used to determine the optical depths at $1-\mathrm{nm}$ intervals from 350 to 2500 nm. Columnar water vapor is derived using a modified Langley approach. The retrieved columnar water vapor is used as an input to MODTRAN to

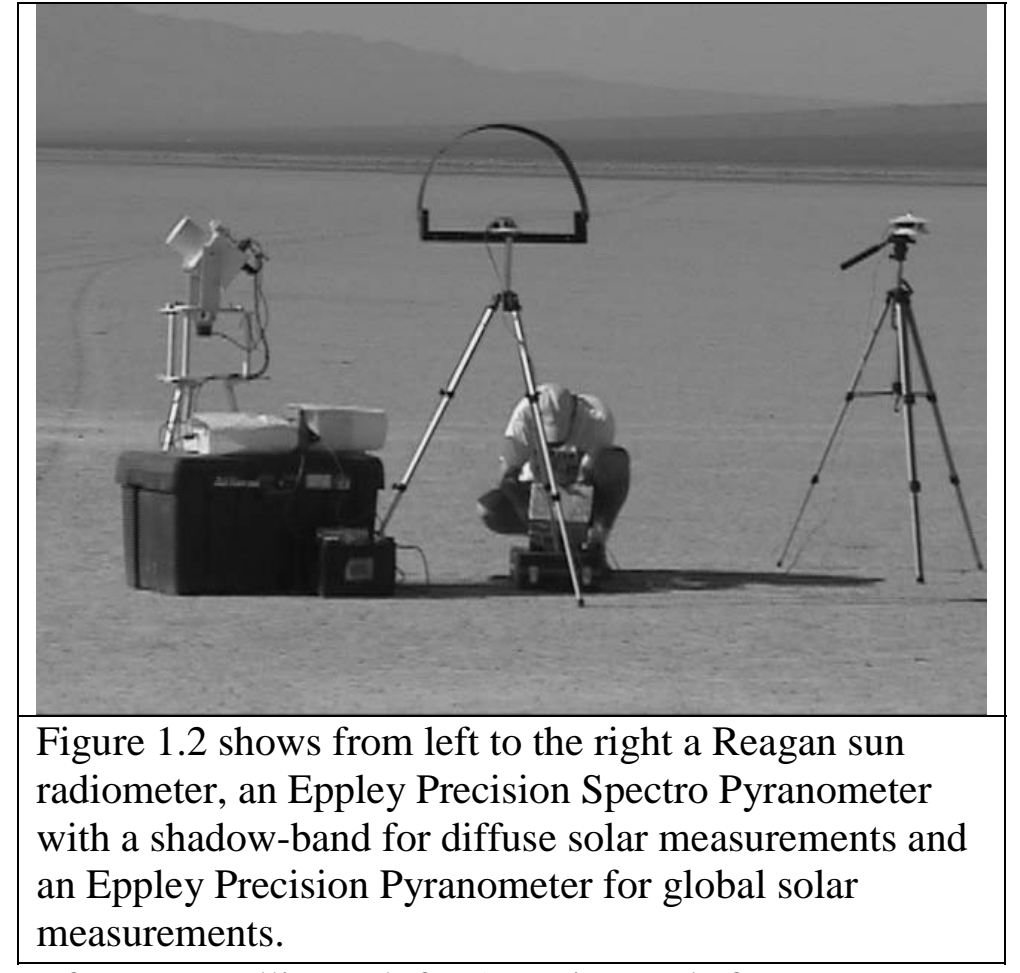
determine transmittance for the sun-to-surface-to-satellite path for 1-nm intervals from 350 to $2500 \mathrm{~nm}$. Figure 1.2 shows the Reagan sun radiometer, and the Eppley Precision Pyranometers for diffuse and global sun radiance measurements.

The hyperspectral data in conjunction with the radiative transfer code are used to predict top-of-the-atmosphere radiances with reflectance-based calibrations. The radiometric calibrations are obtained with the average of the digital numbers of the selected site as reported by the sensor to the predicted radiances from the reflectance-based calibrations. 


\section{MTI Thermal Measurements}

The MTI satellite has five thermal bands in the short-wave and longwave infrared regions. The thermal bands are designated as J, K, L, M, and $\mathrm{N}$. Band $\mathrm{J}$ is affected by contributions from solar reflection and is used in calibrations during nighttime imaging. Calibration of the thermal bands is primarily accomplished with water targets such as the ocean targets, natural lakes and power plant heated lakes. Calibration campaigns consist of measuring surface and bulk water temperatures at different depths, air temperature, humidity, and wind speed. Surface temperatures are measured with calibrated point and imaging radiometers. Field calibration of the radiometer is accomplished by measuring the surface temperature of bulk water (10" or deeper) from a fountain generator device with the radiometer and a NIST calibrated standard thermometer. Ponds at the nearby golf course from Ivanpah Playa were used in temperature retrievals.

During the vicarious calibration campaigns, balloons equipped with radiosonde are released to measure atmospheric profiles of pressure, temperature and humidity. Figure 1.3 shows the release of a helium-

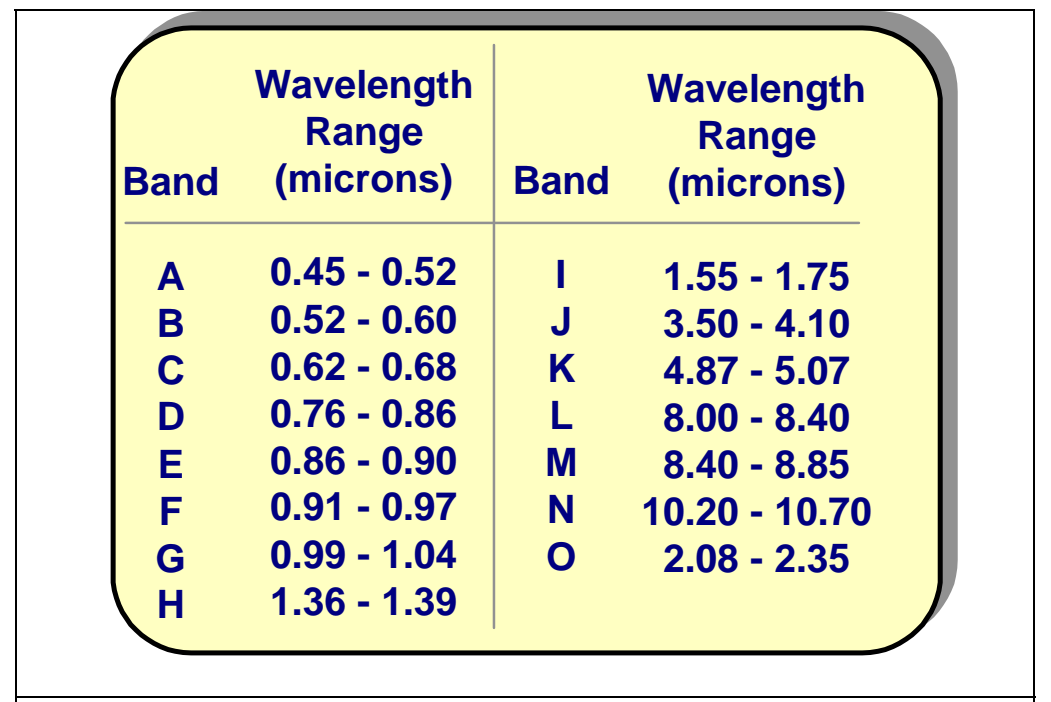

Table 1.1 shows the bands and wavelength designations.

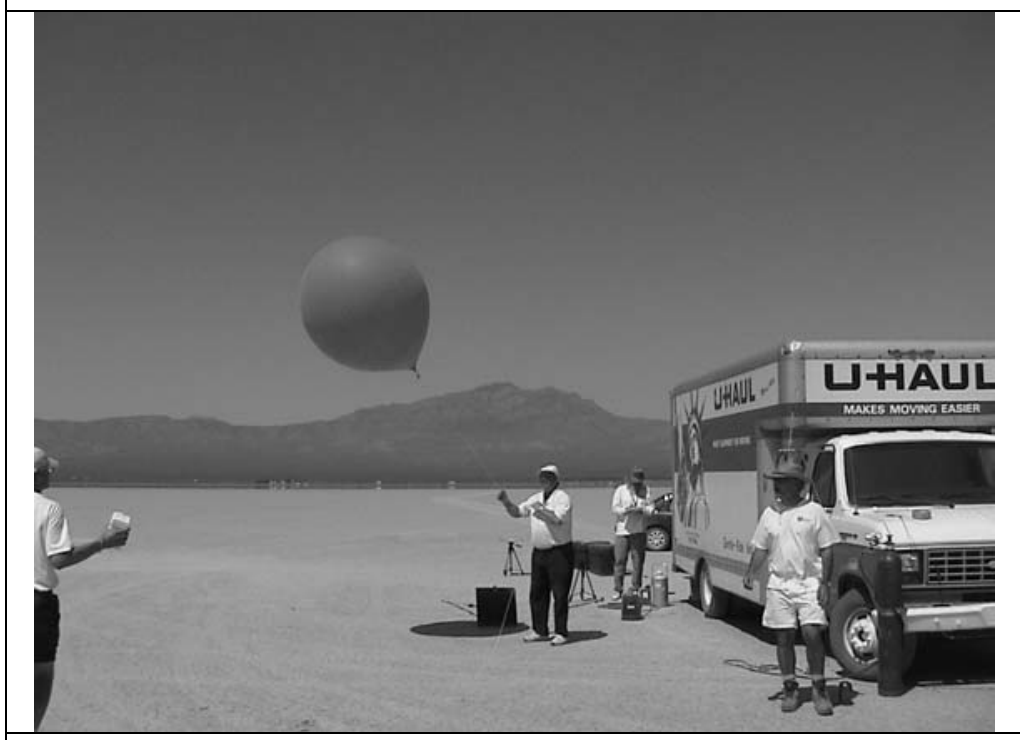

Figure 1.3 shows the release of a helium-filled balloon equipped with a radiosonde for atmospheric elevation profile measurements (pressure, temperature, and humidity).

filled balloon equipped with a radiosonde at Ivanpah Playa.

Thermal calibration campaigns on land targets are conducted with instruments capable to measure wavelength dependent radiance and apparent surface temperature. The primary instrument to measure wavelength dependent radiance from the soil surface at Ivanpah Playa is a Fourier transform infrared spectrometer (FTIR). The FTIR model \# M2400 manufactured by Midac Corporation was used in our surface measurements. The FTIR 
uses a robust Michelson interferometer design. The FTIR was modified in our laboratory to fit in a mobile cart for playa surface radiance measurements. The spectrometer has a $3.8 \mathrm{~cm}$ aperture diameter with a 40 milliradians field of view (FOV). The spectrometer is equipped with mercury cadmium telluride (MCT) detector cooled with liquid nitrogen to $77 \mathrm{~K}$. An insulated jacket and heating blankets housing is used to maintain the FTIR spectrometer at 50C. The FTIR spectrometer temperature is maintained within $0.2 \mathrm{C}$ of the selected temperature with the aid of a temperature controller.

The FTIR spectrometer is attached to a jack with bolts through a rubber-insulating mat for mechanical vibration reduction control. The FTIR spectrometer/jack combo is attached to a garden cart as shown in Figure 1.4. The FTIR spectrometer window entrance is set to approximately 21 " from the soil surface. A platform with a steering beam mirror made out of stainless steel rods is attached to the FTIR spectrometer front surface. The gold-coated mirror is placed at 45 degrees for nadir measurements steered the soil radiance into the spectrometer. The mirror is also adjusted appropriately for offnadir measurements. Figure 1.4 shows the FTIR spectrometer, blackbodies, battery, power inverter and computer assembled in the cart.

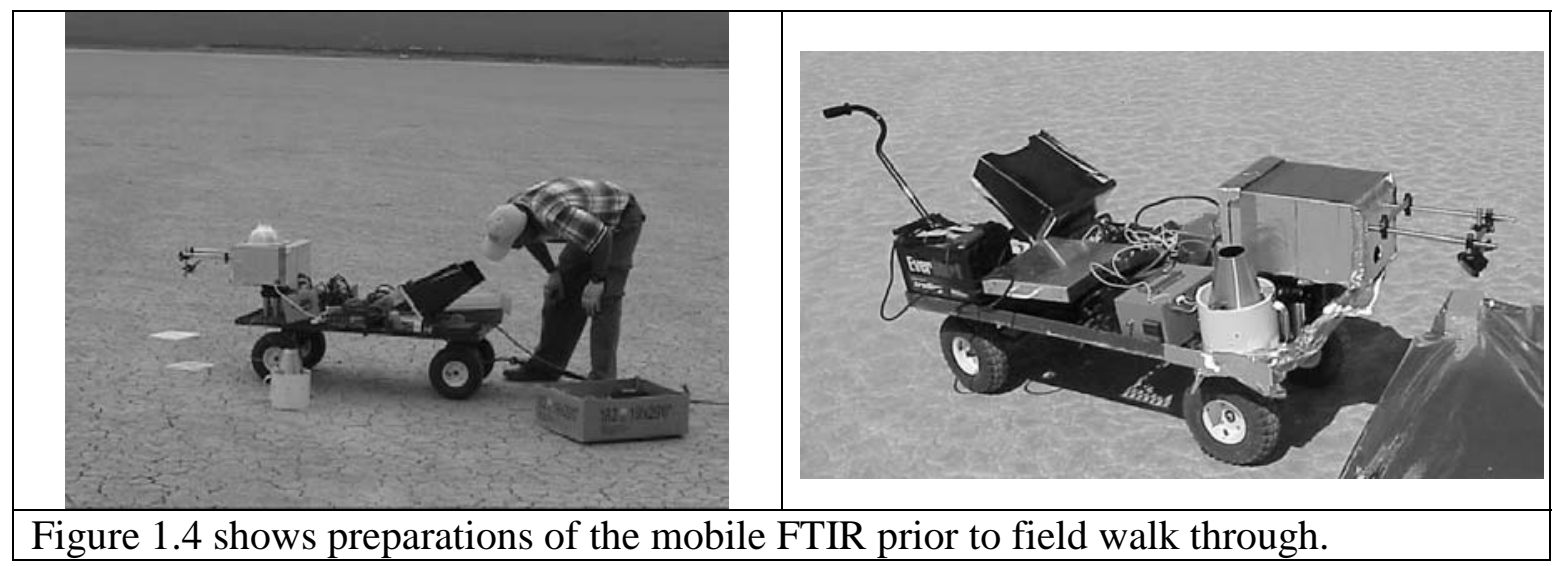

Field calibration of the FTIR spectrometer is accomplished through the use of two blackbodies held at two temperatures. The temperature of the hot blackbody is set approximately $10 \mathrm{C}$ above the soil surface with the aid of a temperature controller. The air temperature (30-40C) primarily determines the temperature of the cold blackbody. Two hundred fifty six spectra are co-added during the blackbody and sky background measurements. The sky background is measured with a diffuse infragold-coated plate manufactured by Labsphere. The temperature of the infragold-coated plate and the blackbodies are monitored with thermistor probe manufactured by Omega with $0.02 \mathrm{C}$ accuracy. The soil target radiance is measured by collecting spectra every 2 seconds in our calibration area. Approximately 20 minutes worth of data is acquired during the 15 passes at the calibration site measuring $80 \mathrm{~m} \times 280 \mathrm{~m}$.

Accurate calibration of the satellite requires soil surface emissivity and temperature measurements. The emissivity is an intrinsic property of the particular soil surface. Inhomogeneous soil surface with variable emissivity results in variable soil surface temperature. The emissivity/temperature surface homogeneity is studied using the FTIR 
spectrometer and an infrared camera (Inframetrics SC2000). Variable wind speed and air temperature can induce temperature variability at the soil surface. The effects of the air temperature, and the wind speed are studied using an experimental setup equipped with a Heimann radiometer $(8-14 \mu \mathrm{m})$, an anemometer, and sensors for air temperature and relative humidity measurements. Figure 1.5 shows the experimental setup for soil surface temperature, air temperature, wind speed and humidity.

Surface apparent temperature is measured with an 8-14 micron bandwidth Heimann radiometer model KT19 manufactured by Heitronics and calibrated in the laboratory to within $0.2 \mathrm{C}$. The radiometer is positioned approximately 1 meter above the soil surface. Humidity and wind speeds are measured with a Vaisali50Y and Met One anemometer respectively. A data logger (Campbell 21X) is used to store the experimental data from the multiple sensors from the wind/temperature tower. Two duplicate towers are placed at the southeast and northwest corners of the calibration site.

The average soil temperature is calculated from the best fit of the

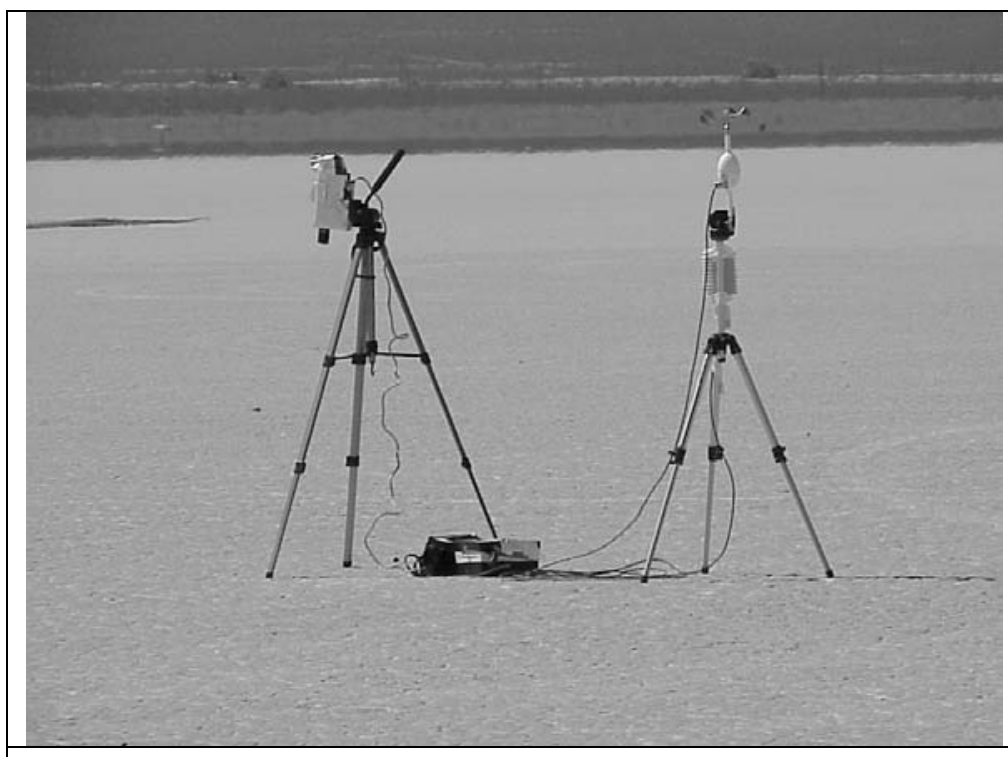

Figure 1.5 shows the experimental setup for soil surface apparent temperature, air temperature, wind speed and humidity. calibrated soil in the $14-15 \mu \mathrm{m}$ region. Figure 1.6 shows a typical Planckian best fit to the radiance measured from Ivanpah Playa.

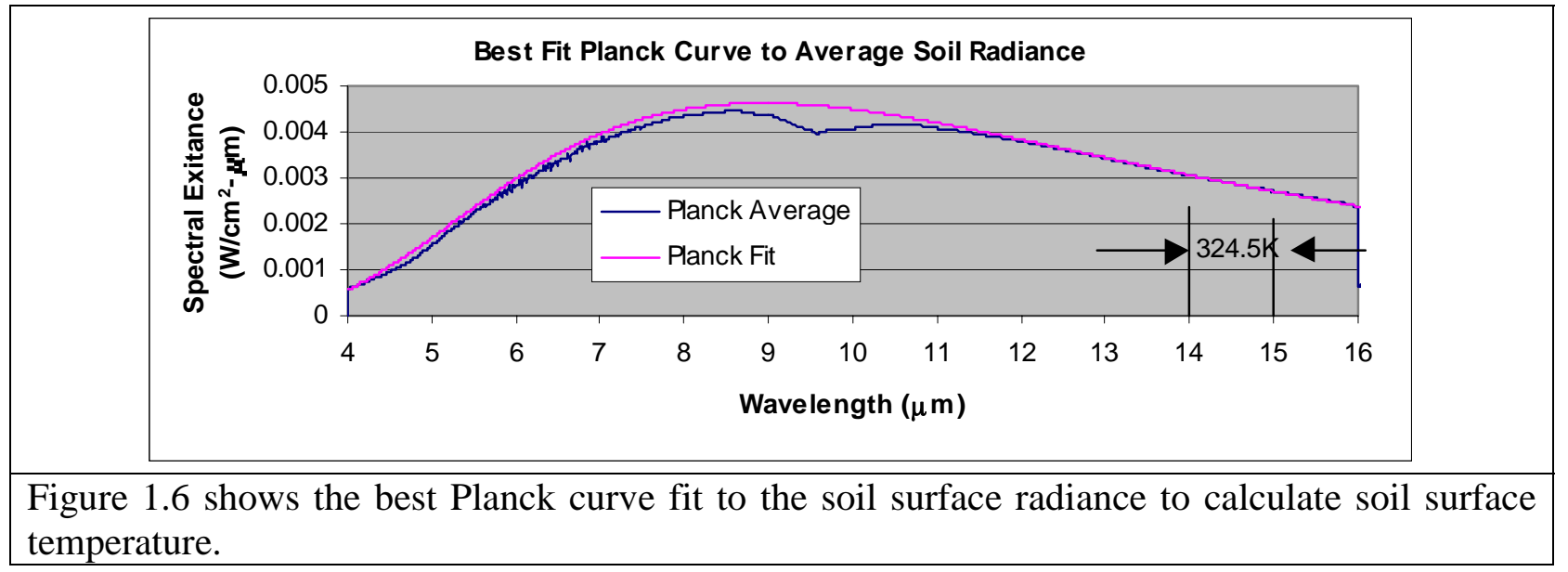

Once the best fit Planckian curve has been calculated, the average soil emissivity can be calculated from equation 1 as shown below where $L_{\text {soil }}$ is the radiance from the soil 
surface, $\mathrm{L}_{\text {sky }}$ is the background radiance and $\mathrm{L}_{\text {soil_bb }}$ is the radiance of a blackbody at the soil temperature. Figure 1.7 shows typical emissivity curve measure at Ivanpah Playa.

$$
\varepsilon=\frac{\left(L_{S o i l}-L_{S k y}\right)}{\left(L_{\text {Soil_BB }}-L_{S k y}\right)}
$$

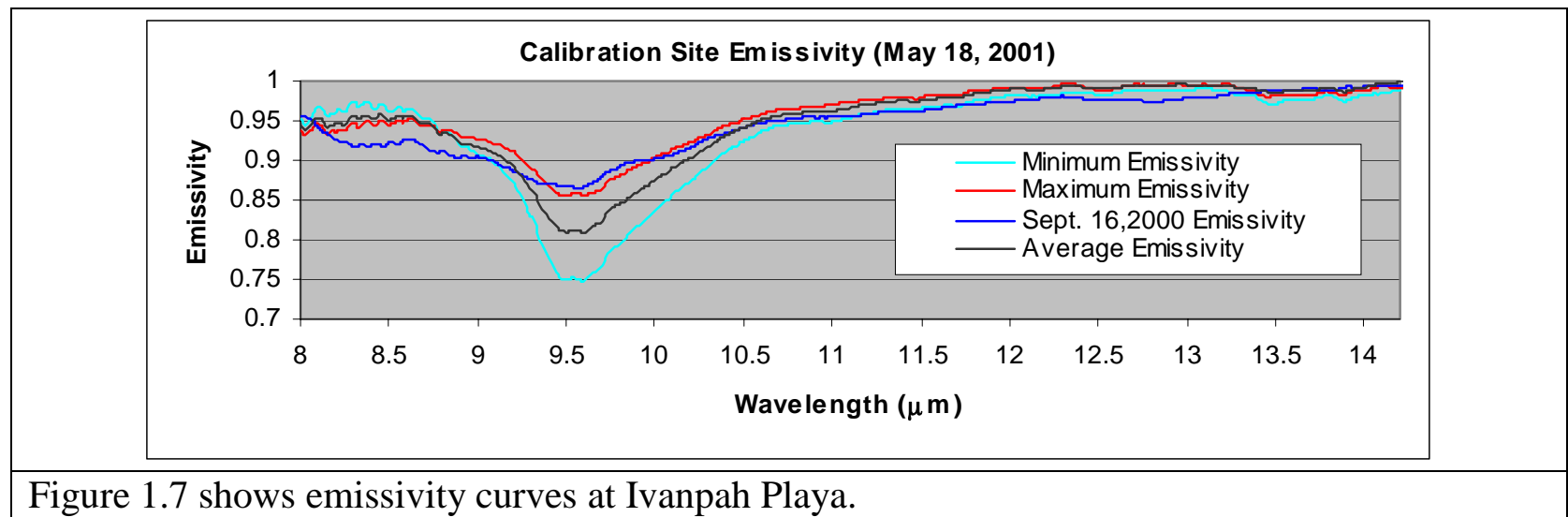

Surface Thermal Imaging

Surface homogeneity studies at Ivanpah Playa were conducted with two infrared cameras. The two cameras used by SRTC at Ivanpah Playa were the SC2000 and 760 models from Inframetrics. The crack/tile surface area and its temperature profile and its effect to temperature measurement by the mobile FTIR were analyzed. Figure 1.8 shows the typical crack/tile in the visible and in the infrared. The crack/tile areas influence the ground surface temperature measurements by point sensors.
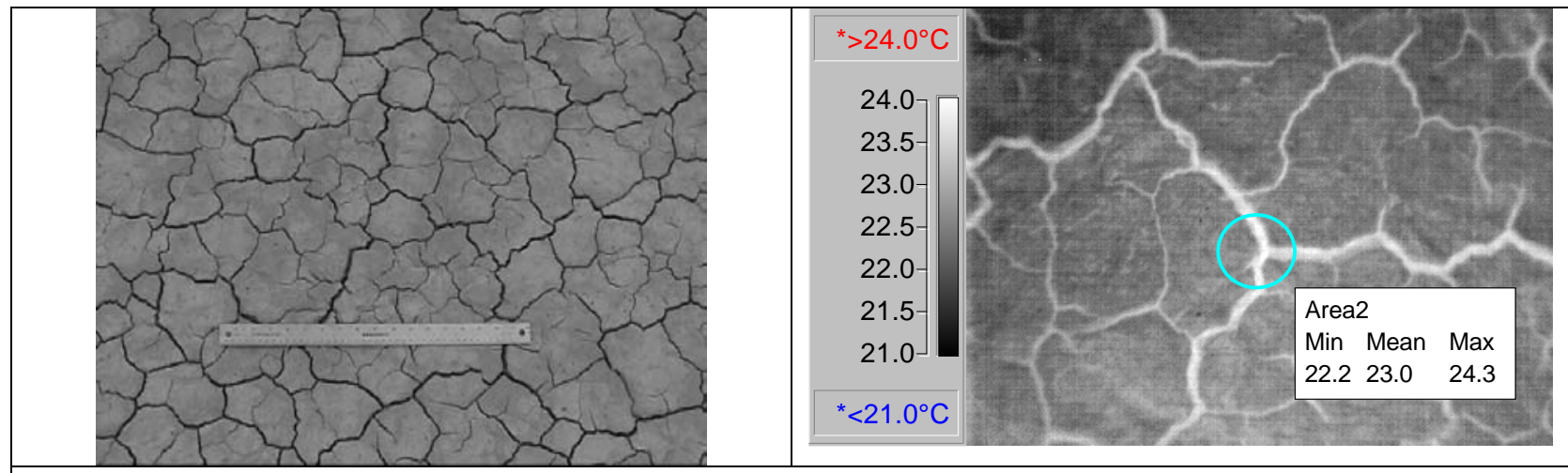

Figure 1.8 a typical soil surface picture on the left and a typical infrared image on the right side.

\section{Aerial Surveys}

Aerial thermal imaging surveys at Ivanpah Playa were also conducted with visible and infrared cameras attached to the side of the helicopter. The thermal cameras provided a unique view of the thermal properties of the soil surface. Figures $9 \mathrm{a}$ and $9 \mathrm{~b}$ show the camera assembly and helicopter over the playa. The setup used 


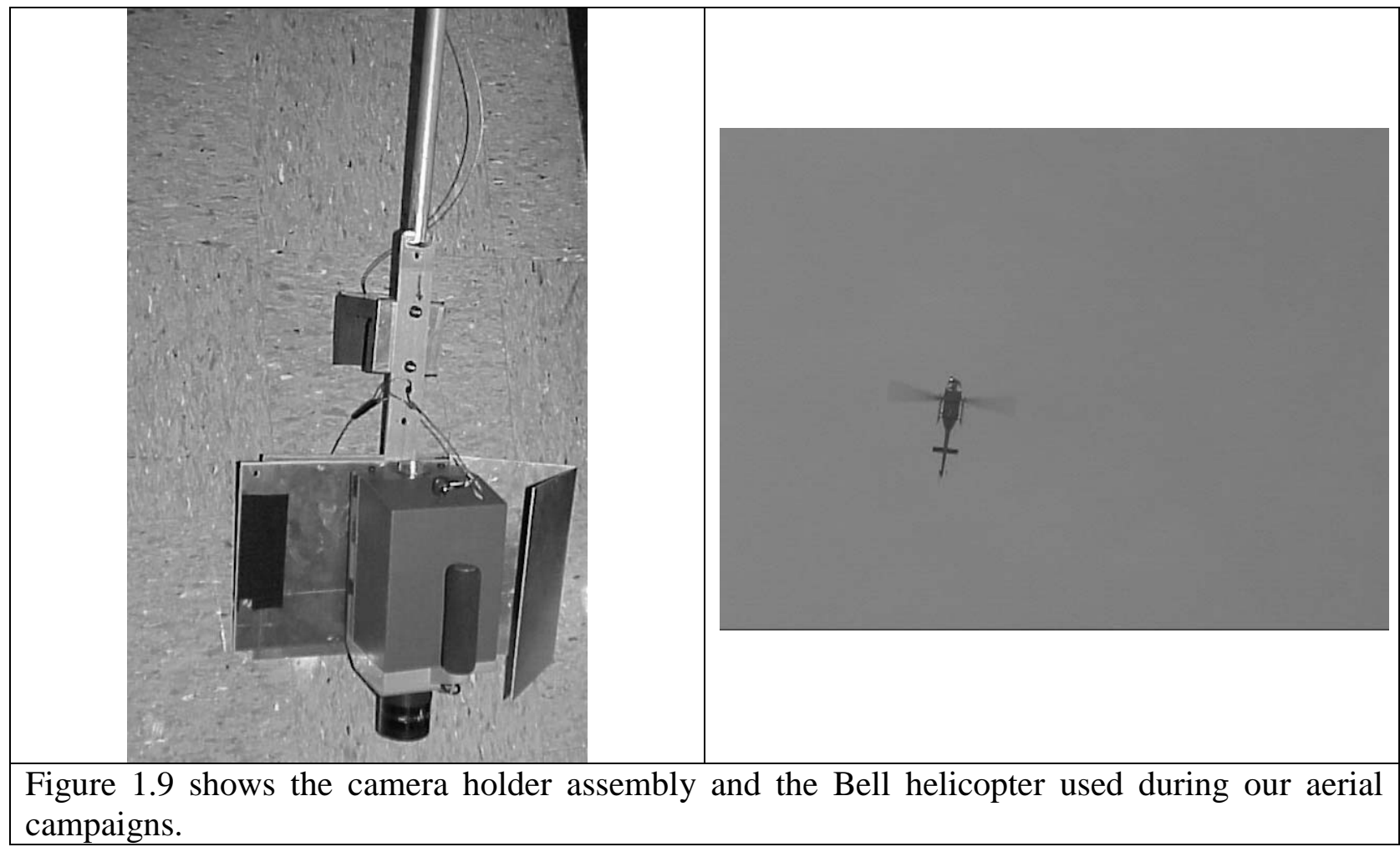

\section{Vicarious calibration sites}

The most critical part of vicarious calibration is the proper selection of suitable test sites. In this section, we describe the characteristics that reduce the uncertainties in the calibration and then describe four test sites that are in current use.

\section{Desired characteristics}

Vicarious calibration requires careful selection of the test site used.

1) A relatively bright site reduces the impact of errors in determining the path radiance component during the radiative transfer calculations. A nominal site reflectance greater than 0.3 ensures that the site radiance is the dominant contributor to the TOA radiance.

2) An elevation of at least one-kilometer reduces the amount of atmospheric aerosols and the errors associated with predicting their characteristics and concentrations.

3) High spatial uniformity over a large area minimizes the effects of mis-registration when performing a cross-calibration. The level of uniformity required is difficult to quantify other than to say "the more uniform the better." By simulating reflectance errors in a radiative transfer code calculation, it becomes clear that reflectance errors induce nominally a one-to-one correspondence in errors in TOA radiance calculations, and the corresponding gain coefficients (the errors vary some depending on the sensor band and atmospheric conditions). 
4) Minimal seasonal variations are desired if possible as well as a site that is free of vegetation that can affect seasonal variability, as well as BRF characteristics. An arid region is also desired to improve the probability of cloud-free days and to minimize reflectance variations due to ground moisture content.

5) The site should be nearly lambertian to decrease uncertainties due to changing solar and view geometry when cross-calibrating sensors on different platforms. A flat site also has the advantage of reducing BRF effects and eliminating shadow problems.

6) Spectral uniformity of the site is considered important over as wide a region as possible to simplify sensor mismatch corrections. In particular, it is desired that the site have the same reflectance from the VNIR into the SWIR to accommodate ASTER, ETM+ and MODIS sensors.

7) Accessibility of the site since field measurements are supported by a mobile laboratory which requires passable roads.

There is no ideal calibration site that satisfies all of the above conditions. In the Southwestern United States there are several fairly uniform reflectance sites which have been used by many groups over the course of many years for calibrations of Landsat-TM, SPOT-HRV, and other airborne and satellite-borne imaging sensors.

\section{White Sands Missile Range}

The White Sands Missile Range test site, shown in Figure 1.10 has been in use for vicarious calibration since the mid-1980s. It is located in the desert southwest of the United States in a region of low aerosol loading and an elevation of $1.2 \mathrm{~km}$. The test site used for small footprint sensors is commonly referred to as Chuck Site and is located in the alkali flats region. This area is relatively devoid of vegetation. The surface near the test site includes regions of greater vegetation and large gypsum dunes. In the VNIR, the White Sands site has a fairly flat spectral reflectance that is quite high, however, the reflectance is much lower and spectrally structured in the SWIR. The reflectance varies with season with the lowest reflectance values during the winter months when portions of the test range are either underwater or wet from the higher water table. Highest reflectance values are

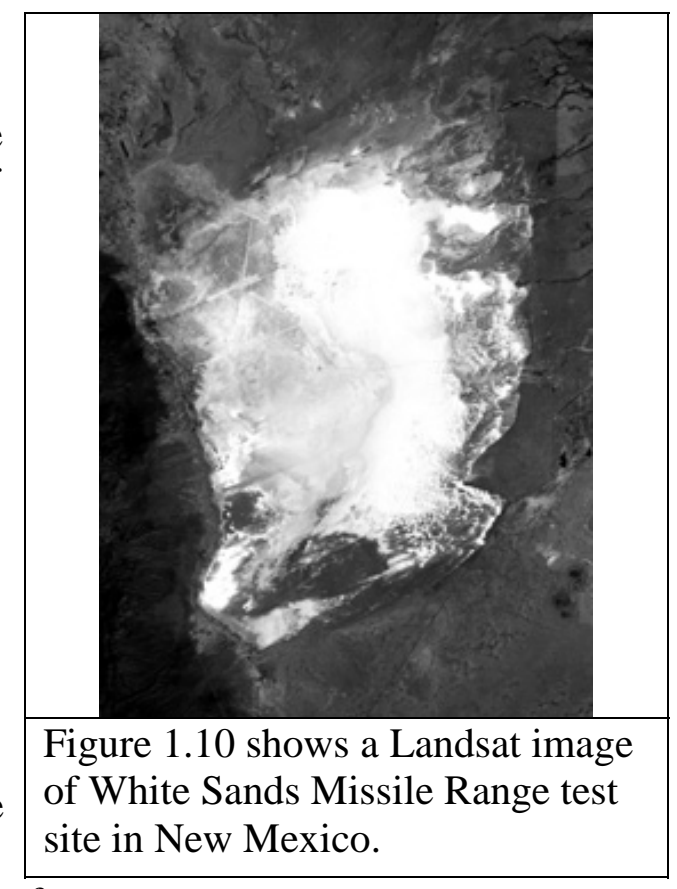
typically seen in late fall after the surface has dried after summer-season. 


\section{Playa Sites}

Ivanpah Playa, Lunar Lake Playa, and Railroad Valley Playa are dry lakebeds whose composition is dominated by clay. This provides reasonable reflectance levels and small spectral variations in the VNIR and SWIR. These are desert sites where the aerosol loading of the atmosphere is typically low with correspondingly reduced corrections. Railroad Valley in Nevada is the largest of the playa test sites, but is still only one-fourth of the area of White Sands. While the spectral reflectance of the playa sites is much lower than that of White Sands in the visible part of the spectrum, the spectral reflectance is reasonably flat over most of the VNIR and SWIR. The Ivanpah Playa calibration site is at an elevation of $0.8 \mathrm{~km}$ of $0.8 \mathrm{~km}$ and the other two are above 1.3 $\mathrm{km}$ so that atmospheric corrections are typically small. Figure 1.11 shows the reflectance spectra recorded at White Sands (October 1999) and Ivanpah Playa (September 2000). Figure 1.12 shows an MTI image of Ivanpah Playa. All three sites are devoid of vegetation and Lunar Lake Playa, while being the smallest of the sites, is the most spatially uniform of all of the test sites. All three sites suffer from surface moisture affecting the spectral reflectance during winter and early spring. The Lunar Lake site suffers from standing water on the site during late winter and early spring due to runoff of water from local mountains.

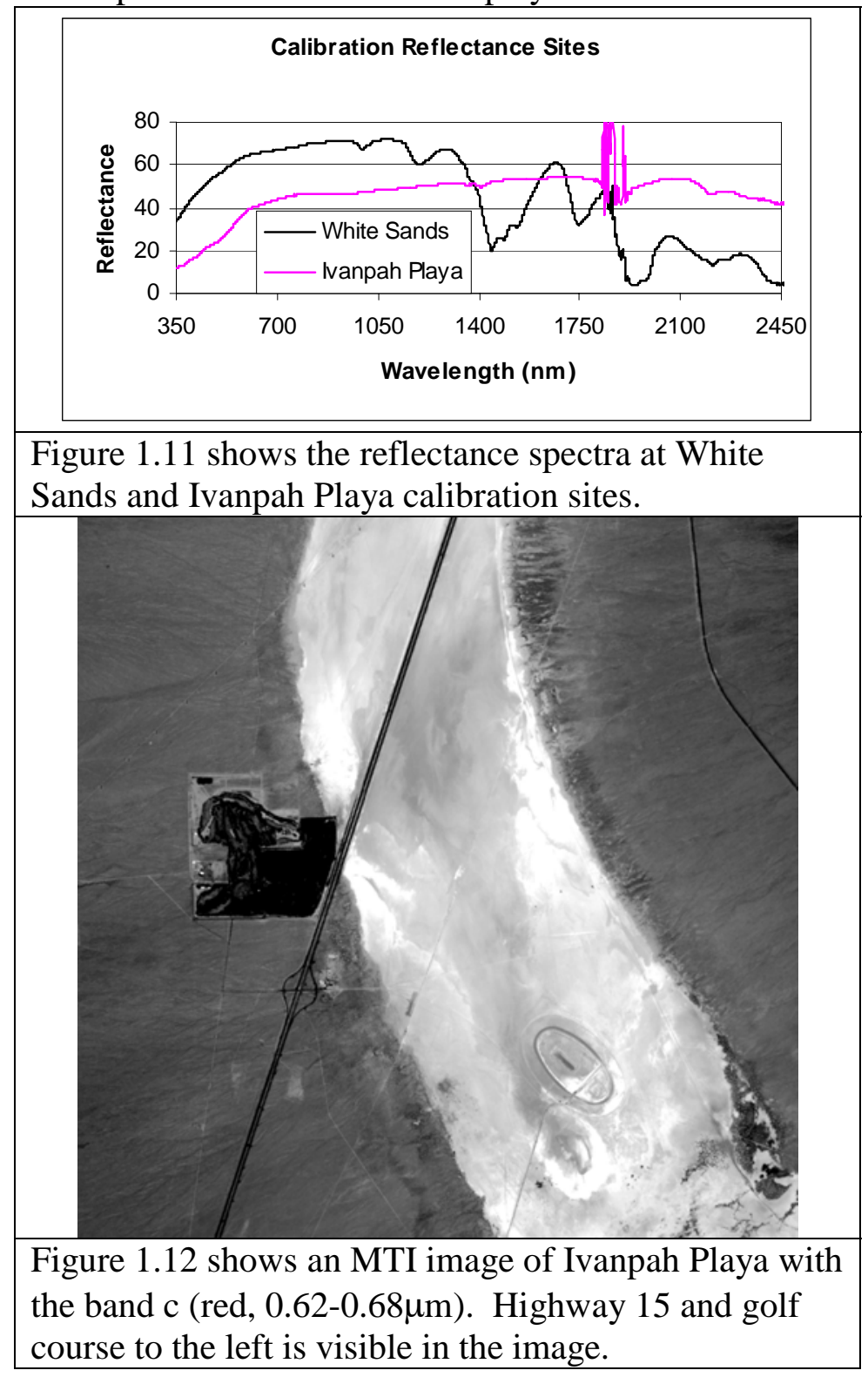

\section{Uncertainties}

\section{Reflectance-based approach}

Table 1.2 lists the error sources identified for a wavelength region in the green portion of the visible spectrum corresponding to band B of MTI. The error column is the percent error in the quantity listed in the source column. The total error column is the error in 
TOA radiance in percent at the sensor caused by the item in the source column. The total is the root sum of squares of all the error sources. The choice of the root sum of squares is not necessarily valid, as the sources are not known to be independent.

These uncertainties clearly depend on wavelength with larger uncertainties in spectral regions with strong absorption. For example, the uncertainty in the atmospheric correction increases with shorter wavelengths and the ozone correction is very small or insignificant at longer wavelength. The results in the table are for a typical calibration day of current test sites: cloud free with visibility of $50 \mathrm{~km}$ or more. As seen from the table, the largest sources of error are in the atmospheric characterization and the surface reflectance retrieval.

\begin{tabular}{|c|c|c|}
\hline \multicolumn{3}{|l|}{ Table 1.2} \\
\hline Source & Error & $\begin{array}{l}\text { Total } \\
\text { Error }\end{array}$ \\
\hline Aerosol complex index (1.44-0.005i) & & 1.5 \\
\hline Choice of aerosol size distribution & & 1.5 \\
\hline Optical depth measurement & 5 & 1.0 \\
\hline Column ozone uncertainty & 20 & 1.3 \\
\hline Vertical distribution of aerosols & & 1.0 \\
\hline Inherent RTC accuracy & 1. & 1.0 \\
\hline Non-lambertian ground characteristic & 1.2 & 1.2 \\
\hline Ground reflectance measurement & 1.5 & 1.5 \\
\hline Total Error (root sum of squares) & & 3.6 \\
\hline $\begin{array}{l}\text { Reflectance-based method error sources, with referenc } \\
\text { atmospheric irradiance. The values are quoted as one- }\end{array}$ & $\begin{array}{l}\text { to solar } \\
\text { gma pe }\end{array}$ & \\
\hline
\end{tabular}

We estimate the directional reflectance error of the field standard is no more than $1.5 \%$ and the precision of the radiometer measurements of the sand and the standard are $0.5 \%$ due to sampling errors and limitations of the instruments and data loggers. We correct the nadir reflectance factor for the component of diffuse light in the field, which is not present during the laboratory calibration of the standards. This correction has an uncertainty of about $0.5 \%$.

It is important to recognize that the total of these errors could add to much more than the root sum of squares. Also, these are in reference to the exo-atmospheric solar irradiance 
and as shown in Table 1.2, there is still significant uncertainty in the conversion from relative radiance to absolute. These uncertainties were also derived for a near-nadir look. For the large off-nadir look of MTI there are additional sources of uncertainty when applying a reflectance-based approach. The large view angle requires much better characterization of atmospheric effects due to the longer view path. This view angle also requires an improvement in the characterization of the surface bi-directional reflectance.

The site selected for the MTI calibration is the Ivanpah Playa site. It provides better reflectance for bands $\mathrm{O}$ and I than the White Sands site. The spectral reflectance of the Ivanpah test site is also sufficient to keep uncertainties in the VNIR bands A-G to a low level. The uncertainty in band A will be higher at Ivanpah Playa than at White Sands due to the spectrally varying nature of the reflectance in that band.

The size of the test was $280 \mathrm{~m}$ by $80 \mathrm{~m}$ to give a total of $5620-\mathrm{m}$ pixels. The site was oriented so that the long side of the site is in the cross-track direction of MTI. The amount of time required to collect these data was 30 to 40 minutes. At the same time as the reflectance measurements, diffuse-to-global meter and solar radiometers was used to collect atmospheric data.

To assess the test site at higher spatial resolution than the 20-m scale, reflectance measurements was conducted in a portion of the site at the 5-meter scale. The site for this work was $80 \mathrm{~m} \times 80 \mathrm{~m}$. These data was collected approximately one hour prior to overpass and was used only to assess the spatial homogeneity of the site and not for absolute reflectance. Another additional measurement was the collection of the surface reflectance at a look angle equal to that of the off-nadir look for MTI. These data was used to check both the BRDF retrieval of the camera system as well as provide input to the radiative transfer code (RTC) used by the Remote Sensing Group of the University of Arizona for the calibration of the off-nadir look. 


\section{Visible and Near-Infrared Vicarious Calibration Campaign at Ivanpah Playa}


On March 2000, the Multispectral Thermal Imager (MTI) satellite sponsored by the Department of Energy (DOE) was launched to kickoff the beginning of a research and development project for accurate surface temperature retrieval. The MTI mission is to demonstrate the efficacy of highly accurate multispectral and thermal imaging for passive characterization of industrial facilities and related environmental impacts from space. The MTI goal is to compare the remotely sensed information from the satellite instrument to information available directly at the cooperative sites being observed. In this role, MTI is a technology demonstration experiment, and is designed to

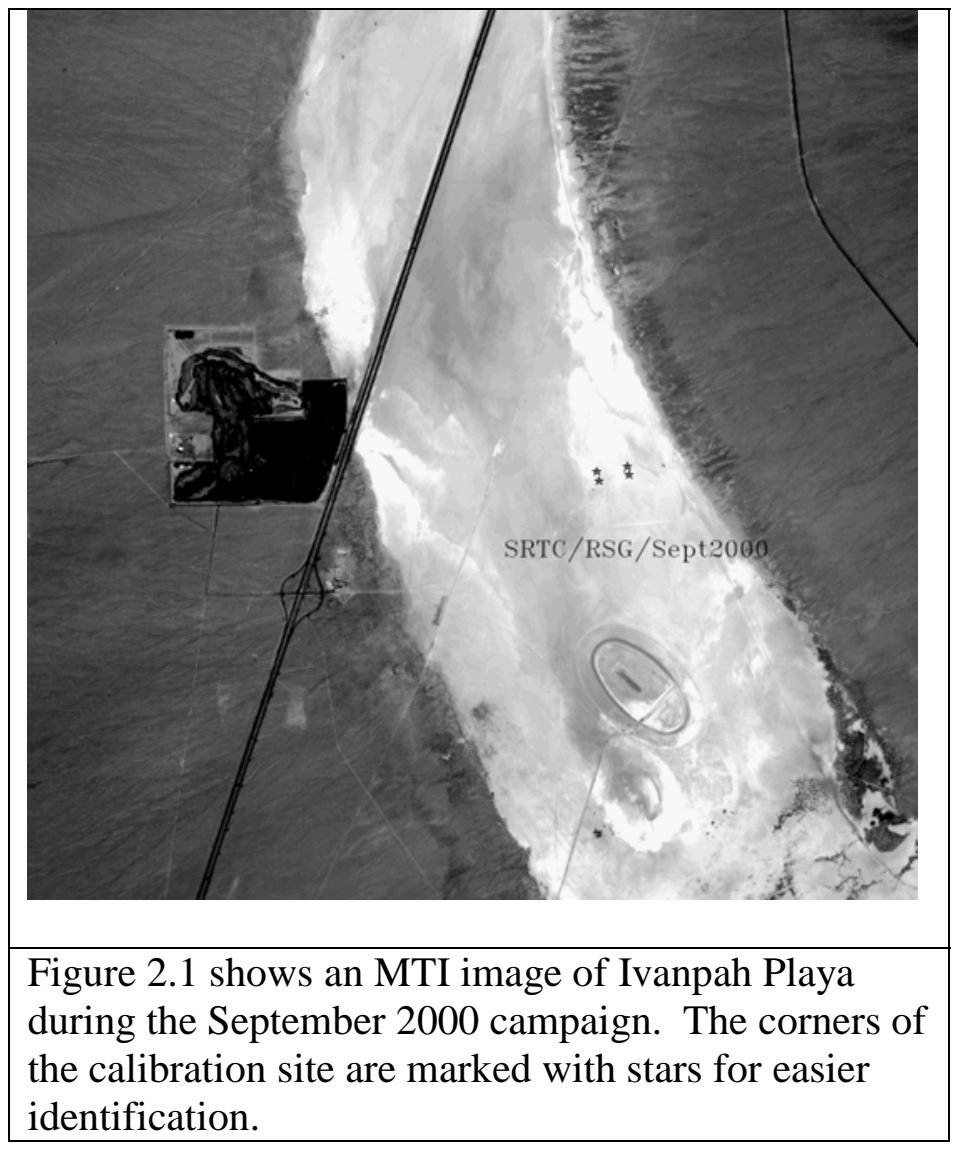
observe a very limited number of selected sites per day, with modest spatial coverage and spatial resolution.

Once the satellite was launched, summer 2000 became the most important time to conduct the first vicarious calibration campaign. Ivanpah Playa was selected as the calibration site for bands in the visible and near-infrared spectral regions. In order to ensure the availability of instrumentation and the quality of data, SRTC requested the Remote Sensing Group of the University of Arizona to help during the calibration. SRTC and RSG conducted joint campaigns on July and September 2000. Although ground truth data was collected on the July campaign, imagery was not available due to an unexpected shutdown of the MTI satellite. In contrast to the July campaign, the September campaign proceeded smoothly and significant data was measured for the calibration in the visible, near-infrared and thermal spectral regions. The results shown below demonstrate the usefulness of our data in the calibration of the MTI satellite. 
Figure 2.1 shows the Ivanpah Playa image recorded by the MTI satellite during our September 2000 campaign. Band C (0.62$0.65)$ was used in the creation of the grayscale image. The spectral variability across the playa is evident from the picture. The calibration site was annotated in the image with stars at the corners. Although not visible in this image, the northeast and southwest corners were marked on the ground with blue tarps. Figure 2.2 shown a magnified image of the calibration site. In the image, the NE and SW tarps are clearly visible. The location of control camp and the vehicles is also evident.

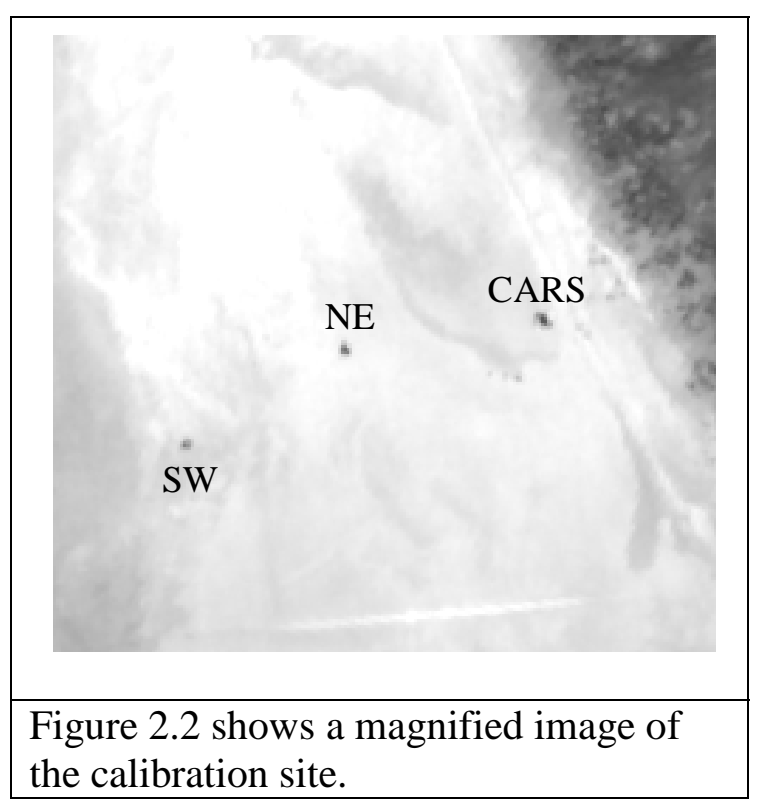

\section{Atmospheric Characterization Measurements}

The equipment used for the atmospheric measurements was the 10-band solar radiometer. Diffuse-to-global data were also collected on both days. The results of these measurements are summarized in Figures 2.3 and 2.4 for the September 15 overpass for two wavelengths not affected by atmospheric absorption. From the figures it is clear that the atmospheric extinction was not constant during the measurements period with peak-to- peak variations in optical depth on the order of 0.02 for $440 \mathrm{~nm}$ and 0.008 at $870 \mathrm{~nm}$. These results have already removed any variability due to changes in atmospheric pressure (less than $3 \mathrm{mb}$ peak-to peak for most locations). Thus, the variability seen in these figures in attributed to either variability in the instrument or in atmospheric aerosol loading. Past experience with measurements of this type show that the values seen in Figures 2.3 and 2.4 are

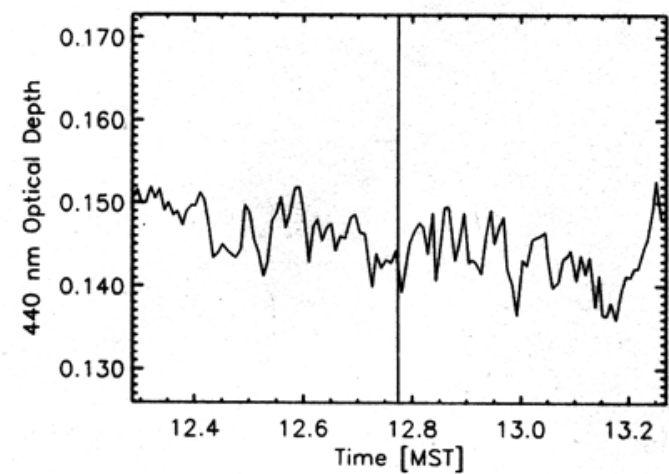

Figure 2.3 shows the atmospheric transmission at $440 \mathrm{~nm}$ during the overpass of the satellite. 
typical values for the Ivanpah test site and the variability seen is indicative of a cloudless day. The results at $870 \mathrm{~nm}$ are especially telling in that the overall trends seen at 440nm are not as apparent in the data set collected at $870 \mathrm{~nm}$. This shows that the variability seen at $870 \mathrm{~nm}$ is strongly affected by instrumental variation in addition to atmospheric changes. The results for all bands are summarized in Table 2.1 gives the 10 -minute average of the non-molecular optical depth for each of the bands not affected strongly by atmospheric absorption. Also included in the table are the 1-sigma standard deviations of these averages for the 20 data points collected during this period. These standard deviations are good indicators of the relative stability of the atmosphere about the time of the satellite overpass. As can be seen from the table and the figures, there is a definite correlation between the wavelength of the solar extinction measurements and the optical thickness. This correlation is used as part of an inversion scheme to derive the aerosol size distribution. This inversion is done using software developed by the RSG and assumes that the aerosols size distribution follow a power law or Junge size distribution. If the aerosols follows such as distribution, the optical depth as a function of wavelength is proportional to the wavelength to a power that is determined from the extinction coefficient measurements.
Table 2.1

Non-molecular optical depths for all nine nonabsorbing bands of automated solar radiometer

\begin{tabular}{|c|c|c|c|}
\hline $\begin{array}{c}\text { Band } \\
\#\end{array}$ & $\begin{array}{c}\text { Wavelength } \\
(\mathrm{nm})\end{array}$ & $\begin{array}{l}\text { Non- } \\
\text { molecular } \\
\text { optical depth }\end{array}$ & $\begin{array}{l}1 \sigma \\
\text { standard } \\
\text { deviation }\end{array}$ \\
\hline 1 & 380 & 0.207 & 0.003 \\
\hline 2 & 400 & 0.163 & 0.002 \\
\hline 3 & 441 & 0.144 & 0.003 \\
\hline 4 & 521 & 0.133 & 0.002 \\
\hline 5 & 611 & 0.127 & 0.001 \\
\hline 6 & 671 & 0.088 & 0.002 \\
\hline 7 & 781 & 0.077 & 0.003 \\
\hline 8 & 870 & 0.055 & 0.001 \\
\hline 9 & 940 & Water Vapor Absorption \\
\hline 10 & 1030 & \multicolumn{3}{|c}{0.058} & 0.001 \\
\hline
\end{tabular}

Figure 2.5 shows the results from Table 2.1 plotted on a log-log scale. The solid line indicates the best straight-line fit to these data when ozone absorption is taken into account in bands 2.7. The large deviation from the line around $940 \mathrm{~nm}$ is strong water vapor absorption feature. The slope of this line allows the Junge parameter to be determined and for this case, the Junge parameter was determined to be $3.284 \pm 0.019$ (where the errors here are again a 1 sigma standard deviation about the average). The line also allows the aerosol optical depth to be determined at all wavelengths given the value at a single reference wavelength. This wavelength is typically chosen to be 
$550 \mathrm{~nm}$, and in this case the aerosol optical depth was found to be $0.112 \pm 0.002$.

Given the Junge parameter and aerosol depth at the reference wavelength, the optical depths in bands 4,5 , and 6 can be used to determine residual attenuation due to ozone absorption and this residual attenuation can be converted to a columnar ozone amount $(0.234 \pm 0.008 \mathrm{~cm}$-atm in this case). Using a similar philosophy and slightly different algorithm allows the columnar water vapor to be retrieved from the data collected in the 940-nm water vapor band. Here, the average columnar water vapor was found to be $1.88 \mathrm{~cm}$ $( \pm 0.02 \mathrm{~cm})$.

Summary plots of the derived 550-nm optical depth, Junge parameter, column water vapor, and column ozone as a function of time for the one-hour period about overpass are shown in Figures 2.6, 2.7, 2.8, and 2.9. The nominal uncertainties of these results are the 0.01 for the aerosol retrieval, 0.3 in Junge parameter, $10 \%$ in water vapor, and $20 \%$ in the ozone retrieval. The effects of these uncertainties are described in more detail in the section on radiative transfer.

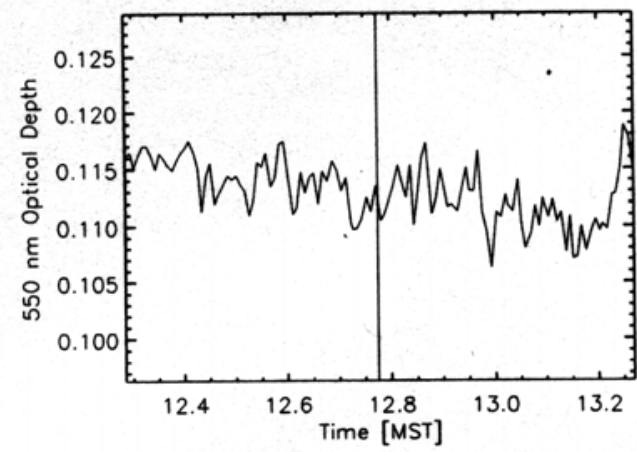

Figure 2.6 shows the aerosol optical depth at 550-nm derived from inversion for the one-hour period about the MTI overpass.

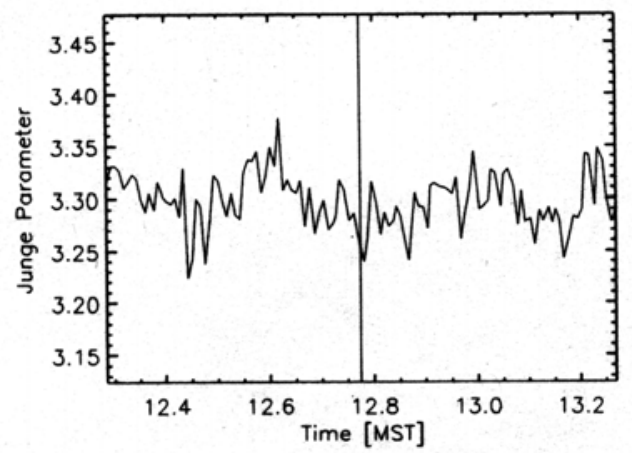

Figure 2.7 shows the derived Junge parameter from aerosol inversion for the one-hour period about the MTI overpass. 


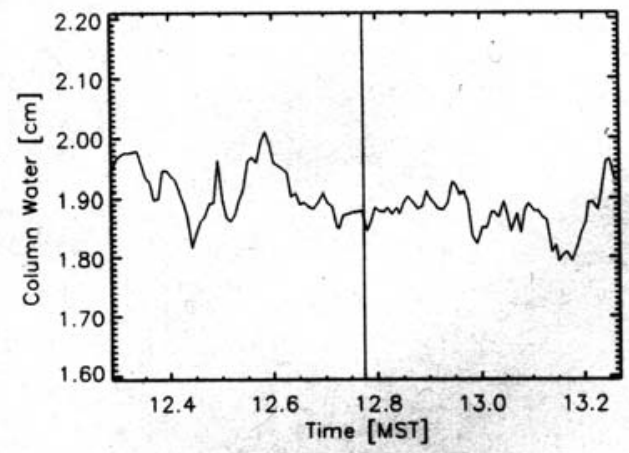

Figure 2.8 shows the columnar water vapor for the one-hour period about the MTI overpass.

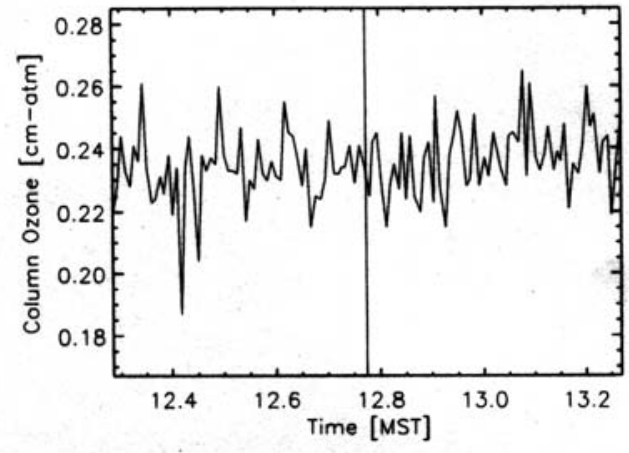

Figure 2.9 shows the columnar ozone for the one-hour period about the MTI overpass.

The uncertainties in aerosol optical depth are primarily a function of the accuracy of the calibration of the solar radiometer. This uncertainty is typically less than $2 \%$, but the results shown in Figure 2.5 for bands 1 and 10 of the radiometer show that even such small uncertainties can cause noticeable and significant effects on the slope of the Junge inversion. An additional source of error is that the aerosols do not follow a Junge law. In this case, the results in Figure 2.5 indicate that this assumption should not create a significant source of uncertainty. The uncertainty in water vapor retrieval is due primarily to uncertainty in the calibration of the water vapor band of the solar radiometer (known to 5\%). The uncertainty in the ozone retrieval is primarily due to the low sensitivity of the total optical depth in these bands to ozone absorption relative to the effects due to aerosols.

\section{Surface Reflectance Retrieval}

The reflectance-based approach relies on ground-based, surface reflectance measurements of a selected site. The calibration site selected for MTI is a rectangular area that is $280 \mathrm{~m} \mathrm{x} 80 \mathrm{~m}$ with the long side of the site oriented approximately in the crosstrack direction of MTI (80-260 degree azimuth direction). The size of the site is a compromise between sampling a large enough area of the ground to provide adequate sampling of the MTI detectors yet small enough that the site can be covered in a reasonable amount of time. The site is then further split into 20 - $\mathrm{m}$ squares, thus giving a total of 56 areas on the ground that are to be sampled as described below.

The reflectance of the test site is obtained with a spectroradiometer that is transported across the entire site. The primary instrument for the surface-reflectance collection is the ASD FieldSpec FR which is a commercially-available spectrometer that gives 1.4-nm spectral resolution from 350 to $1000 \mathrm{~nm}$ and $10-\mathrm{nm}$ resolution for the 1000-nm to 2500 $\mathrm{nm}$ spectral range. The output form the spectroradiometer is interpolated within the data collection software to report results at a 1-nm spacing across the entire spectral range. The instrument is transported across the site using a backpack device that extends the instrument away from the body of the user and raises the foreoptics to a height of about $2 \mathrm{~m}$ above the ground. An 8-degree field of view is used for the measurements giving a 
circular sample on the ground of approximately $0.3 \mathrm{~m}$ in diameter. A larger field of view would give better spatial sampling but would be more susceptible to surface bidirectional reflectance effects. Smaller field of view forces a longer integration time and thus increases the time needed to measure the test site. The backpack approach also includes a pointing capability of \pm 55 degrees in the "along-track" direction of the radiometer. That is, the foreoptic can be pointed forwarded and backward in the direction that the user walks. SRTC and RSG used four FRs for this work (ASD serial numbers 6128 and 6170 (SRTC) and 687 and 614 (RSG)). The RSG only has a single backpack device and this was paired with the ASD687. The ASD614 and 6128 were used with the fanny-pack device supplied by ASD with the spectroradiometer. The foreoptic is extended away from the user with the aid of a telescoping pole held at the hip height of the user.

To collect data, the user walks a path parallel to the along-track direction of MTI through the center of the four cross-track "pixels" for all 14 along-track "pixels." The spectroradiometer is configured to average 20 spectral per sample and 8 samples are collected within a single "pixel." This gives a total of 8,960 spectra collected over the site and 448 samples. It took less than 30 minutes to collect these data when the reference measurements are included.

The reflectance of the site is determined by rationing the measurements described above to those of the reference panel for which the bi-directional reflectance factor has been determined in the laboratory. Measurements of the reference are made at the start and end of the data collection, as well as after every 8 pixels (or equivalently, every 64 testsites samples). This level of sampling reduces the level of uncertainty due to changes in instrument response with time and changing atmospheric conditions, while keeping the data collection time to a reasonable level. Knowing the bi-directional reflectance of the reference allows the reflectance of each sample to be computed taking into account effects due to sun-angle changes and reflectance panel bi-directional reflectance over the 30 minutes of data collection. Once each of the spectral samples of the site is converted to reflectance, all 448 data points are averaged to give a single spectral reflectance for the entire site.

It should be clear that a critical part of this reflectance retrieval is the characterization of the reference panel in the laboratory. The calibration of this panel is done with reference to a standard made from pressed polytetrafluoroethylene based on a prescribed approach defined by National Institute of Standards and Technology (NIST). The calibration reference is a directional-to-hemispheric reflectance standard provided by NIST. Polynomial fits are made to the measured data to calculate the reflectance of the field standard for the sun-view geometry and wavelengths for a given set of field measurements. The Spectralon sample is calibrated for a nadir viewing sensor with a variety of solar illumination angles. The measurements are made in only one plane, but this does not create problems in the field because the Spectralon panel is aligned in the field such that the solar incident angle stays in this same plane. Two different, 18-inch, monolithic Spectralon panels were used for this work (RSG serial numbers 6 and 7) and 
for all measurements, the \#6 panel was paired with ASD687 and \#7 was paired with the ASD 614 and ASD 6128.

On September 15, data were collected with the ASD687 viewing at 55 degrees with the foreoptic pointing towards the southern direction to simulate the off-nadir view of the sensor. The operation of the system was such that measurements of the reference were made at nadir and then the foreoptic was tilted to the appropriate angle using a inclinometer to obtain the appropriate view angle. The data collection began at the northeast corner of the site. As mentioned, collection took approximately 30 minutes with the collection ending approximately 20 minutes after overpass. When the collection of the site was completed, the foreoptic was pointed to nadir and collection of the site was repeated beginning a the northwest corner and collecting data for the westernmost 24 pixe3ls. The purpose of these data was to allow comparison of the results between the ASD614 and the SRTC ASD6128 results.

The ASD614 collection mimicked that of the ASD 687 except that the foreoptic of the ASD614 remained in the nadir-pointing orientation for the entire collection. Unfortunately, the collection on September 15 with the ASD614 was done improperly due to a misunderstanding between the operator and the person operating the panel. The misunderstanding led to a lack of reference panel data for the collection. Thus, the data could be processed using absolute radiance, but as will be described below, the collection from September 16 combined with that from September 15 allows for adequate determination of the surface reflectance such that the need for processing the September 15 data is minimal. For September 16, the data collection process was repeated in an identical fashion. In this case, all data collected were without problems. The results from the collections are summarized to some extend in Figures 2.10 through 2.14.

Figure 2.10 shows the nadirviewing reflectance derived from the ASD614 on September 16 and the 1 sigma standard deviation as a percent of this reflectance. This percent deviation gives an indication of the spatial homogeneity of the test site which from the figure, can be seen to be quite small. This is further indicated by examining the nadirviewing reflectance from both September 15 and 16 derived for the western 24 pixels using the ASD687. Figure 2.11 further indicates the homogeneity by displaying the percent difference between the dates is an indication that sampling creates little effect

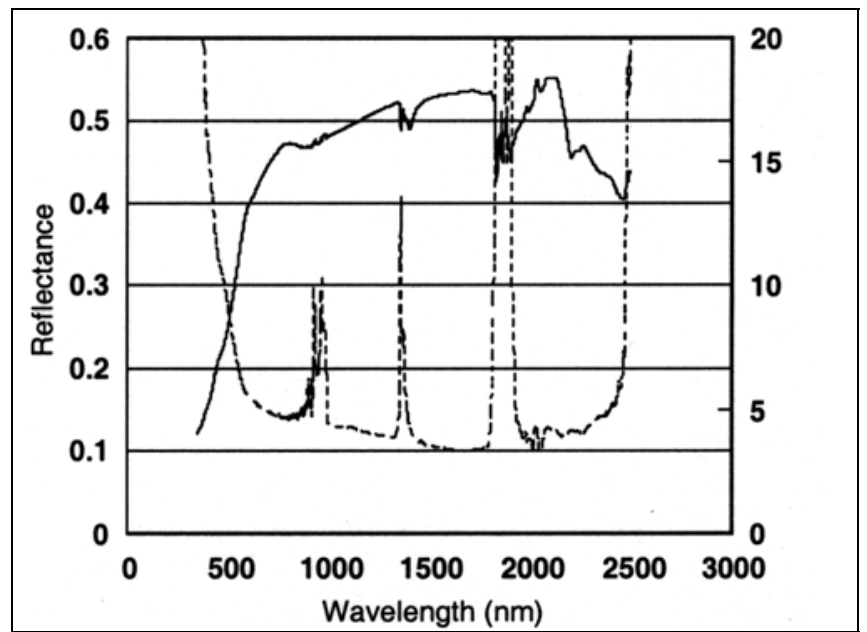

Figure 2.10 shows the surface reflectance retrieved from the test site. The second axis with dotted line shows the percent standard deviation of average. 
and temporal changes in the reflectance of the playa from one day to the next is minimal.

Further indication of the sensitivity of the sampling is shown in Figure 2.12. The figure shows the percent difference between the reflectance obtained for the western 24 pixels for each of the three ASDs used in this experiment on September 16 (the ASD687 and ASD614 from RSG, and the ASD6128 operated by SRTC). All data have been processed using the RSG's software and Spectralon BRDF. Past work has shown that the accuracy of the reflectance retrievals is $\pm 2 \%$ of the reflectance. Thus the values shown in Figure 2.12 are well within these uncertainties for most of the spectrum and indicates that there is little bias between the ASD687 and ASD614. Finally, Figure 2.13 shows the percent difference between the reflectance for the nadir and off-nadir views from

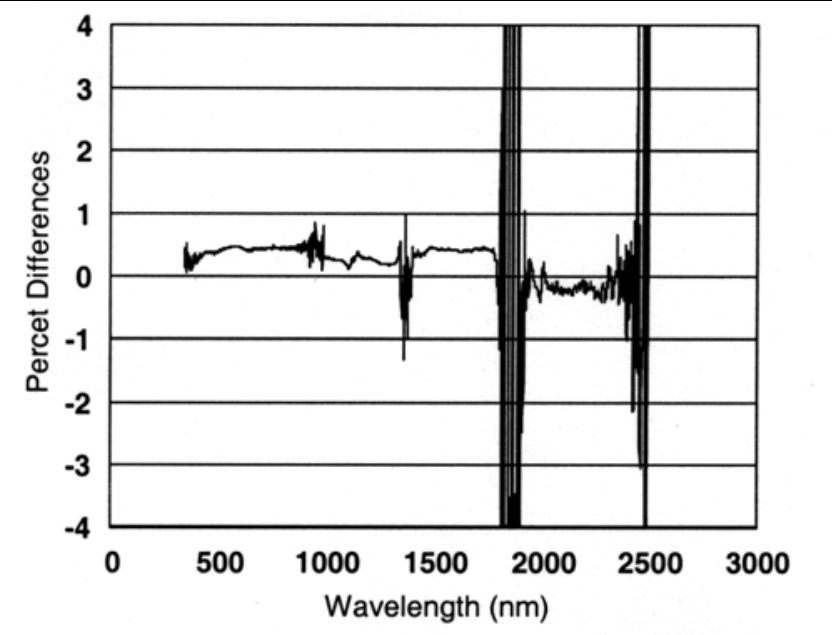

Figure 2.11 shows the percent difference between nadir-viewing reflectance of westernmost 24 pixels on September 15 and September 16.

September 16 and Figure 2.14 shows the percent difference between the nadir -viewing reflectance for the full site to that collected of the westernmost 24 pixels on September 16. What these figures show is that there is a small but significant change in reflectance based on view angle. This effect is spectral in nature due to mostly to the fact that the reflectance is lower at small wavelengths. Figure 2.14 shows that there is a difference in reflectance across the site. This is well known and repeatable. While the effect is small, it is a point of consideration when comparing the predicted radiance to that reported to the sensor. Figure 2.15 shows a mosaic image of the reflectance distribution at the calibration site. The satellite image of the calibration site is shown in Figure 2.16. Figure 2.17 shows the reflectance variability along the calibration site. The corresponding reflectance data transect obtained

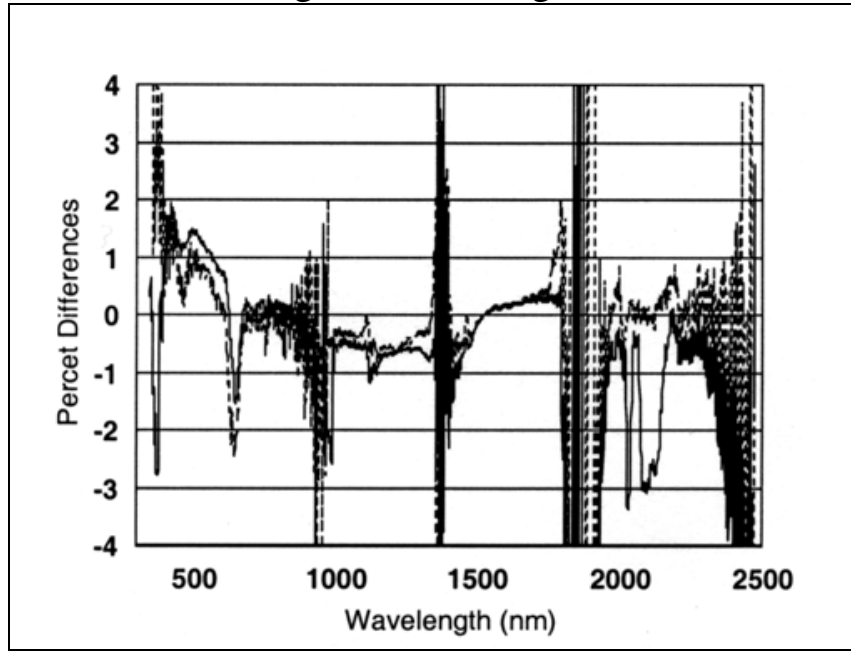

Figure 2.12 shows a comparison of nadirviewing reflectances retrieved on September 16. Solid line indicates percent difference between results from RSG ASDs 687 and 614. Dotted line indicated percent difference between RSG ASD 687 and the results from the SRTC ASD. 
from the MTI satellite image is shown in Figure 2.18. The agreement of the satellite image and the ground truth is evident in the figures.

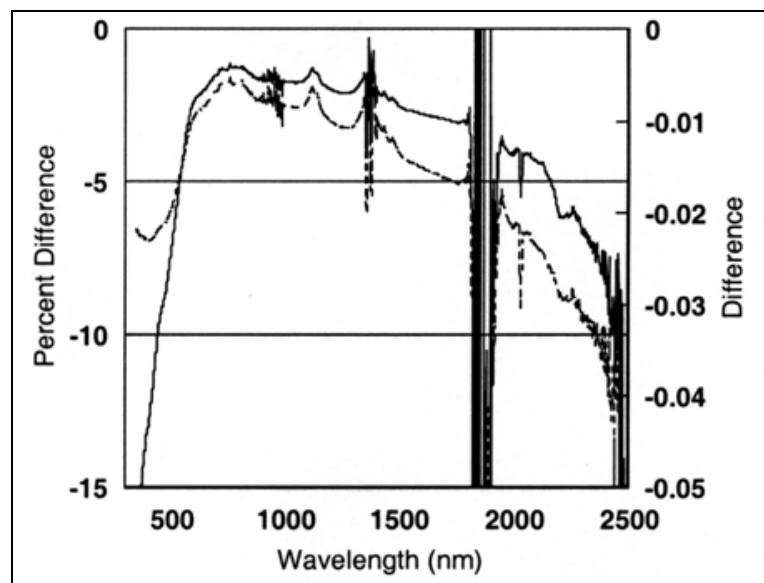

Figure 2.13 shows a comparison of nadir and off-nadir measurements with ASD 687 on September 15.

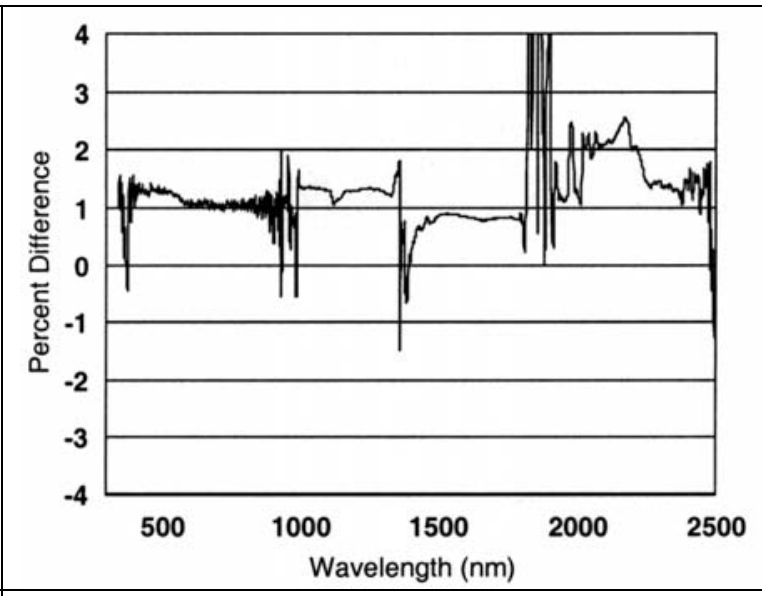

Figure 2.14 shows the percent difference between nadir-viewing reflectance for full site to those of the westermost 24 pixels as measured by the ASD 614 on September 16.

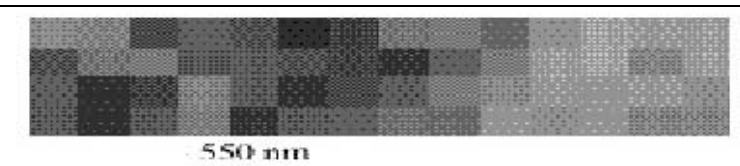

Figure 2.15 shows a mosaic image of the reflectance distribution at the September calibration site $(280 \mathrm{~m} \times 80 \mathrm{~m})$.

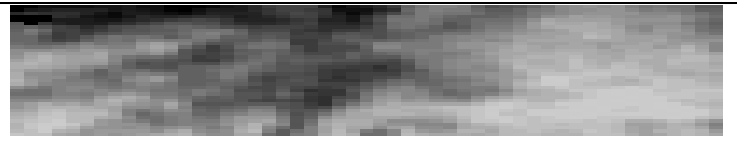

Figure 2.16 shows the satellite image of the September calibration site $(280 \mathrm{~m} \times 80 \mathrm{~m}$. 


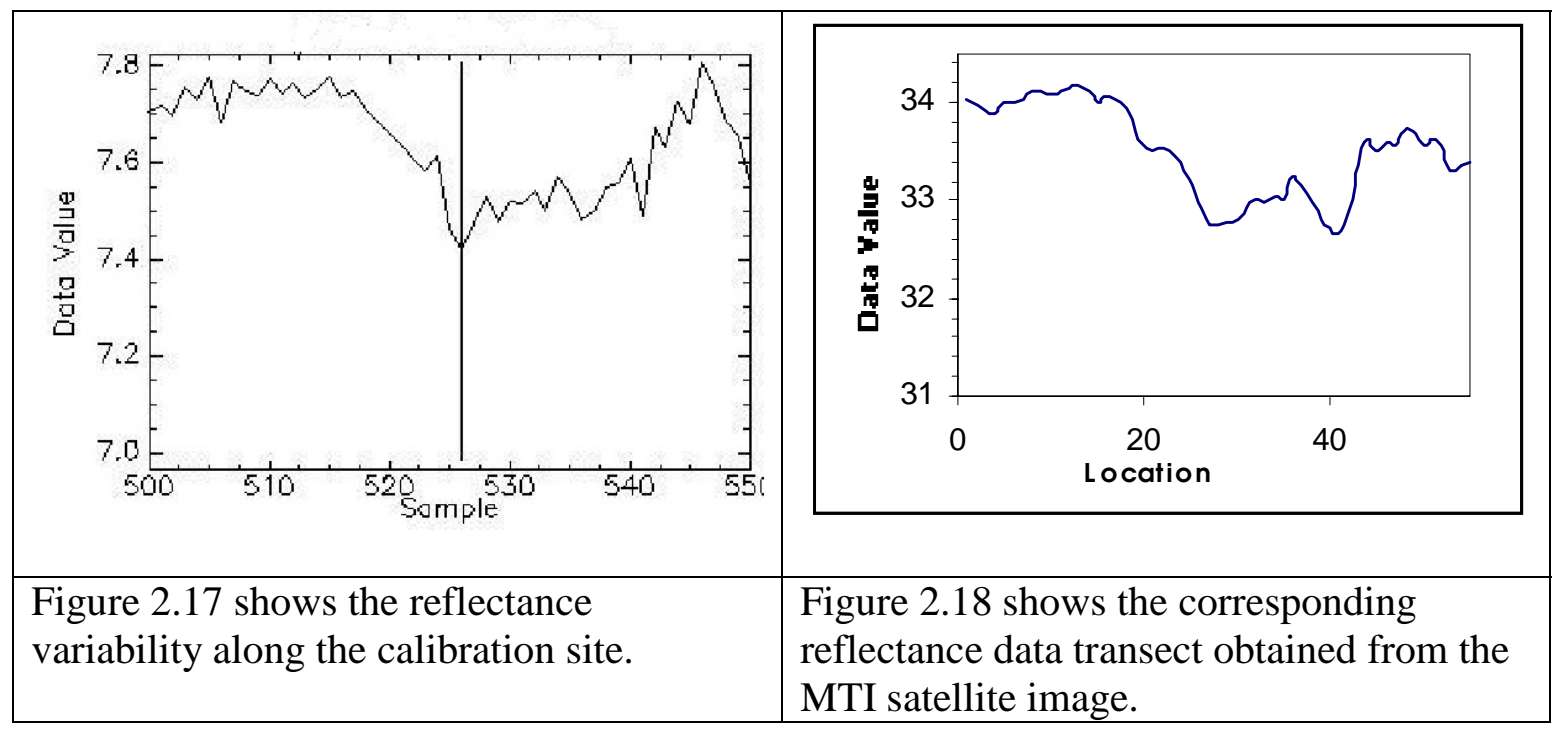

\section{Radiative Transfer Calculations}

These atmospheric and surface data are inputs to a radiative transfer code that computes hyperspectral, at-sensor radiances based on a Gauss-Seidel iteration approach. The code assumes a plane-parallel, homogeneous atmosphere and divides this atmosphere into layers to account for the vertical distribution of scatters and weak absorption due to ozone in the visible and near infrared (approximately the 400 to $800 \mathrm{~nm}$ spectral range known as the Chappuis absorption band). The Junge parameter described above that is derived form the solar radiometer measurements are used to compute Mie scattering phase functions used in the code. While the radiative transfer code can include non-lambertian effects of the surface, bi-directional reflectance measurements of the surface were not available for this work, so the surfaces are assumed to be lambertian. The off-nadir, atsensor radiances were computed assuming a lambertian surface with reflectance as measured in the off-nadir direction simulating the view of MTI.

Strong gaseous absorption effects due to water vapor are determined using MODTRAN3 to compute transmittance for the sun-to-surface-to-satellite path for 1-nm intervals from 350 to $2500 \mathrm{~nm}$. This sun-to-ground-to-sensor transmittance is multiplied by the at-sensor radiance output form the radiative transfer code to correct the radiances for this strong absorption. While this approach is an approximation that excludes interactions between diffusely-scattered radiances and absorption, it does not cause large uncertainties for application to MTI because of the small effect of the absorption within the MTI bands and the high surface reflectance of the test site used in this work.

The relative radiances that are the output of the radiative transfer code are converted to absolute radiances by multiplying by a supplied solar irradiance curve corrected for changes in earth-sun distance. The solar irradiance standard used in this work is that of the Modtran4 and is identical to the spectrum selected for NASA's Landsat 7 project by RSG. The predicted at-sensor radiance results are shown in Figure 2.19 and 2.20 for the nadir and off-nadir views for September 15 respectively. Also shown in Figure 2.20 is 
the percent difference between the predicted radiances shown in Figure 2.19 to those of Figure 2.20.

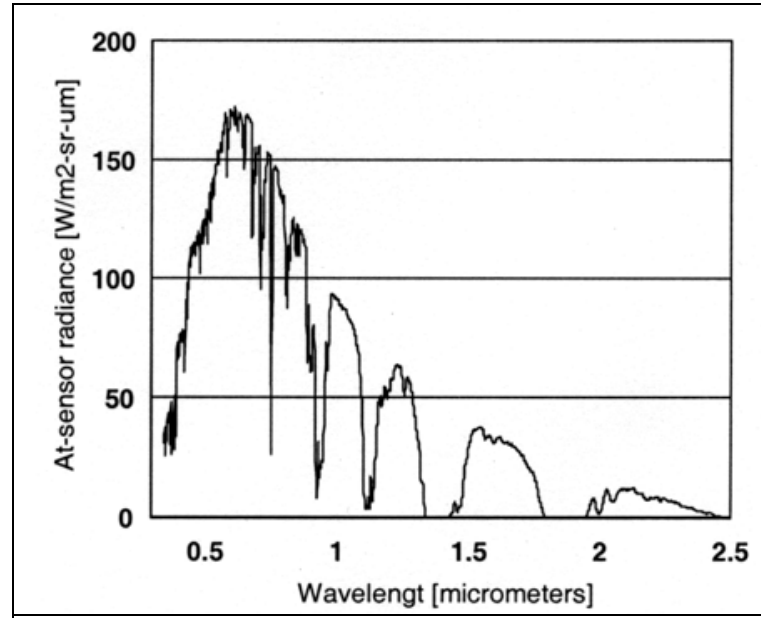

Figure 2.19 shows the at-sensor radiances predicted for the nadir-view of MTI on September 15.

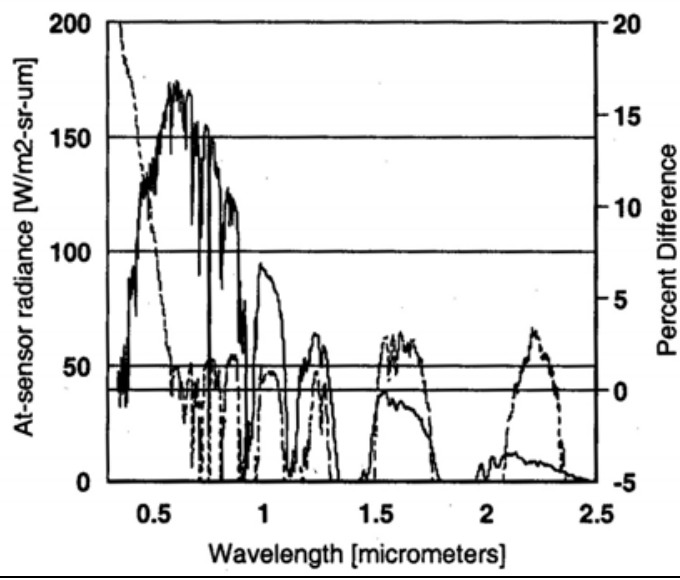

Figure 2.20 shows the at-sensor radiances for off-nadir view of MTI as well as percent difference between nadir and offnadir views.

\section{Quality Assessment}

Two approaches have been used to estimate the uncertainties of the reflectance-based method for near-nadir-viewing sensors. The first was a sensitivity analysis examining the uncertainties of each separate field measurement and then determining how these uncertainties impact the predicted at-sensor radiance. The other compared independently derived results from several groups measuring the same site at the same time for identical spectral bands. There are three basic areas of uncertainty in the method: 1) atmospheric characterization, 2) surface characterization, and 3) radiative transfer code. The results of earlier studies are summarized in Table 4, where the uncertainties form the radiative transfer code are due to its inherent numerical accuracy and assumptions.

Uncertainties in the surface characterization are difficult to quantify because there are two errors to consider. The first is that of an individual measurement estimated to be less than $2 \%$ for the range of reflectance seen at typical field sites (that is a reflectance value of 0.01 at a reflectance of 0.50 ). Effects due to spatial variability are not felt to be significant sources of uncertainties in this data set based on the results shown in Figures 2.10 through 2.14 .

In addition to the surface reflectance measurement, there are effects due to surface bidirectional effects. These bi-directional reflectance effects include the conversion of nadir-measured reflectance to that of the sensor's view angle, as well as that due to multiple scattering interactions between the surface and atmosphere. This latter, diffuseradiance viewing is computed assuming a lambertian surface is compared to those including measured surface bi-directional reflectance. The majority of the $1.2 \%$ effects 
listed in Table 2.2 is due to uncertainties in covering the surface reflectance of the test site measured at a nadir view to that of a near-nadir viewing sensor.

The last area of uncertainty is the atmospheric characterization. Much of the uncertainty here is due to an incorrect determination of the aerosol type, that is, the aerosol size distribution and the aerosol complex index of refraction. These two parameters lead to topof-the-atmosphere-radiance uncertainties of $2.0 \%$ and $3.0 \%$, respectively. In addition, there is a $1.1 \%$ uncertainty due to errors in the knowledge of the column amount of atmospheric aerosols. Not shown in the table are effects due to gaseous absorption that are difficult to quantify unless specific spectral bands are studied. For the most part, the accuracy of the RSG's ozone retrieval leads to uncertainties in predicted at-sensor radiances that are less than $1 \%$ for bands that fall between 500 and $600 \mathrm{~nm}$. The RSG's retrieval of column water vapor has an uncertainty of $20 \%$ and this leads to small
Table 2.2

Estimates of at-sensor radiance uncertainties due to uncertainties in parameters given.

\begin{tabular}{|l|c|}
\hline \multicolumn{1}{|c|}{ Error Source } & $\begin{array}{l}\text { At-sensor } \\
\text { radiance } \\
\text { uncertainty }\end{array}$ \\
\hline $\begin{array}{l}\text { Radiative transfer } \\
\text { code }\end{array}$ & 1.0 \\
\hline $\begin{array}{l}\text { Vertical distribution of } \\
\text { scatterers }\end{array}$ & 1.0 \\
\hline Surface reflectance & 2.1 \\
\hline Surface BRDF & 1.2 \\
\hline $\begin{array}{l}\text { Aerosol index of } \\
\text { refraction }\end{array}$ & 2.0 \\
\hline $\begin{array}{l}\text { Aerosol size } \\
\text { distribution }\end{array}$ & 3.0 \\
\hline Aerosol optical depth & 1.1 \\
\hline Root Sum Square & 4.7 \\
\hline
\end{tabular}

uncertainties for most of the bands that are typically studied b the RSG.

If it is assumed that the errors are independent, then a root-sum square approach leads to an overall uncertainty of $4.7 \%$. In addition, there is an error due to the registration of the ground-based data to the satellite imagery. This is minimal of the small footprint of the MTI because tarpaulins placed at the corners to the test site allow the site to be found in the imagery. Verification of this estimated uncertainty has been found through joint field campaign to various test sites. These comparisons showed that the above $4.7 \%$ is not unreasonable. Considering the results shown in Figure 15 related to the Junge size distribution and the results of the reflectance measurements shown in Figures 2.10 through 2.14, it is reasonable to assume that the accuracy of the predicted at -sensor radiance for the near-nadir view is better than $4.7 \%$.

The above discussion refers to cases where the sensor being calibrated is viewing at a near-nadir view (within \pm 20 degrees of nadir). For the off-nadir, backward look of MTI for this campaign these uncertainties are still valid for the most part because of the low solar zenith angle seen during the overpasses. Past work shows that the uncertainties in the radiative transfer code do not increase significantly with view angle until the solar zenith angle exceeds 80 degrees. Those due to aerosol optical depth and size distribution uncertainties do not increase significantly until the solar zenith angle exceeds 40 degrees. The only significant uncertainty that is larger for the off-nadir case is that due to surface BRDF. Sensitivity analysis shows that assuming a lambertian surface can lead to an underestimation of approximately $3 \%$ for he solar zenith angle of the current work. 
To summarize the ground truth reflectance campaign, it is expected that the uncertainty results for the nadir view will be less than 5\% for wavelengths between 600 and $1000 \mathrm{~nm}$. At shorter wavelengths, the lower reflectance of the playa will lead to slightly larger uncertainties, though still less than $7 \%$ in the extreme cases. At longer wavelengths, the uncertainty is again slightly larger due to uncertainty in the solar irradiance and larger uncertainties in the retrieved surface reflectance. For the off-nadir view, the uncertainty in the $600-1000 \mathrm{~nm}$ spectral range will still be at the 5\% level. At shorter wavelengths, the uncertainty is larger due to larger uncertainties from the surface BRDF and the lower surface reflectance. Fortunately, these two uncertainties counteract each other. That is, as the surface reflectance decreases, the effect of surface BRDF is mitigated. Thus, the uncertainties are again expected to be less than 7\%. At longer wavelengths in the SWIR, the surface BRDF has minimal impact due to the lower scattering optical depths, thus, uncertainties are expected to be similar to those of the nadir case.

\section{MTI Reflectance Calculations}

The data measured during the ground truth campaigns (reflectance from ASD spectroradiometer, optical depths from sun radiometer, atmospheric profiles from radiosonde, etc. was provided to Los Alamos National Laboratory (LANL) for their independent calculations of the top of the atmosphere radiances).

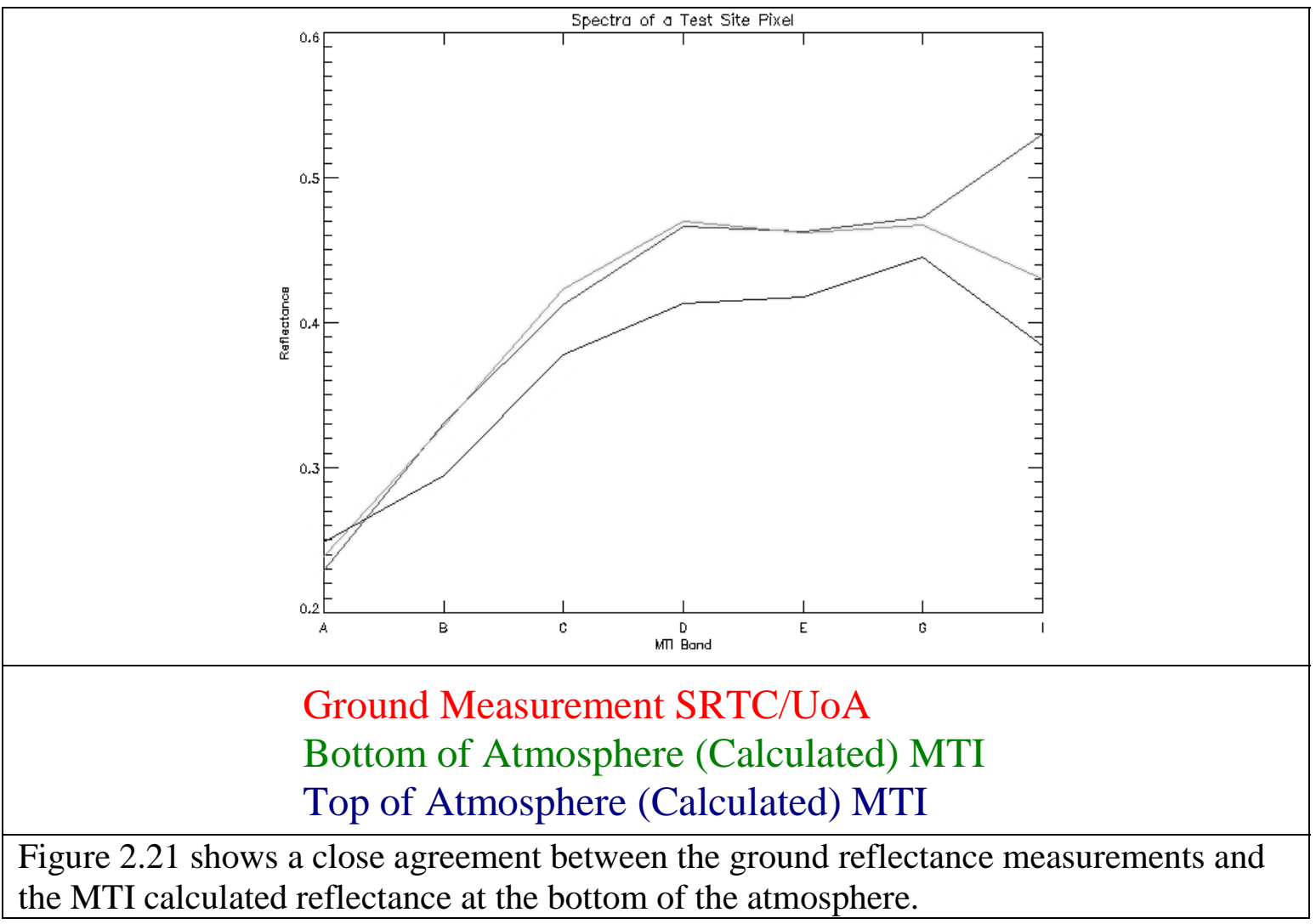

Agreement between the ground truth reflectance and calculated reflectance from MTI measurements demonstrate the quality of data recovered by the satellite. Except for Band 
I, the difference between the ground truth reflectance and the calculated MTI reflectance is within 3\%. Band I has been demonstrated to be anomalous even with the in-board MTI calibration system.

\section{MTI Pixel Resolution Support Studies at Ivanpah Playa}

A series of targets separated at 5, 10, and 25 meters were deployed at Ivanpah Playa during the September campaign for the satellite resolution studies. The tarps were approximately $6 \mathrm{~m}$ x $6 \mathrm{~m}$. Similar deployment was conducted during the May 2001 campaigns. Figure 2.22 shows the tarp arrangement next to a variety of instruments for atmospheric measurements.

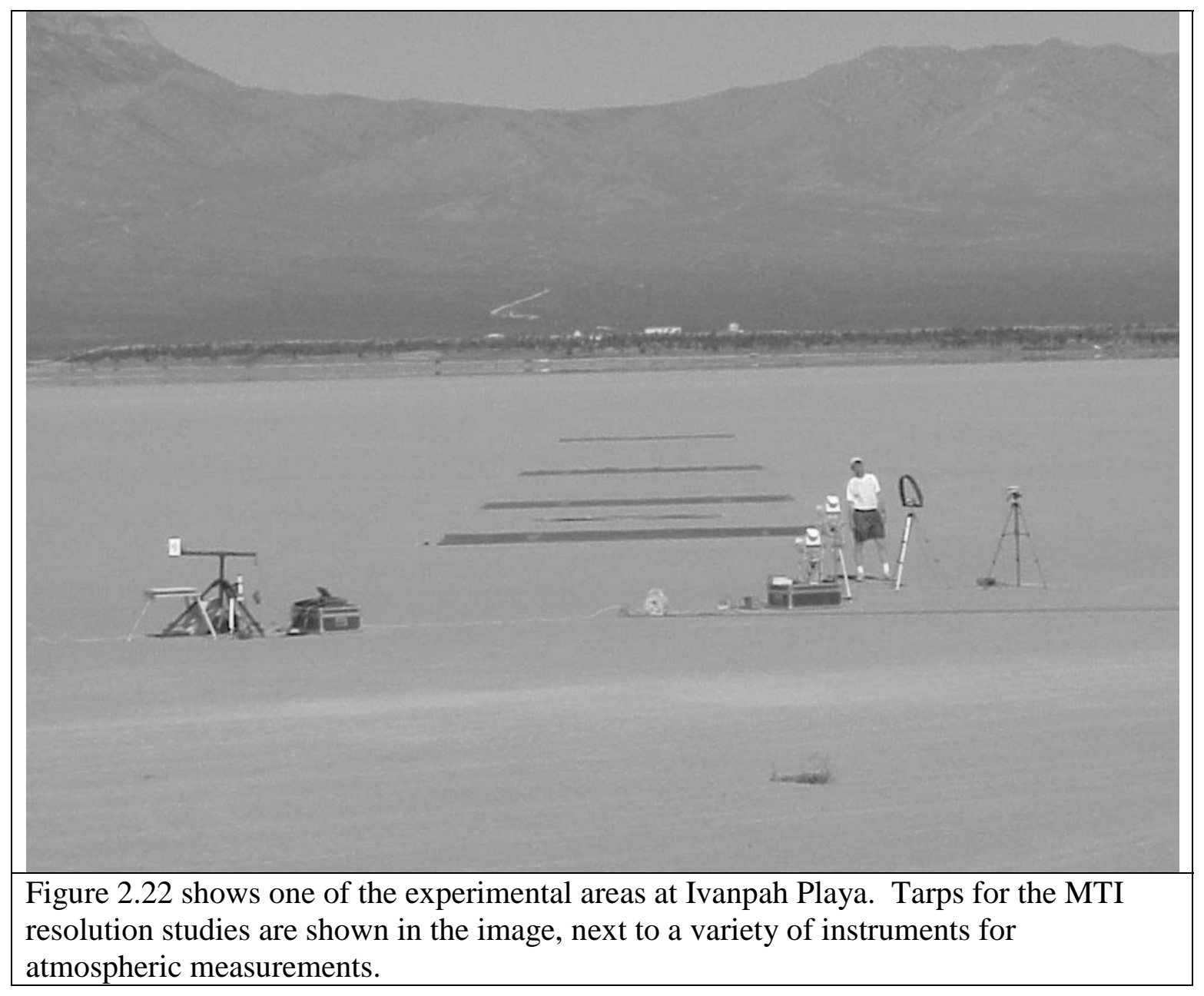

Figure 2.23 shows the MTI satellite image on September 16, 2000. The location of the tarps is evident in the image. Identification of the two tarps with a 5-meter resolution was difficult in the image. The satellite image also shows that the location of the site selected for the tarps had a small contrast with the surrounding soil. 
WSRC-TR-2002-00043

Final MTI Data Report: Ivanpah Playa (U)

Savannah River Technology Center

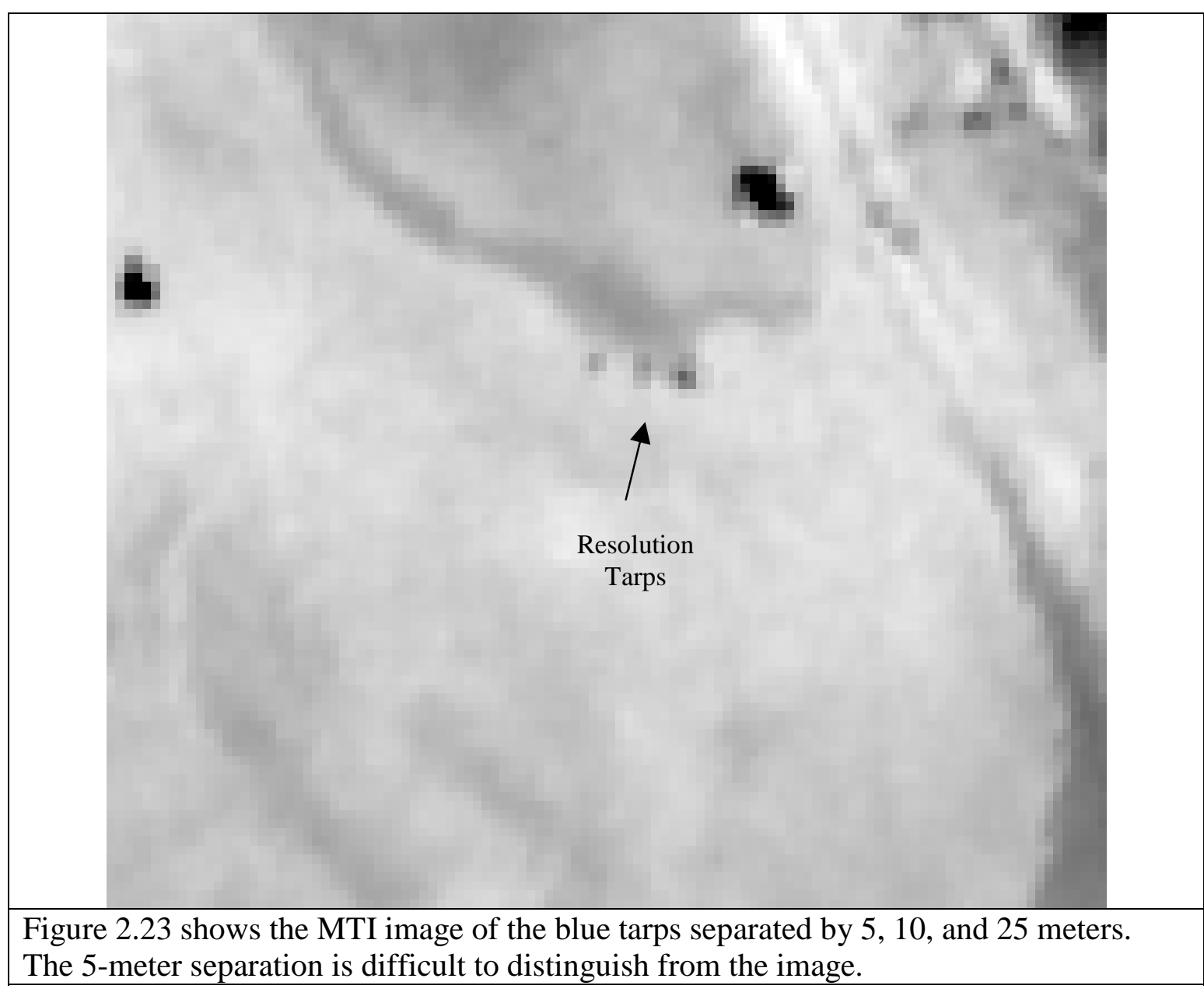




\section{Thermal Vicarious Calibration}

\section{Campaign at Ivanpah Playa}


The ground surface temperature measurements with satellite sensors are conducted through the measurement of top of the atmosphere (TOA) radiances. The MTI satellite uses five thermal spectral bands in the MWIR and LWIR spectral regions (bands J [3.50-

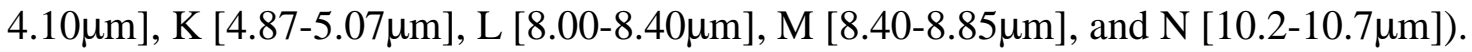
The TOA radiances from these bands in conjunction with other bands for atmosphere characterization and a variety of algorithms are used to retrieve ground surface temperatures. The validation and verification ground truth targets for the temperature algorithms are primarily heated/unheated lakes. Power plant heated lakes provide a field laboratory to study an extensive range of water temperatures. The temperature range found in natural water targets and power plant heated lakes are from 1 to 50C. Besides water targets, land targets provide the opportunity to study temperatures and changes in material emissivity. Ivanpah Playa located in the Nevada/California border is one of the locations used in the calibration of the satellite. Figure 3.1 shows a visible image (band C) of Ivanpah Playa recorded on September 15,2000 . The calibration site is annotated with stars for easier identification. The high reflectivity and uniformity of the terrain at a high elevation $(0.8 \mathrm{~km})$ makes Ivanpah Playa ideal for the vicarious calibration in the visible and near-infrared spectral regions. A research and development program was conducted to study the feasibility of using the playa as a thermal calibration site. Equipment was developed to measure the surface emissivity and temperature at a selected calibration site during the

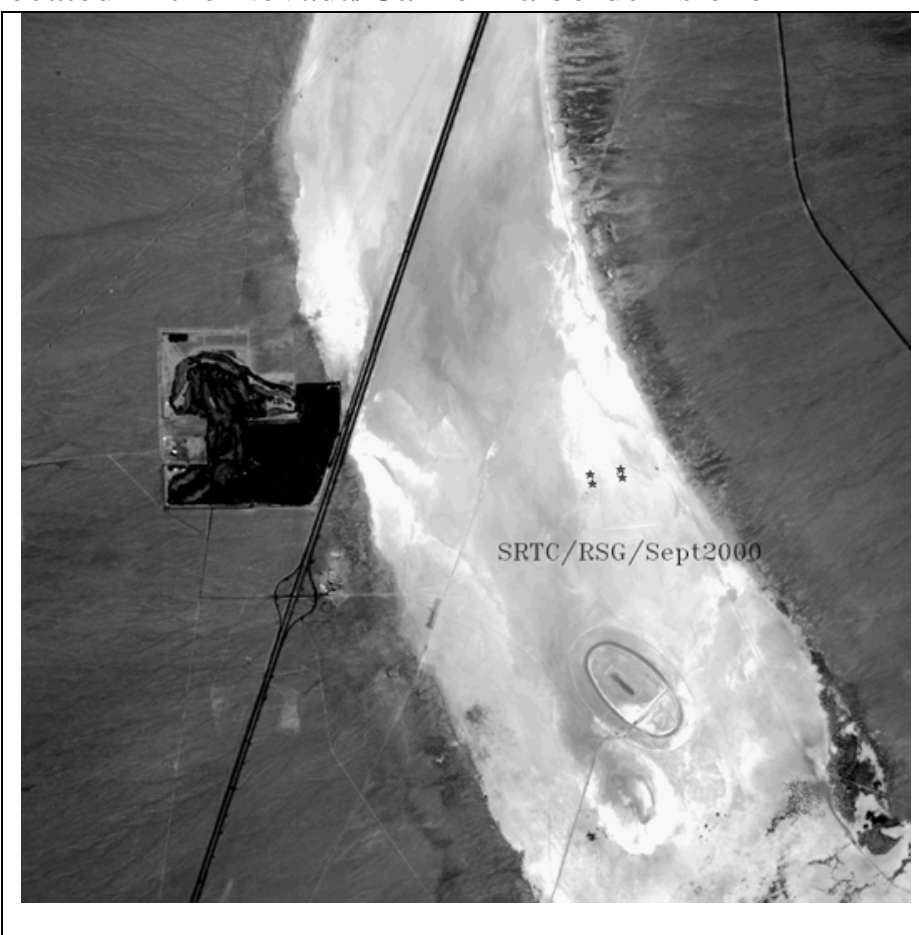

Figure 3.1 shows an MTI image (band C) of Ivanpah Playa. The corners of the calibration site are marked with stars for easier identification. satellite overpass. The ground truth measured data in four campaigns (July 2000, September 2000, May 2001 and March 2002 show that there are two predominant distinct surface emissivities. Satellite imagery and 2-d scatter plots of reflectance versus radiance shows that the thermal band $\mathrm{N}$ is an ideal band for temperature measurement of the ground surface. Scatter plots of TOA radiances from bands $L$ and $M$ versus band $C$ surface reflectance show a complicated temperature and emissivity dependency.

\section{Experimental Measurements}

A Fourier transform infrared spectrometer (FTIR), manufactured by Midac Corporation (M2400 series, the illuminator), was used to measure wavelength dependent radiance of 
Ivanpah Playa soil surface. The FTIR spectrometer by Midac was designed and built with a Michelson interferometer. The spectrometer has a $3.8 \mathrm{~cm}$ aperture diameter with a 40 milliradians field of view (FOV). The spectrometer was equipped with mercury cadmium telluride (MCT) detector cooled with liquid nitrogen to $77 \mathrm{~K}$. The housing of the FTIR spectrometer was maintained at 50C with the aid of an insulated jacket with heating blankets. Heating blankets were placed above and below the FTIR. The heating blankets attached to the FTIR spectrometer were insulated from the ambient air with Styrofoam sheets and an aluminum shield. A thermocouple was attached to the FTIR spectrometer housing for temperature monitoring and control. The temperature controller maintained the FTIR spectrometer temperature within $0.2 \mathrm{C}$ of the selected temperature. A fan was placed inside of the spectrometer to circulate the air and to improve temperature equilibration. The instrument was warmed-up for $1 \frac{1 / 2}{2}$ hours prior to data acquisition.

Water vapor inside of the instrument was a problem in previous experiments. The primary water vapor source was water condensation onto the instrument surfaces during the transfer of liquid nitrogen to the MCT detector dewar. A battery-powered air pump with a dessicant tube was used to produce dry air for the FTIR spectrometer. The water vapor problem was eliminated through the continuous flow of dry air generated by the pump.

The FTIR spectrometer was attached to a jack with bolts through a rubber-insulating mat for mechanical vibration reduction control. The jack with the FTIR spectrometer was attached to a garden cart as shown in Figure 3.2. A platform with a steering beam mirror made out of stainless steel rods was attached to the FTIR spectrometer front surface. The gold-coated mirror placed at 45 degrees for nadir measurements steered the soil radiance into the spectrometer. The mirror was adjusted appropriately for off-nadir measurements. Figure 3.2 shows the FTIR spectrometer, blackbodies, battery, power inverter and computer assembled in the cart. The cart grill dimensions are 2' $x 4$ '. The cart grill is 12 " from the ground (10" diameter inflated tires). Motion vibrations during the walk-around the calibration site were reduced with the air-inflated cart tires. The FTIR spectrometer window entrance was 21 " from the soil surface.

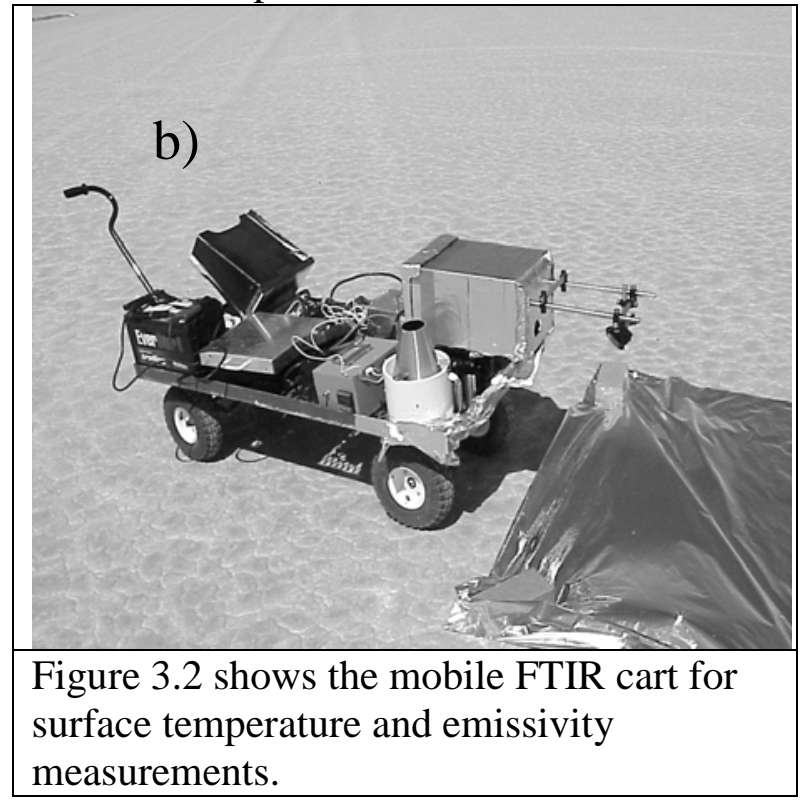

Calibration of the FTIR spectrometer was accomplished with two blackbodies held at two temperatures. The temperature of the hot blackbody was set at $58 \mathrm{C}$ with the aid of a temperature controller. The air temperature (30-40C during the course of the experiment) 
primarily determined the temperature of the cold blackbody. Two hundred fifty six spectra were co-added during the blackbody and sky background measurements. The sky background was measured with a diffuse infragold-coated plate manufactured by Labsphere. The temperature of the infragold-coated plate and the blackbodies were monitored with thermistor probe manufactured by Omega with $0.02 \mathrm{C}$ accuracy.

The soil target radiance was measured by collecting spectra every 2 seconds in our calibration area.

Approximately 20 minutes worth of data was acquired during the 15 passes at the calibration site measuring $80 \times 280 \mathrm{~m}^{2}$. Figure 3.3 shows the GPS track during the walk around through the calibration site area.

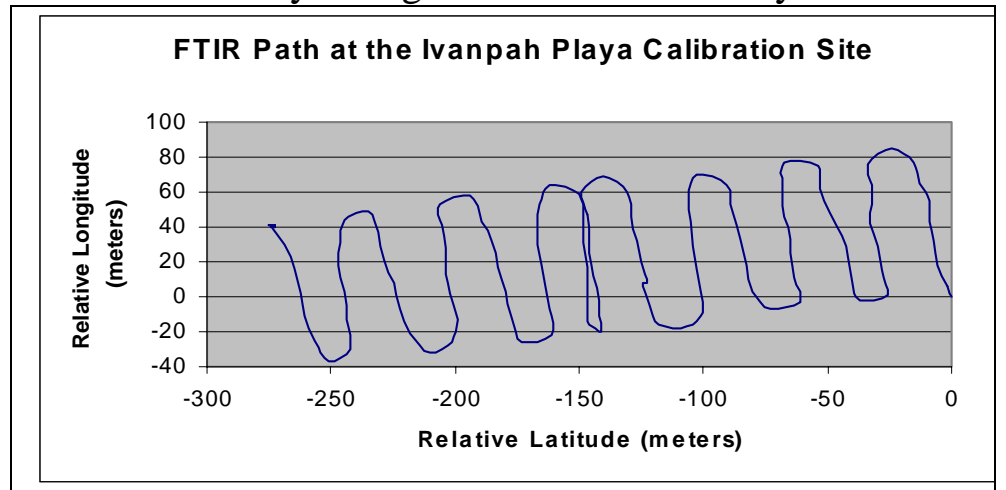

Figure 3.3 shows the path taken over the calibration site with dimensions of $280 \mathrm{~m} \times 80 \mathrm{~m}$.

The recorded data was acquired in the following manner: 1) measure radiance of cold blackbody, 2) measure radiance of hot blackbody, 3) measure radiance of gold-coated infragold plate 4) measure soil radiance and 5) measure hot and cold blackbody radiances.

Angle dependent radiance measurements were also conducted by rotating the steering beam mirror. The angle was measured using a digital inclinometer with 0.1-degree accuracy. In these experiments, the radiance of the selected soil surface was measured with the steering beam mirror inclined at angles of 45, 40.7, 35.7, 30.6 and 25.4 degrees. The mirror inclination angles correspond to nadir, 8.6, 18.6, 28.8 and 39.2 degrees offnadir viewing angles. The cart was moved away from the soil target area accordingly to ensure measurements at the same location. Careful alignment to the surface was made with a laser pointer attached to the FTIR spectrometer window.

Accurate calibration of the satellite requires soil surface emissivity and temperature measurements. The emissivity is an intrinsic property of the particular soil surface. Inhomogeneous soil surface with variable emissivity results in variable soil surface temperature. The emissivity/temperature surface homogeneity was studied using the FTIR spectrometer and an infrared camera (Inframetrics SC2000).

Variable wind speed and air temperature can induce temperature variability at the soil surface. The effects of the air temperature, and the wind speed were studied using an experimental setup equipped with a Heimann radiometer $(8-14 \mu \mathrm{m})$, an anemometer, and sensors for air temperature and relative humidity measurements. Broadband IR and visible solar radiation were obtained with radiometers manufactured by Eppley (models PIR and PSP respectively). Surface temperature was measured with an 8-14 micron bandwidth Heimann radiometer model KT19 manufactured by Heitronics and calibrated in the laboratory to within $0.2 \mathrm{C}$. The radiometer was positioned approximately 0.5 
meters above the soil surface. Humidity and wind speeds were measured with a Vaisali50Y and Met One respectively. A data logger (Campbell 21X) was used to store the experimental data from the multiple sensors from the wind/temperature tower. Two duplicate towers were placed at the southeast and northwest corners of the calibration site for the May 18-19, 2001 period ground truth campaign. One meteorological tower was used at the southeast corner on May 20, 2001 and also during the September 2000 and March 2002 campaigns.

\section{FTIR Measurements}

Thermal calibration of the MTI satellite at Ivanpah Playa, in contrast to water targets, is complicated by the heterogeneous nature of the soil surface. Besides the spectral and spatial variability, the wind speed over the playa also affects the surface temperature. Single point measurements at the playa can be biased due to the above mentioned problems. In order to average out soil radiance measurements, the FTIR spectrometer was assembled in a mobile platform and moved over the calibration site to sample hundreds of points within \pm 10 minutes of the satellite flight time.

Prior to the soil-sampling step, the FTIR spectrometer was calibrated by calculating the instrument response function (IRF) with the aid of two blackbodies. The IRF was calculated as

$$
I R F=\frac{B B_{H o t}-B B_{C o l d}}{L_{H o t}-L_{C o l d}} .
$$

where $\mathrm{BB}_{\mathrm{Hot}}$ and $\mathrm{BB}_{\text {Cold }}$ are the raw machine units for the hot and cold blackbodies and $\mathrm{L}_{\mathrm{Hot}}$ and $\mathrm{L}_{\mathrm{Cold}}$ are the Planck distribution functions for the temperatures of the blackbodies. Once the IRF was calculated, the target radiance was calculated from

$$
L_{\text {Soil }}=L_{H o t}-\frac{\left(B B_{H o t}-B B_{\text {Soil }}\right)}{I R F}
$$

The sky background was measured with a diffuse infragold-coated plate. The infragoldcoated plate is not a perfect reflector (emissivity=0.04) and therefore has a small thermal contribution. The plate temperature was used to calculate the small radiance contribution and therefore the correction to the sky measurements. The sky radiance was calculated from

$$
L_{s k y} \downarrow=L_{H o t}-\frac{\left(B B_{H o t}-B B_{s k y}\right)}{I R F}-L(T)_{\text {Gold_Plate }_{\text {Ple }}}
$$


Figure 3.4a shows the spectral exitance of the hot and cold blackbodies and the soil and sky measurements. The spectral exitance was calculated using equations 1 and 2 . The effect of the soil emissivity on the spectral exitance is evident in this figure.

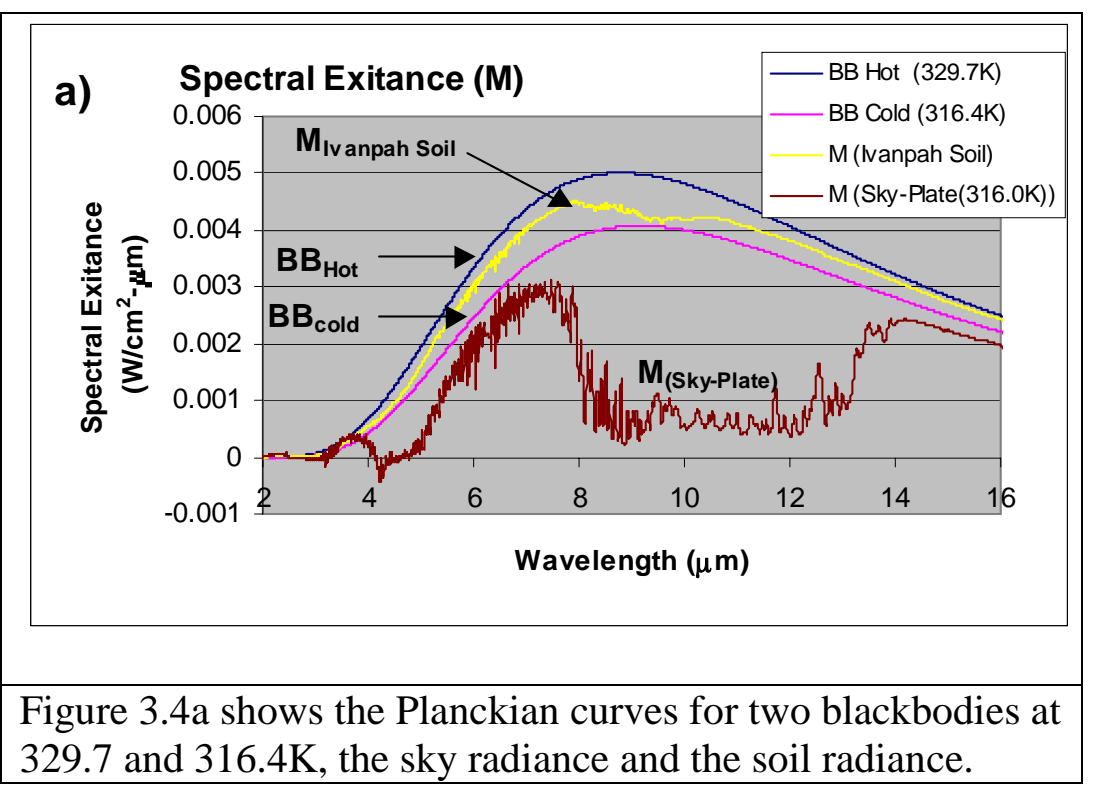

Figure $3.4 \mathrm{~b}$ shows the best Planckian curve fit to the soil spectral exitance and the calculated temperature. The two temperatures shown are the result of two different regions used during the best-fit interactive routine.

Once the best

Planckian curve fit is known $\left(\mathrm{L}_{\text {Soil_BB }}\right)$, the average emissivity of the calibration site

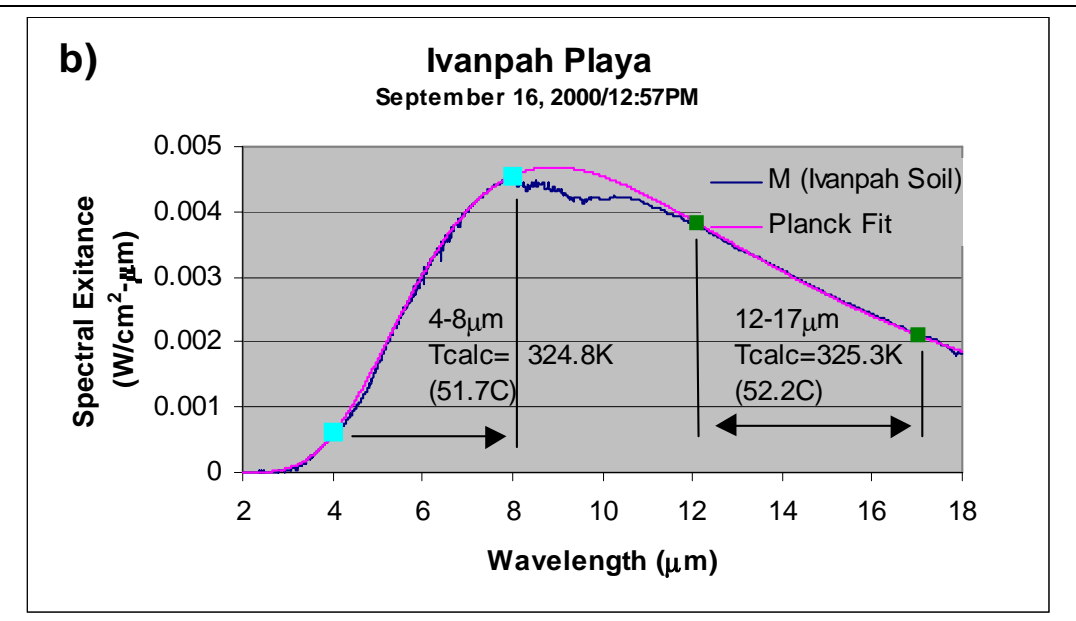

Figure 3.4b shows the best blackbody fit to the experimental radiance and the temperatures calculated by using only part of the experimental curve. was obtained through equation 4).

$$
\varepsilon=\frac{\left(L_{\text {Soil }}-L_{S k y}\right)}{\left(L_{\text {Soil_BB }}-L_{S k y}\right)} .
$$


Figure $3.5 \mathrm{c}$ shows the calculated emissivity for Ivanpah Playa in the $4.5-13.5 \mu \mathrm{m}$ spectral range with and without the sky radiance contribution $\mathrm{L}_{\text {sky }}$. Comparison between temperature retrieval of the Ivanpah Playa calibration site by the MTI satellite and the temperature calculated from the FTIR measurement data is in progress.

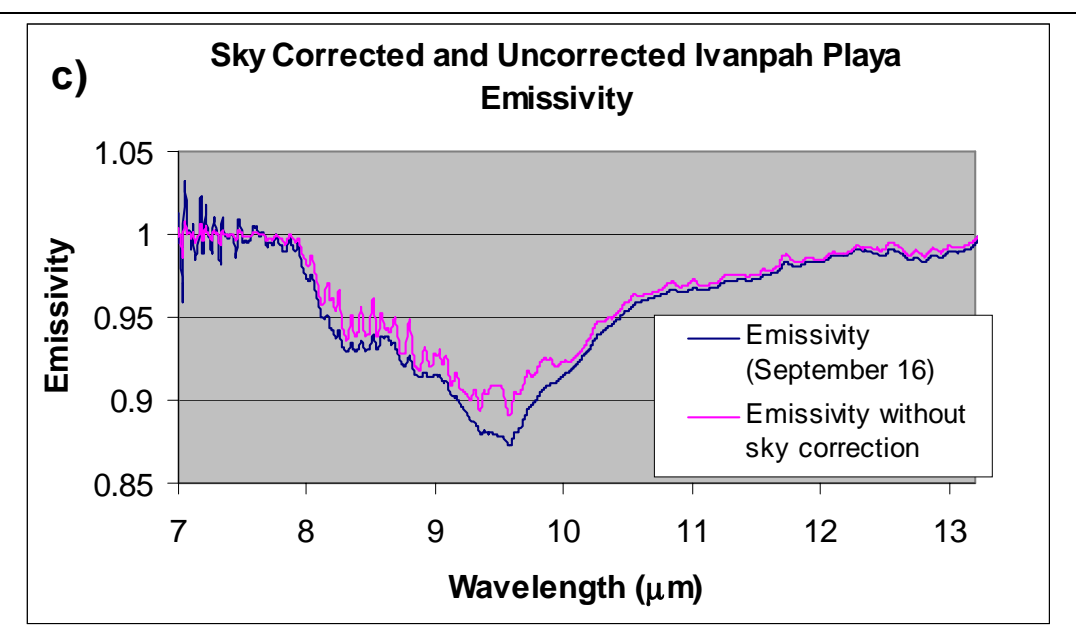

Figure 3.5 shows the average calculated emissivity of Ivanpah Playa soil with and without the sky correction in the September 2000 campaign.

Figure 3.6a shows the Planck fit to the spectral exitance data measured on May 2001 campaign. The methodology employed in May was the same as the methodology employed on September 2000.

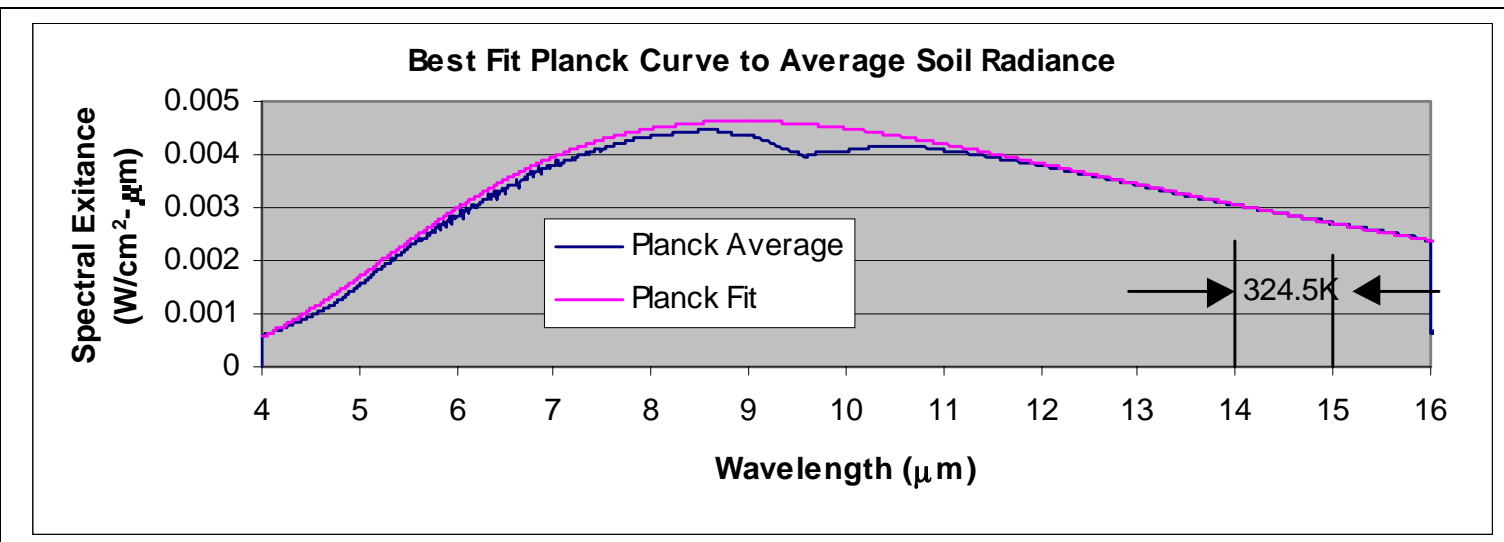

Figure 3.6a shows the best blackbody Planckian fit to the experimental soil curve and the temperatures calculated by using only part of the experimental curve.

Figure 3.6b shows the calculated spectral emissivity for Ivanpah Playa in the $8.0-14.2$ $\mu \mathrm{m}$ spectral range. The wavelength-dependent emissivity intensity values at the calibration site were highly variable ranging from 0.75 to approximately 0.86 at $9.55 \mu \mathrm{m}$. The emissivity spectrum measured at the calibration site resembles very closely the desert varnish emissivity spectrum. Salisbury and D'Aria studied the emissivity/reflectance of terrestrial materials and the masking effect of desert varnish to rock spectrum measurements. Desert varnish is composed of manganese and ferric oxides intimately mixed with montmorillonitic clay. The only spectral feature displayed by desert varnish in the $8-12 \mu \mathrm{m}$ spectral region is the $\mathrm{Si}-\mathrm{O}$ stretching vibration band of the clay. The emissivity spectrum of varnished surfaces closely resembles the simple clay emissivity 
spectrum with minima peaks near 9.6 and $11.0 \mu \mathrm{m}$. The emissivity spectra measured on September 16 and July 4, 2000 campaigns differed from the emissivity spectrum measured on May 18, 2001 at a different calibration site. The emissivity spectra measured on September 16 and July 4, 2000 campaigns were obtained from the same location approximately 200 meters south from the May 18, 2001. The September 16, 2000 calibration site emissivity spectrum was found to contain quartz reststrahlen bands with the characteristic gap in the doublet near $8.6 \mu \mathrm{m}$ and the weak quartz doublet between $12.2 \mu \mathrm{m}$ and $13 \mu \mathrm{m}$. On closer examination, the September 16, 2000 emissivity spectrum is a combination of the desert varnish and quartz spectra.

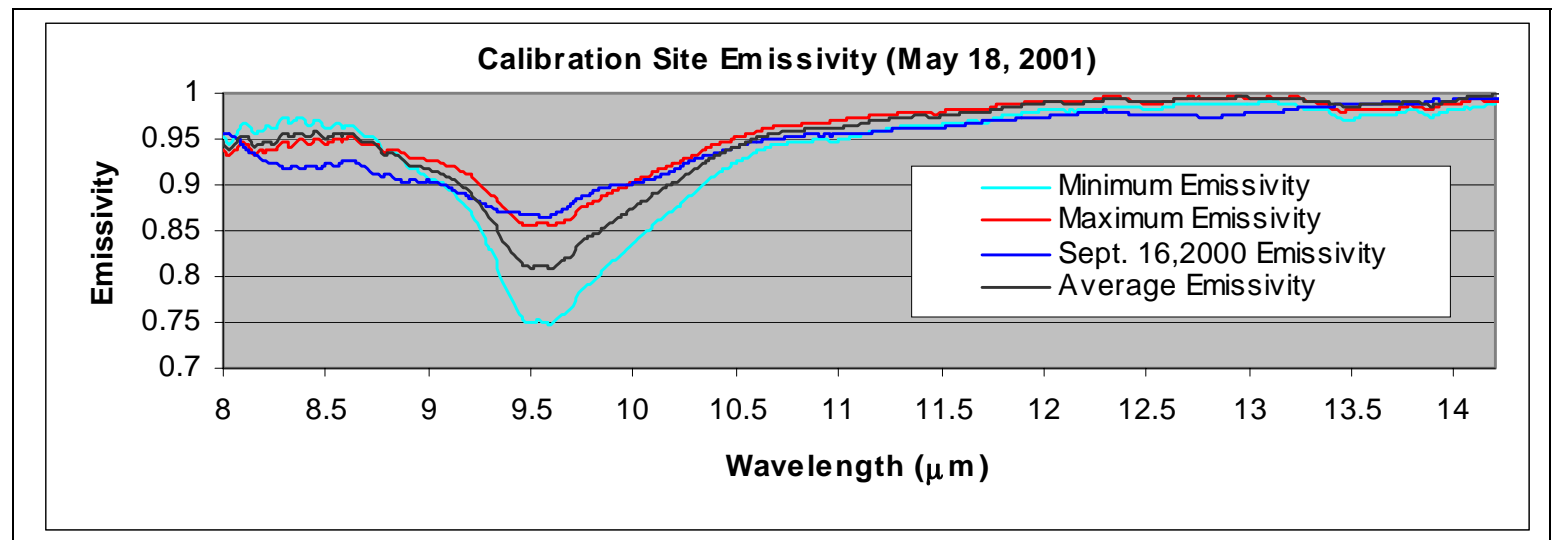

Figure $3.6 \mathrm{~b}$ shows the minimum, maximum, and average emissivity at Ivanpah Playa on May 2001 with emissivity spectrum from September 16, 2000.

The average soil temperature was calculated from the curve fit to the spectral exitance curve in the $14-15 \mu \mathrm{m}$ spectral range. The $14-15 \mu \mathrm{m}$ region was selected in temperature calculations due to the closeness of background radiance to soil radiance (the closer the background radiance to the target radiance the smaller the uncertainty in temperature calculation due to emissivity). The emissivity data acquired on September 2000 and May 2001 campaigns show variability in spectral bands and also in intensity. The 600 emissivity spectra recorded on the May 2001 campaign calibration site were found to have the same spectral features but with large swings in intensity values. The spectrum intensity values were correlated with soil spatial variability. Although the emissivity in the $14-15 \mu \mathrm{m}$ spectral range is unchanged in value, a two-degree temperature difference was calculated for soil surfaces with maximum and minimum emissivity values of 0.87 and 0.75 at $9.6 \mu \mathrm{m}$. The average temperature for the calibration site within the 20-minute period walk around for the September 2000 and May 2001 campaigns were $325.3 \pm 1.1 \mathrm{~K}(52.2 \pm 1.1 \mathrm{C})$ and $324.5 \pm 1.1 \mathrm{~K}(51.4 \pm 1.1 \mathrm{C})$, respectively. The average temperature include the radiance from tile-like surface and crack areas, wind dependent surface cooling and inhomogeneous surface. It is worth to point out that the single Planck curve fit used to determine the temperature is an approximation to the experimental curve produced by multiple radiance sources with numerous emissivity and temperature combinations.

Characterization of emissivity ground properties at different angles is important for the calibration of the MTI two looks (nadir and off-nadir) in the thermal regime. The angle 
dependence spectral emissivity was studied by changing the angle of the FTIR goldcoated steering mirror. A diode laser beam with a special mount attachment to the FTIR entrance window was used to "paint" the ground surface for the study. The radiance of the soil surface at a given location was measured at 0, 8.6, 18.6, 28.8 and 39.2 degrees off-nadir. The laser beam was used in all measurements to ensure analysis of the same soil surface. The emissivity and temperature was calculated from the soil surface radiance. Figure 3.6c shows the emissivity calculated from the soil radiance for the nadir and 8.6, 18.6, 28.8 and 39.2 degrees off nadir angles. The spectral emissivity spectra did not show any wavelength dependent spectral effects with observation angles.

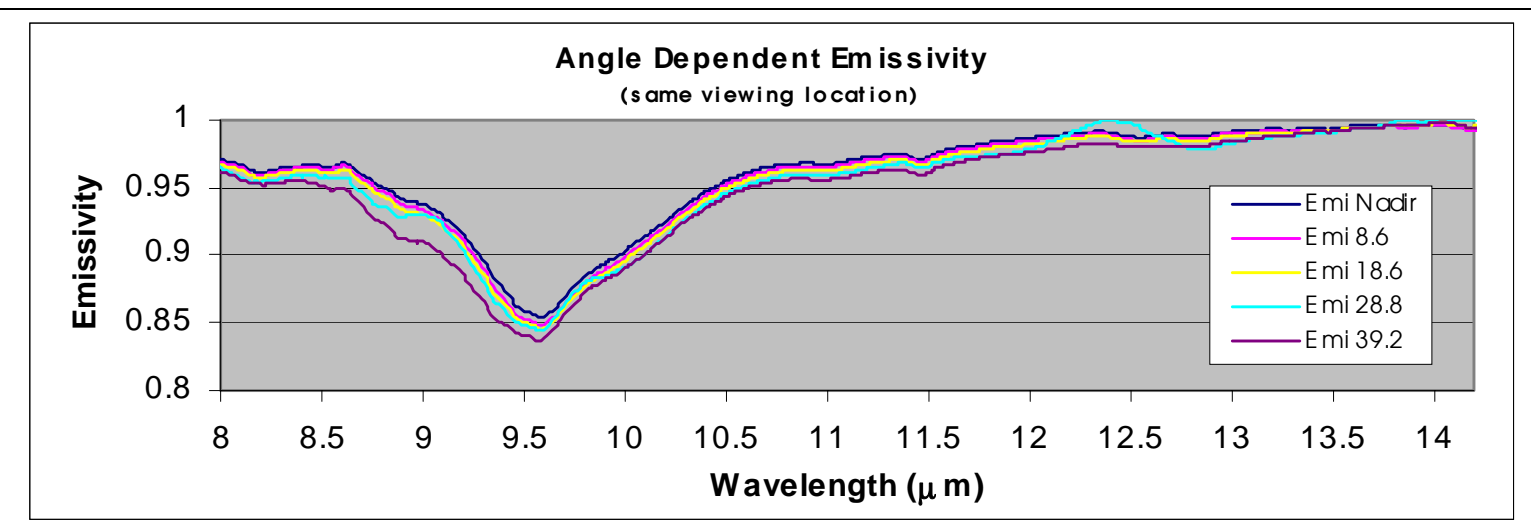

Figure 3.6c shows the emissivity calculated for the nadir and 8.6, 18.6, 28.8 and 39.2 degrees off nadir angles.

\section{Wind Speed Effects}

Ivanpah Playa is an extended dry lakebed covering several miles where soil temperature is "homogenous". The data analysis of the surface cooling by the wind was facilitated by the stable solar radiation during the course of the experiment. Figure 3.7a shows an 80minute time window of the soil surface and air temperature data recorded at the southeast corner of the calibration site on May 20. The satellite over-passed Ivanpah Playa at 60.25

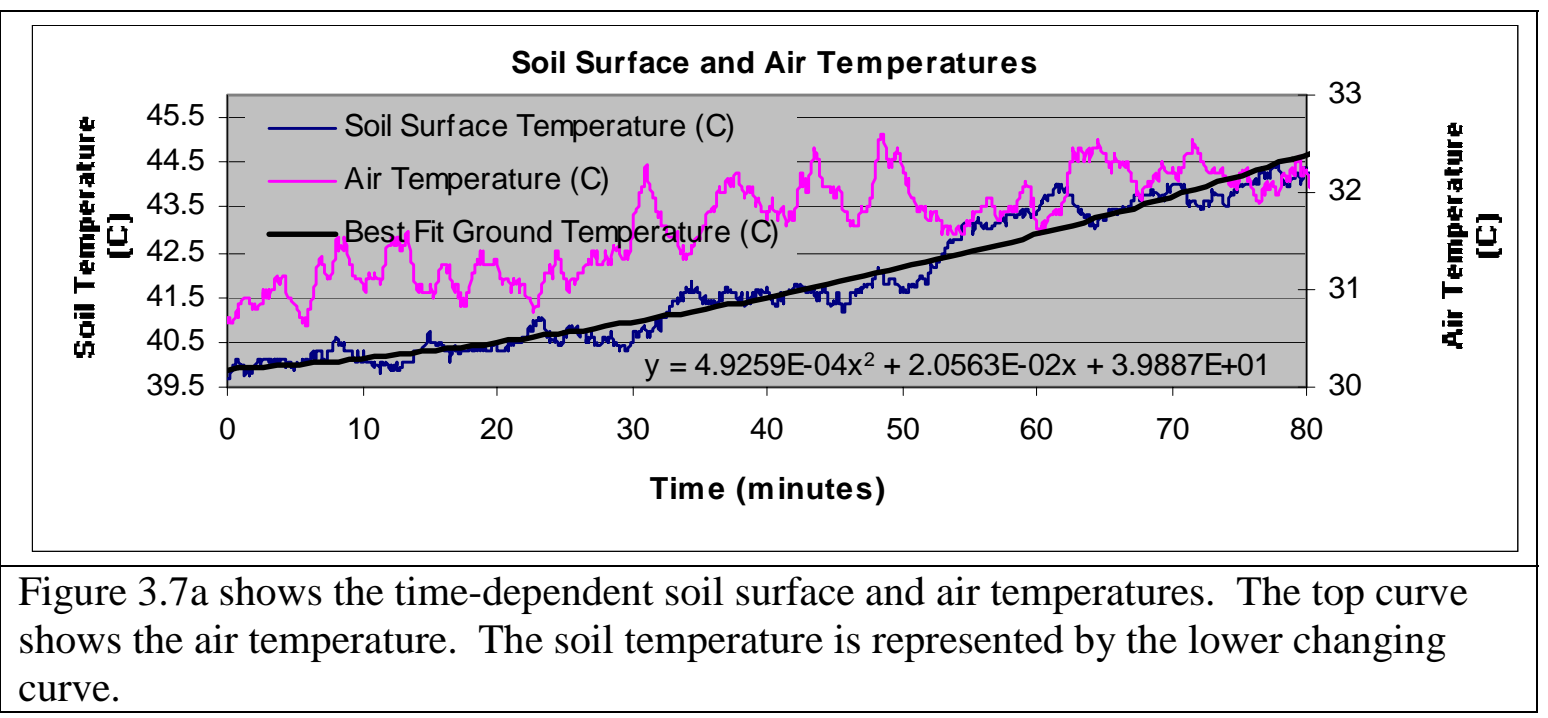


minutes in this graph. The air and soil surface temperatures show up to two degrees variation from temperature transients. The temperature excursions are superimposed on a heating trend. Polynomial fits to the air and surface temperature curves were made to eliminate the long-term time dependent temperature trend in order to analyze the data.

Figure $3.7 \mathrm{~b}$ shows the soil temperature fluctuations and the wind speed curves. A polynomial fit to the soil temperature was used to remove the temperature trend and to produce the temperature fluctuations for analysis. The wind induced temperature standard deviation was $0.35 \mathrm{C}$. The wind speed curve is highly structured and corresponds to vertical and horizontal eddies. Careful examination of the figure shows a mirror image relationship between the wind and surface temperature. The surface temperature is inversely proportional to the wind speed. This relationship holds well in the 0 and 8 meters/second wind speed range. The average wind speed during the course of the experiment was $4.96 \pm 1.70 \mathrm{~m} / \mathrm{s}$.

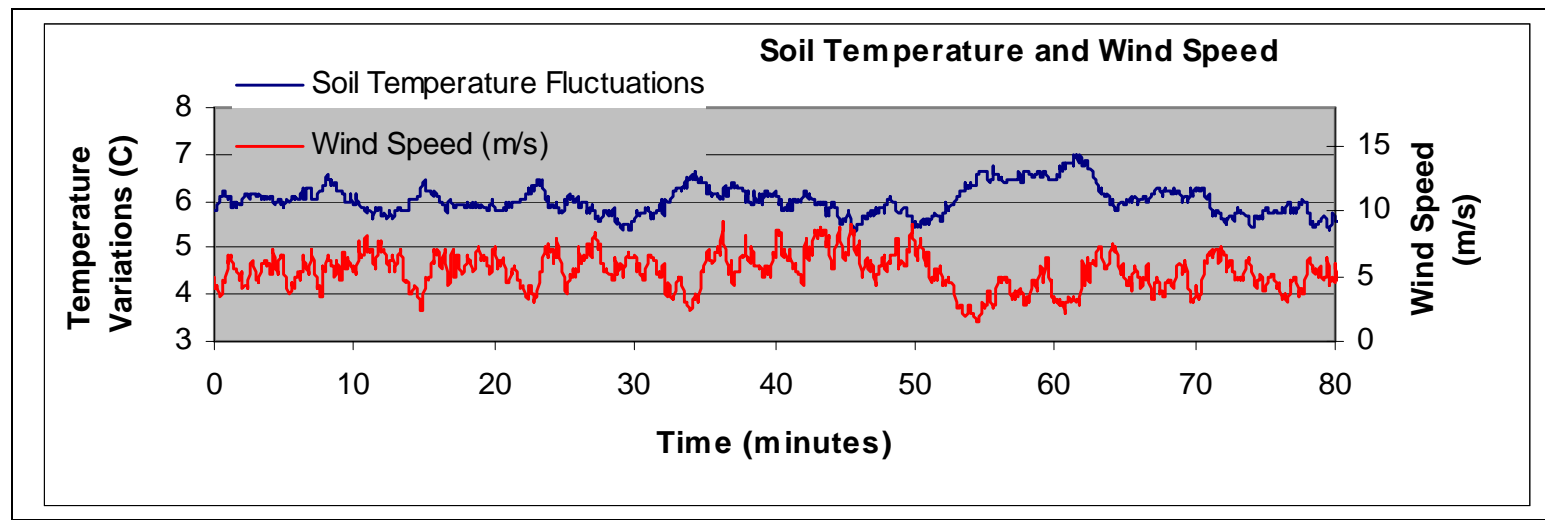

Figure $3.7 \mathrm{~b}$ shows the cooling of the soil surface with the wind.

Figure 3.7c shows the air temperature and wind speed. The figure shows great correlation including time phase matching among these two data sets. On occasions, a large increase in wind speed was not followed by a corresponding increase in air temperature as in the case in the intervals at 24.58 and 27.33 minutes. It is possible that the increase in the wind speed at these times ( 24.58 and 27.33 minute) is primarily due to local downward eddies with cooler air. Further studies will be conducted to determine the local downward eddies effect in temperature characterization. 


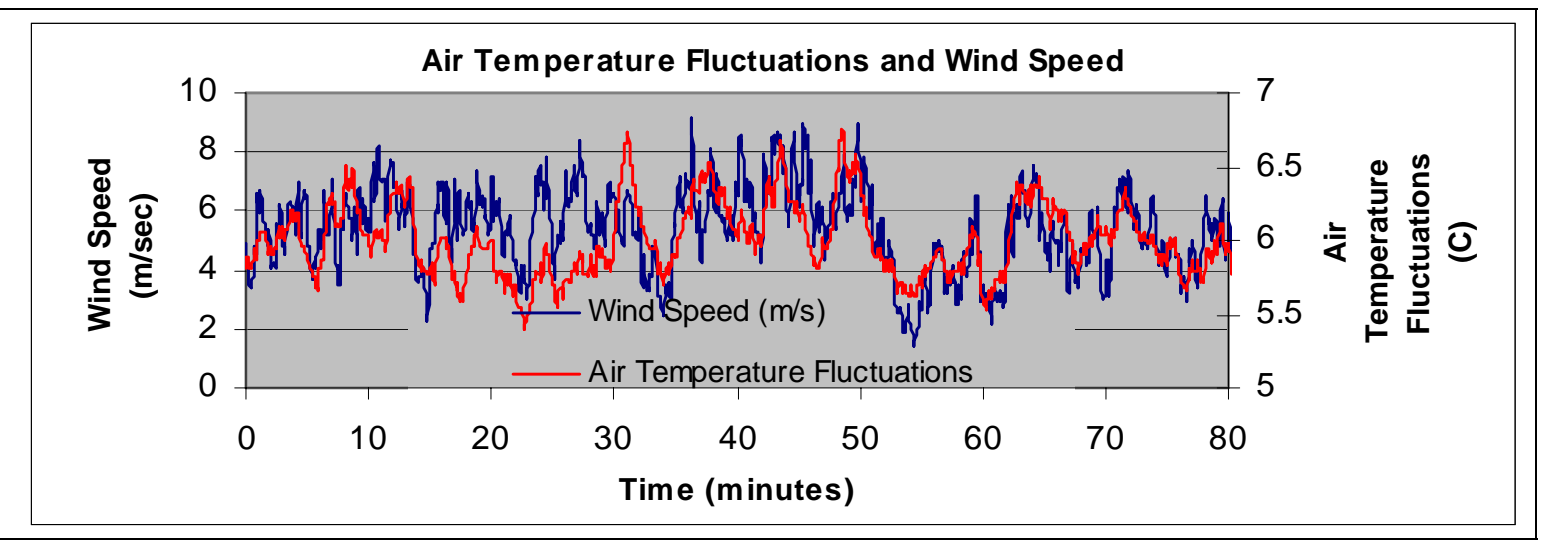

Figure 3.7c shows the close relationship between the air temperature and wind speed.

Figure $3.7 \mathrm{~d}$ shows the air and soil surface temperature variations. The data clearly show the heat exchange between the soil surface and the air. The driving force behind the surface temperature cooling is the resulting energy transfer from the surface to the air powered by the wind speed. The interdependence of the kinetic temperature exchange between the air and the soil is almost one to one where a degree lost by the soil surface corresponds to a degree gained by the air and vice-versa. Since the air temperature variations precede the soil temperature variations, the data suggests that the thermodynamic equilibrium occurred prior to the measurements at the tower location. Further analysis of the data will be conducted to determine the response times and time constants for the different sensors (air, soil, and wind) and for the comparison between the two towers at the southeast and northwest locations. The results obtained at Ivanpah Playa on May 20 during clear skies represent the most ideal case scenario.

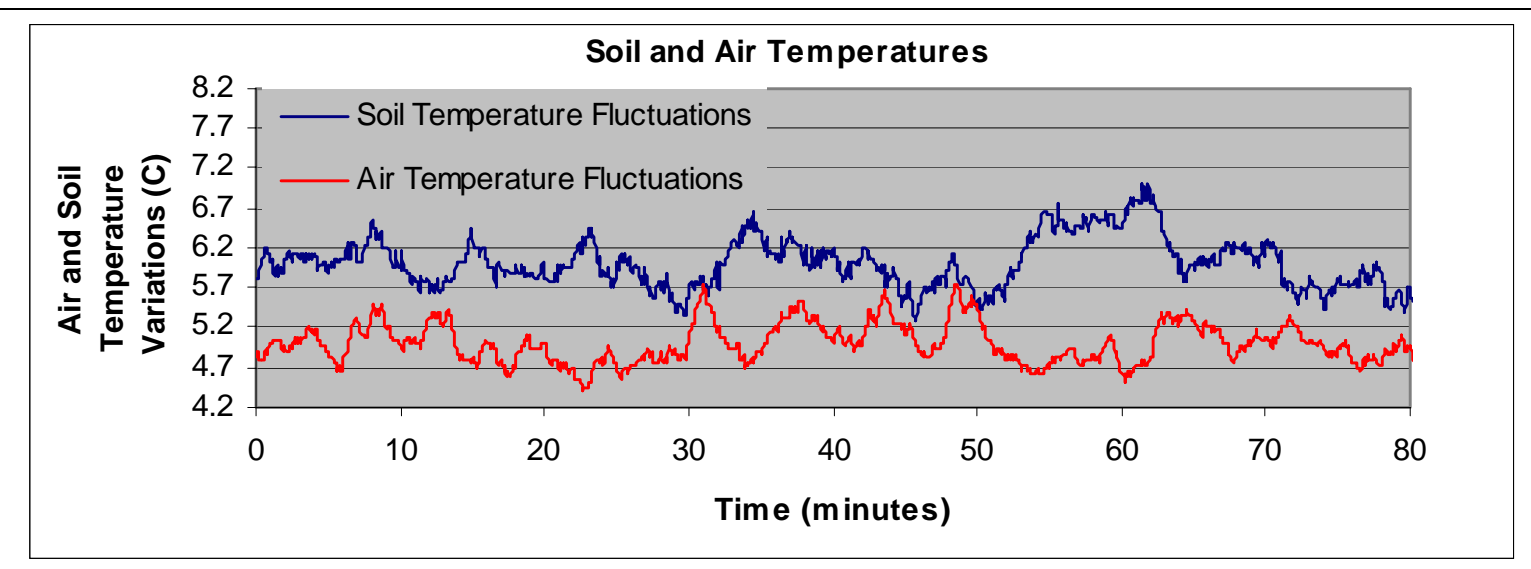

Figure $3.7 \mathrm{~d}$ shows the interdependence between the soil and air temperatures.

\section{Thermal Imaging at Ground Level}

Two different kinds of experiments were conducted at Ivanpah Playa with an infrared imaging radiometer (SC2000). The thermal imaging work conducted was divided into close-up surface analysis (1 meter above the ground surface) and aerial thermal imaging (600 meters above the ground) of the $280 \times 80 \mathrm{~m}^{2}$ dimensions calibration site. 
Ivanpah Playa dry lakebed consists of mud-cracked clay (tile-like) surrounded by cracks. The radiance measured with the Fourier transform infrared spectrometer during the walk around experiment in the calibration site corresponded to two different radiative sources; tile surface and tile/crack combination. Any radiance differences between the two sources could lead to a bias in the reported emissivity and surface temperature by the FTIR work. In order to clarify this issue, close-up experiments were designed with an infrared camera to understand the radiance contributions from the tile-like and crack surface areas.

Figure 3.8 shows the thermal image of the soil surface. At first glance, the thermal image suggests that the cracks are hotter than the corresponding tile surface. The possible scenarios that can explain the thermal image are 1) the same emissivity for the crack and tile surface areas, but different temperatures, 2) the same temperature with different emissivity, 3) same temperature and emissivity but different effective emissivity for the crack surface.

Figure 3.9 shows the playa surface with an aluminum cone cover. Fuchs and Tanner demonstrated the use of a highly reflective aluminum cone in conjunction with an infrared radiometer to measure the true temperature of surfaces. The highly reflective aluminum cone placed over a surface induces the creation of a "blackbody cavity".

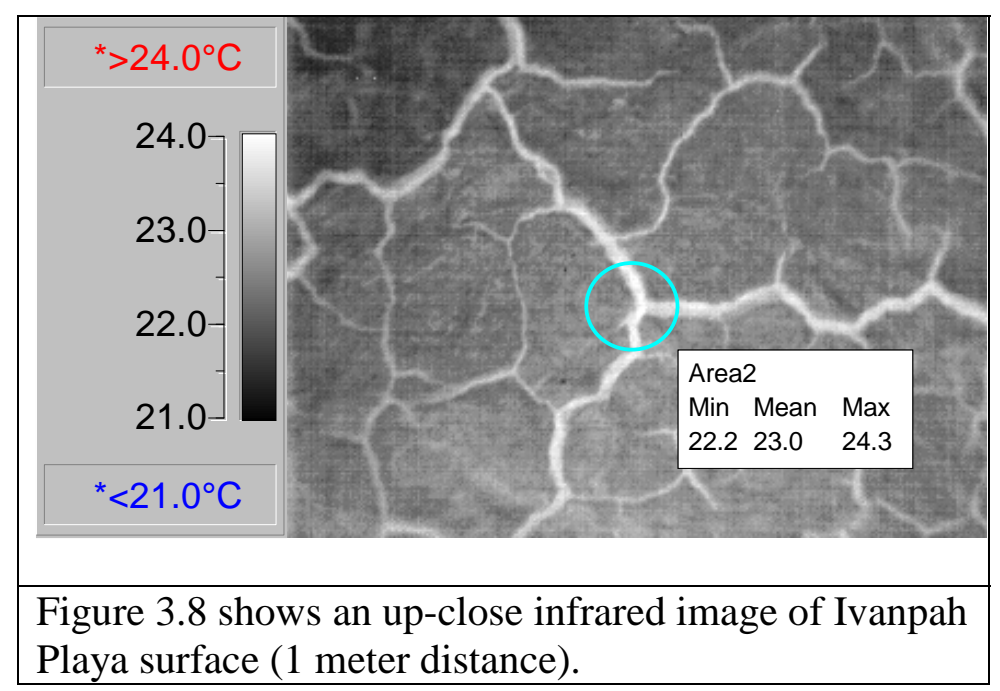

The effective emissivity produced by the cone is described by the equation 


$$
\varepsilon_{\text {effective }}=\frac{\varepsilon_{\text {material }}}{\varepsilon_{\text {material }}+r\left(1-\varepsilon_{\text {material }}\right)},
$$

where $r$ is the ratio of the apex and base areas of the cone. Placement of a highly reflective cone over the crack and tile surface areas with similar emissivity should result in a similar apparent temperature increase. The apparent temperature of the tile surface in area 2 was observed to increase from 22.2 to $22.9 \mathrm{C}$ while the temperature at the intersection of the cracks in area 2 remained at $24.3 \mathrm{C}$. These results can be explained in the context that the walls in the crack surface already acts as a cone to produce an effective blackbody. Therefore, a reflective aluminum cone over the crack temperature has no effect in increasing the apparent temperature.

Crack versus tile surface ratio was also analyzed using visible imagery. The histogram of the images suggests that the crack area can be as high as $14 \%$ of the total area. Statistical analysis of the infrared image shows a minimum temperature of $21.4 \mathrm{C}$ and a maximum temperature of $24.3 \mathrm{C}$. The mean temperature for the tile-crack surface area was $22.5 \pm$ $0.35 \mathrm{C}$. Analysis of the tile surface without cracks show a mean temperature of $22.3 \pm 0.15 \mathrm{C}$. The cone experiments were conducted early in the morning to reduce the influence of temperature changes with solar radiation. Therefore, the tile/crack surface area contributes at least $\pm 0.35 \mathrm{C}$ to the temperature uncertainty measured with the FTIR walk around study at the calibration site.

\section{Aerial Thermal Imaging}

Aerial thermal imaging experiments were conducted on May 20 with an infrared camera attached to the helicopter. Figure 3.10 shows an infrared image of the calibration site with a tarp located in the southeast location from a 600-meter elevation. The tarp in the figure is $9 \times 5.8 \mathrm{~m}^{2}$. The tarp was aligned with the long side in the southnorth direction at 353

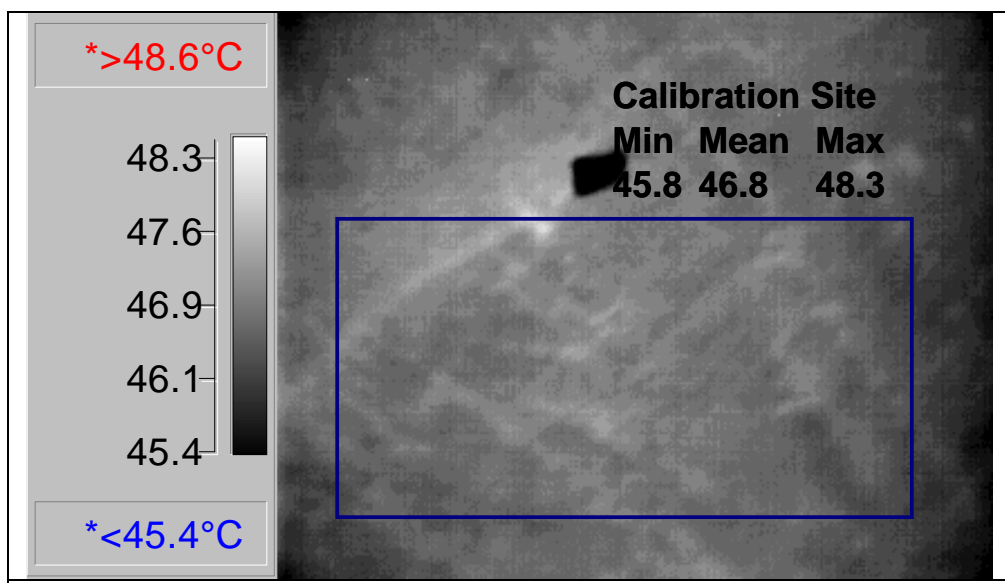

Figure 3.10 shows an infrared image of the calibration site with a tarp located in the southeast location from a 600-meter elevation. degrees (the direction of the satellite overpass). The helicopter hovered over the calibration site at elevations of 600 and 150 meters. A rectangle area of approximately 100-meter long by 50-wide was used to analyze the temperature/emissivity distribution. The maximum, mean and minimum temperatures were $45.8,46.8$ and $48.3 \mathrm{C}$ respectively. A closer inspection in figure 3.11 shows a narrower temperature distribution with a mean temperature of $46.8 \pm 0.22 \mathrm{C}$. In contrast to the fine detail observed in close-up thermal 
imaging experiments for the tile-like and crack surface area, the pixel resolution at the ground level is substantially degraded in aerial imaging. At 600 meters, the pixel resolution corresponds to approximately $0.5 \mathrm{~m}^{2}$. Therefore, significant apparent temperature averaging occurs in aerial infrared imaging with a washout of the tile/crack temperature distribution previously described in close-up experiments. The washout effect is responsible for the small standard deviation $(0.22 \mathrm{C})$ calculated from the aerial image. The temperature uncertainty in the aerial imagery probably describes the soil visible absorptivity rather than infrared emissivity (distribution in the soil reflectance corresponds to a distribution of surface apparent temperature).

\section{Shadow Experiment}

Cold areas with known geometrical dimensions on the desert surface can offer an opportunity for conducting sub-pixel experiments in satellite calibration. Natural cold areas with the proper dimensions and attributes are not easily available and in general require man-made efforts to develop them. Aluminized Mylar with its low emissivity was originally manufactured for space programs to keep satellites safe from solar radiation and heating. Aluminized Mylar can be used to make tarps to reflect solar radiation from the desert surface, therefore creating a cold area spot in the middle of the playa.

Experiments were conducted to study the shielding effect at Ivanpah Playa. . In this experiment, the soil was covered with the aluminized Mylar early in the morning. Figure $3.12 \mathrm{~b}$ shows a graph of the time dependence soil temperature. The temperature of the surrounding soil area was 44.3C. 


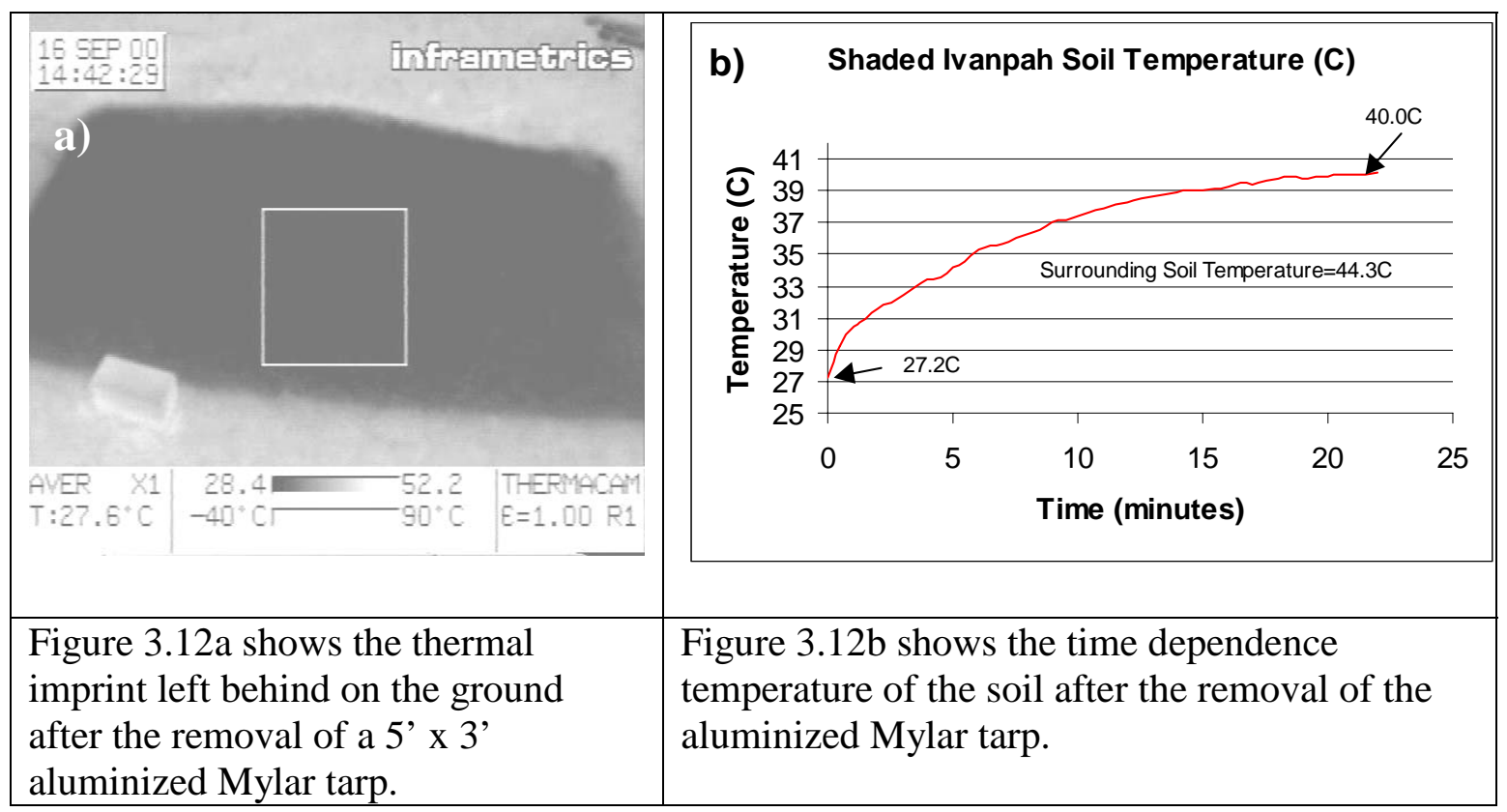

\section{Aluminized Mylar Tarp}

A second type of cold pixel can be created by the reflection of the cold skies (-50C to 20C) by the aluminized Mylar in the direction of the satellite position. The MTI satellite has the capability to image a target with two views (nadir and at 55 degree from nadir). The apparent temperature of the sky is dependent on the observation angle with the coldest at the zenith view. Therefore, the two views of the satellite in the direction of the aluminized Mylar target can produce two completely different apparent temperatures due to the skies sampling location.

The cold sand target allows testing the minimum resolvable temperature of the satellite's detector. The ground sampling distance (GSD) of the satellite is 20 meters. A cold target of $50 \times 50$ meters $^{2}$ ensures that at least one satellite pixel falls in the designated area.

Depending on the alignment of the satellite detector pixel array on the aluminized tarps on the ground, it is possible for the cold target to fill up to two pixels. The $50 \times 50$ meter $^{2}$ also insures that the second view

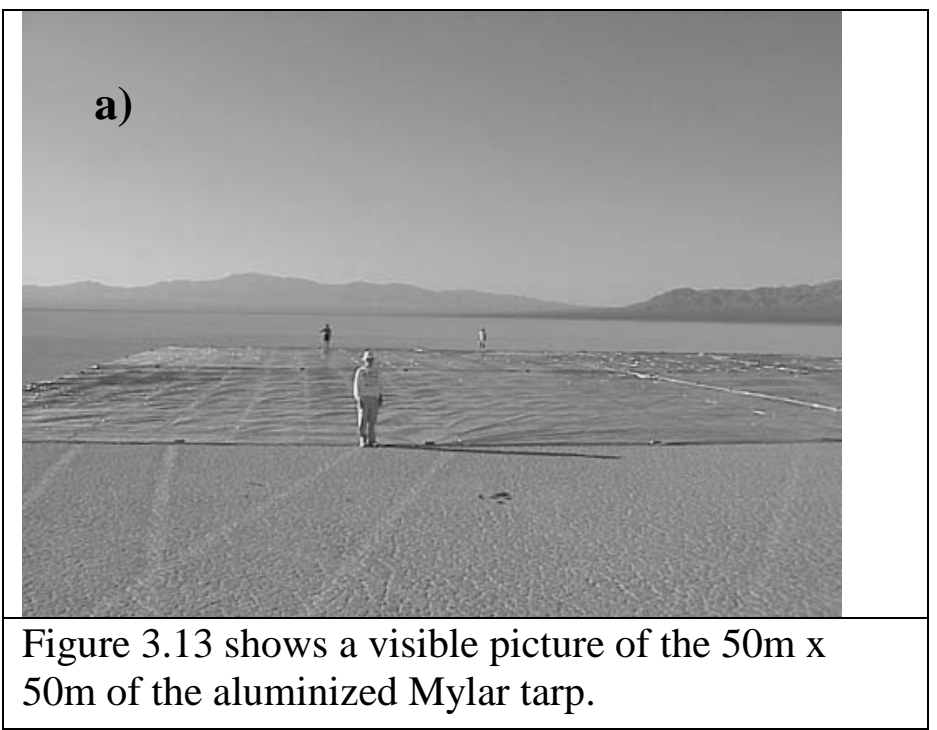
at 55-degree can observe a cold pixel. 
The second cold target created by the reflection of the cold skies by the aluminized Mylar target can test the dynamic response of the detector. The target at a-50C apparent temperature surrounded by sand around $52 \mathrm{C}$ is ideal in producing a thermal step function on the satellite's detector. Figure 3.13 shows a visible picture of the $50 \times 50 \mathrm{~m}^{2}$ deployed on September 15. Strong winds at the satellite overpass precluded the final deployment of the tarp. An aerial overview of the $25 \times 25 \mathrm{~m}^{2}$ tarp deployed on September 16 is shown in Figure 3.14. The satellite was able to image the cold tarp on the hot Ivanpah Playa surface. Figure 3.15 shows the satellite thermal image of the $25 \times 25 \mathrm{~m}^{2}$ aluminized Mylar tarp at Ivanpah Playa.

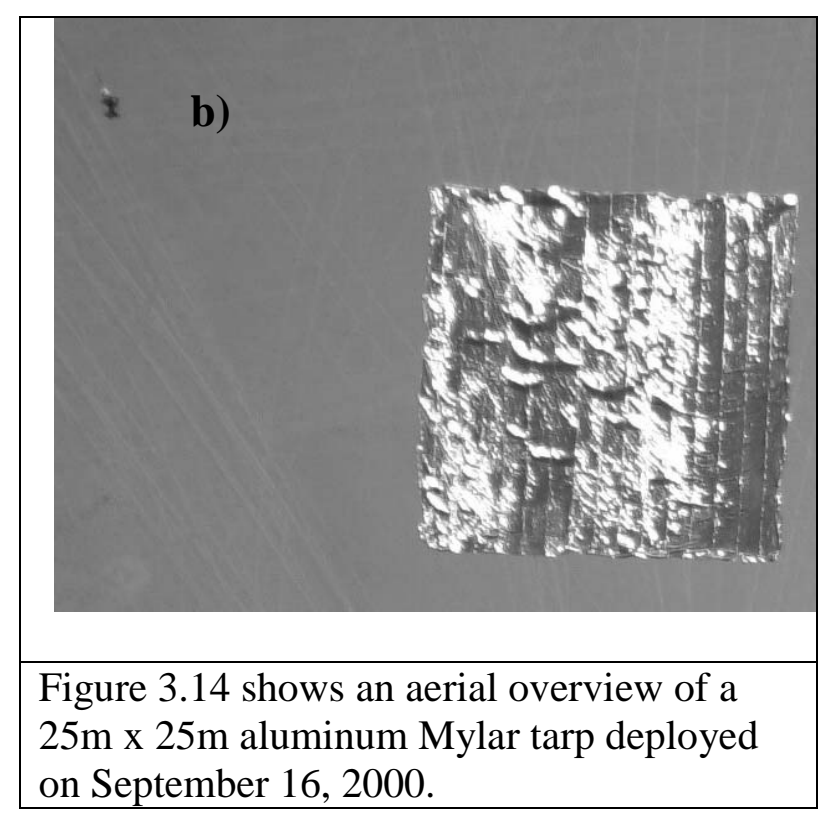

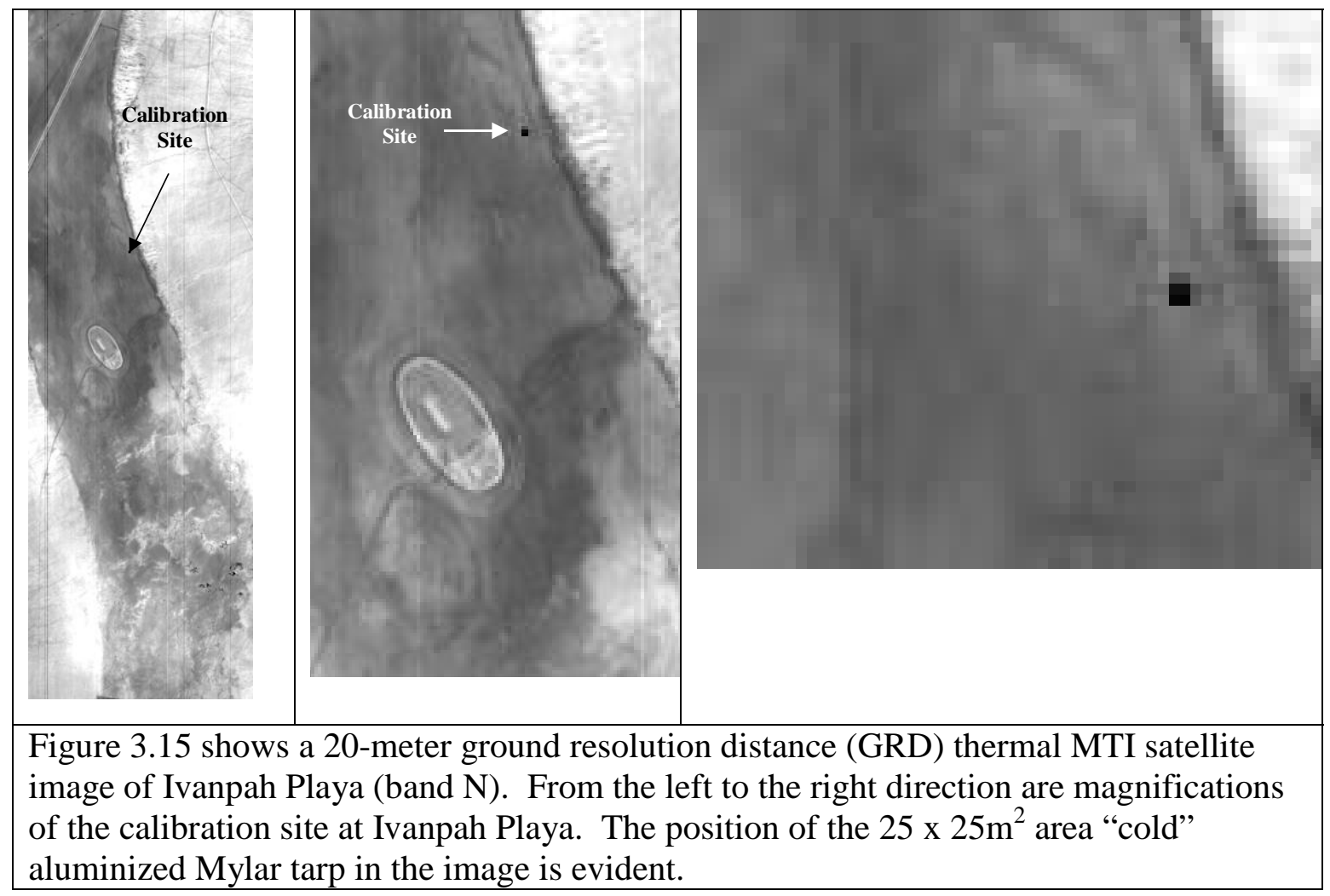




\section{September Satellite Imagery}

Figures 3.16 through 3.21 show several MTI bands used in the analysis of Ivanpah Playa. TOA radiance from band $\mathrm{C}$ with a wavelength average at $0.65 \mu \mathrm{m}$ (red) and a bandwidth of $0.06 \mu \mathrm{m}$ is shown in Figure 3.16. TOA radiance from band $\mathrm{C}$ was used as representative for all TOA radiances from the visible and near infrared bands. Band C Ivanpah Playa ground reflectance was also computed from ground truth at the calibration site. Figures 3.17 through 3.21 are the Ivanpah Playa images corresponding to the TOA radiances from the thermal bands $\mathrm{N}(10.45 \mu \mathrm{m}), \mathrm{M}(8.625 \mu \mathrm{m}), \mathrm{L}(8.2 \mu \mathrm{m}), \mathrm{K}(4.97 \mu \mathrm{m})$, and $\mathrm{J}(3.8 \mu \mathrm{m})$. These bands contain temperature and emissivity information of the soil surface. It is interesting to compare TOA radiance from band $\mathrm{C}$ versus the TOA radiance from band $\mathrm{N}$ in figures 3.16 and 3.17. The radiance from band $\mathrm{N}$ can be seem to be the inverse of the radiance from band $\mathrm{C}$, that is, higher reflectance in band $\mathrm{C}$ corresponds to lower radiance in band $\mathrm{N}$ and vice-versa. In contrast to the negative slope behavior between the radiances from bands $\mathrm{C}$ and $\mathrm{N}$, the radiances from bands $\mathrm{L}$ and $\mathrm{M}$ do not seem to correlate with band $\mathrm{C}$. The TOA radiances of Bands $\mathrm{K}$ and $\mathrm{J}$ do correlate with the reflectance of band $\mathrm{C}$ although band $\mathrm{J}$ is complicated by solar reflection.

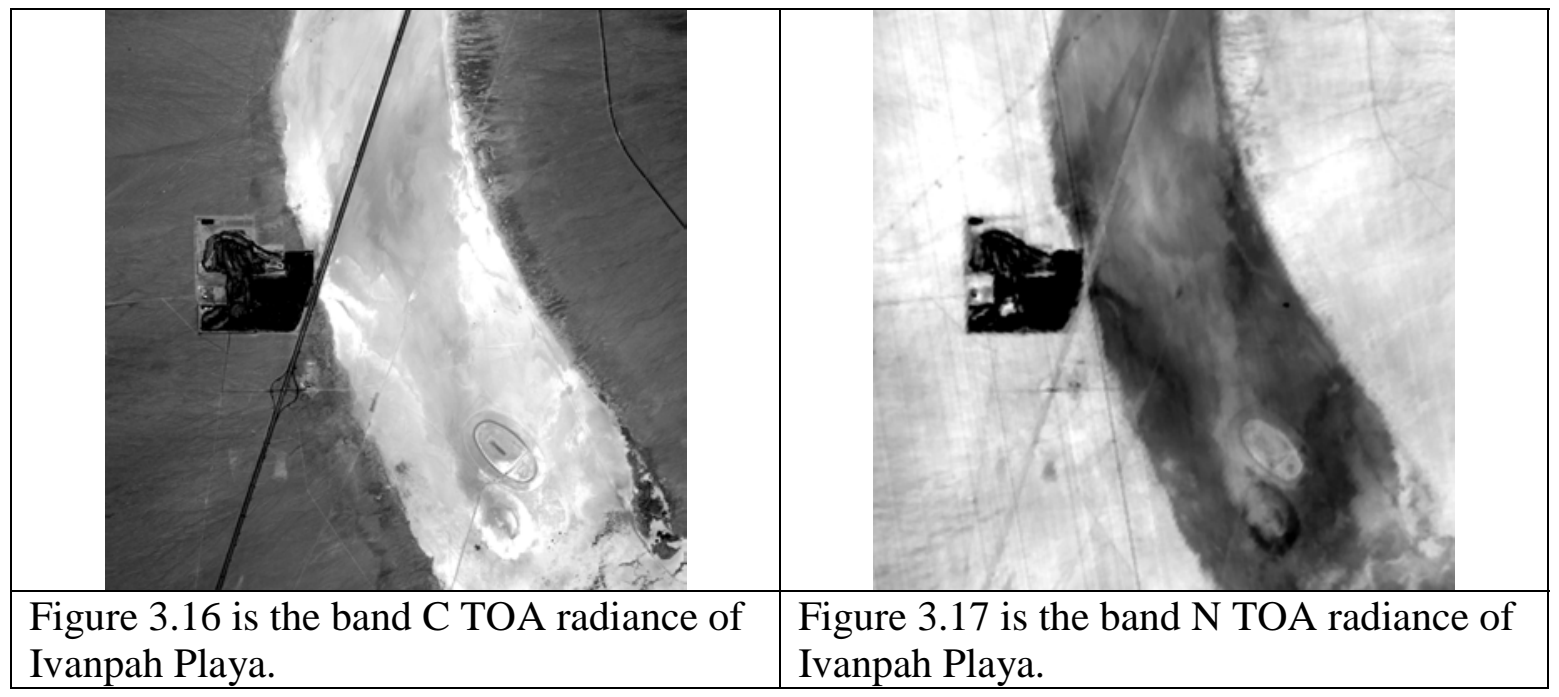

\begin{tabular}{|l|l|}
\hline & \\
\hline Figure 3.18 is the band M TOA radiance of & $\begin{array}{l}\text { Figure 3.19 is the band L TOA radiance of } \\
\text { Ivanpah Playa. }\end{array}$ \\
Ivanpah Playa.
\end{tabular}




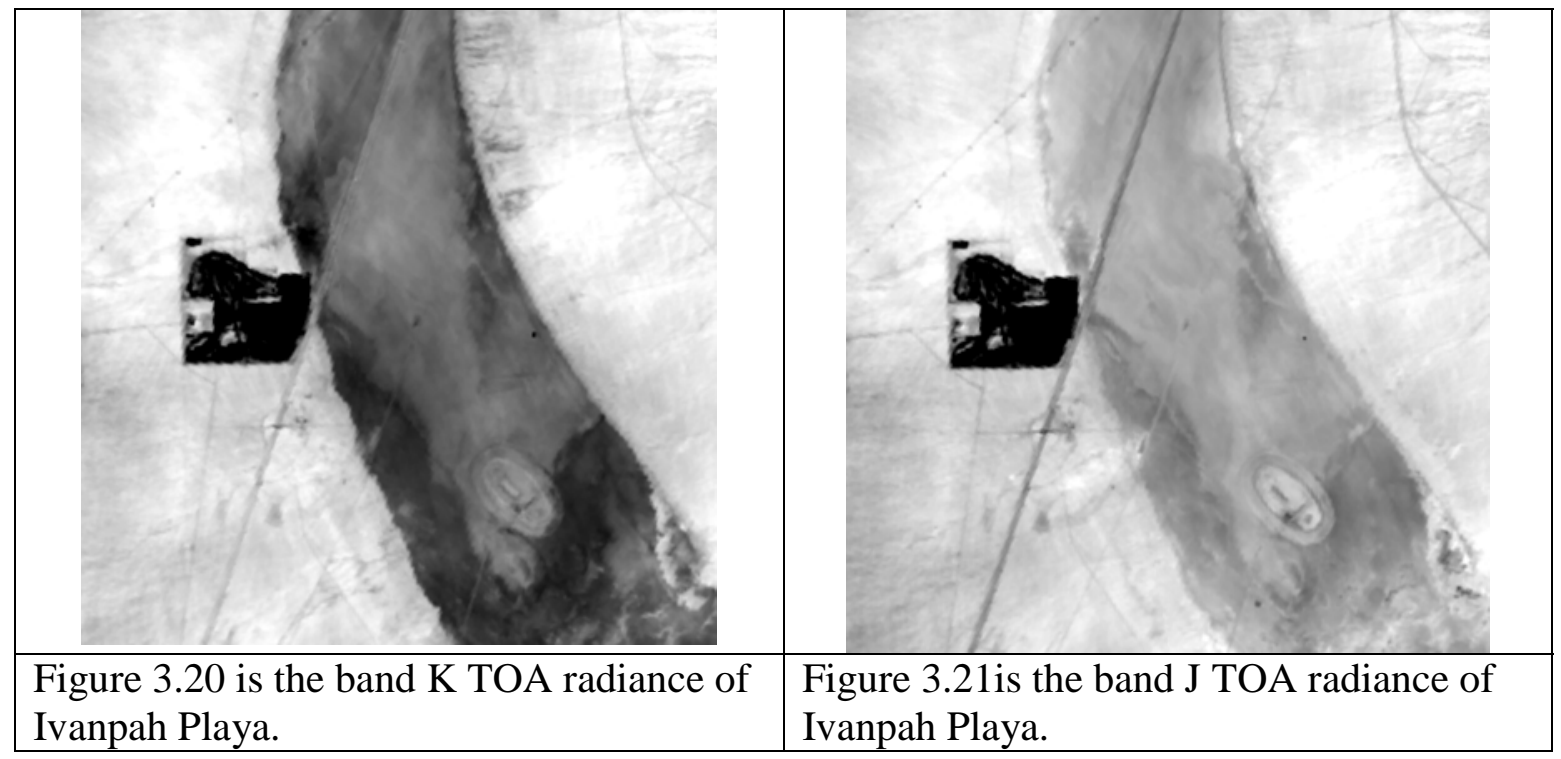

\section{Scatter Plots}

Scatter plots were analyzed in order to understand relationships between reflectances in the visible and near-infrared region versus radiances in the thermal bands. A negative slope is expected between a visible band and the thermal bands $\mathrm{N}, \mathrm{K}$ and $\mathrm{J}$. In contrast, the relationship between the bands $\mathrm{M}$ and $\mathrm{L}$ and the reflectances for the bands in the visible spectral region is not clear. Figure 3.22 shows the selected area for analysis at Ivanpah Playa. The area is $1.7 \mathrm{~km}$ wide by $1.9 \mathrm{~km}$ height. Figures 3.23 through 3.27 shows the 2-d scatter plots of thermal band radiance versus band $\mathrm{C}$ reflectance. Ground reflectances at the playa were calculated using the software ENVI 3.2 by using the ground truth reflectance at the calibration site as a reference. Ground reflectance measured at the calibration site was used to interpolate reflectance across the playa.

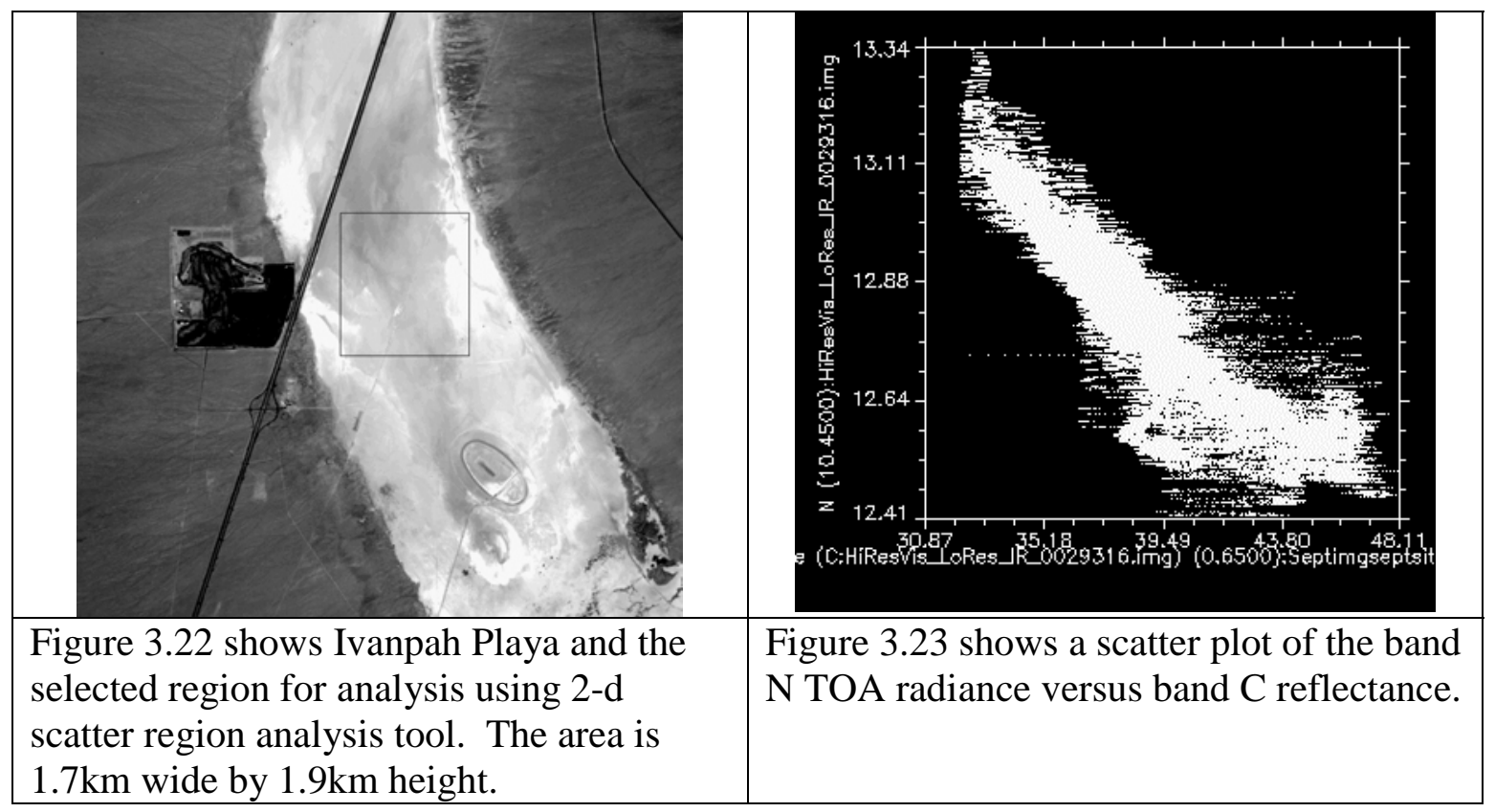


Figure 3.23 clearly shows the relationship between band $\mathrm{C}$ reflectance and the radiance measured by the satellite in band $\mathrm{N}$. The linear relationship results from low variability in the emissivity of the soil in the band $N(10.2-10.7 \mu \mathrm{m})$. The width is an estimate of the emissivity and reflectivity variability. The straight line establishes the cause effect relationship of solar radiance absorption to higher surface temperature and therefore higher emitted radiance.

In contrast to the linear relationship between band $\mathrm{N}$ and band $\mathrm{C}$ reflectance, a simple straight line between bands $\mathrm{M}$ and $\mathrm{L}$ radiances and band $\mathrm{C}$ reflectance is non-existent. Figure 3.24 is the 2-d scatter plot of TOA radiance of band $\mathrm{M}$ versus band $\mathrm{C}$ reflectance. Figure 3.25 is the 2-d scatter plot of TOA radiance of band L versus band $\mathrm{C}$ reflectance. Figures 3.24 and 3.25 suggest a two-pronged scatter plot. The fork seems to have a negative and a positive slope relationship with band $\mathrm{C}$ reflectance. The negative slope ends near $39.5 \%$ reflectance value and could be related to the band $\mathrm{C}$ reflectance in the same way as the band $\mathrm{N}$ is related to band $\mathrm{C}$. The positive slope begins at the same reflectance where the negative slope ended. The band $\mathrm{N}$ scatter plot shows widening around the $39.5 \%$ reflectance, suggesting increasing variability in the emissivity at higher reflectances.

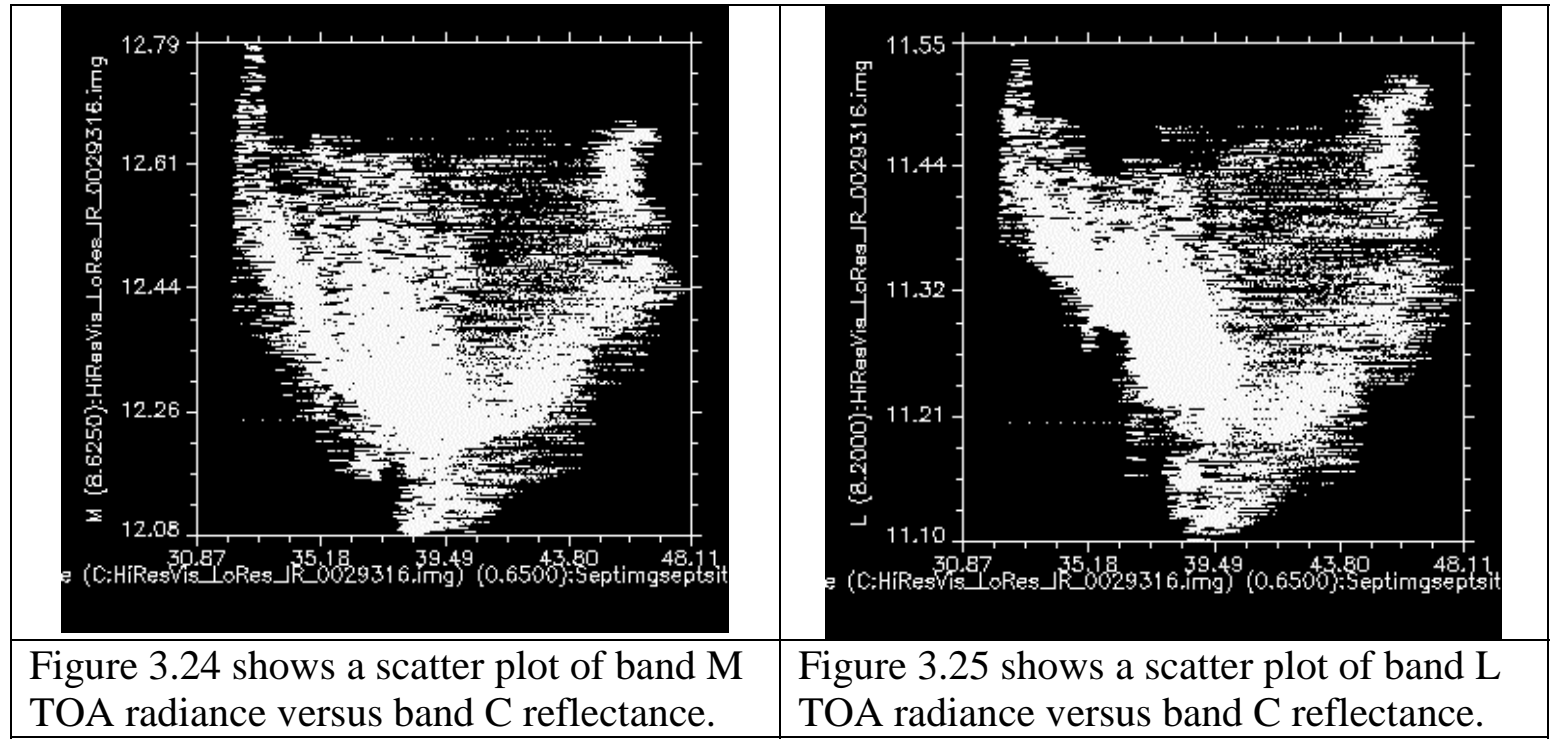

The 2-d scatter plots suggest two predominant effects controlling the TOA radiances from bands $\mathrm{M}$ and $\mathrm{L}$. The negative slope is determined primarily by one material with a different emissivity from the material encountered in the positive going slope. The wishbone-shaped 2-d scatter plot suggests that both materials are present in both regions, but the ratio varies with ground reflectance. This assumption also suggests that the material with higher emissivity is preferentially encountered above the $39.5 \%$ reflectance and the material with lower emissivity is found with a reflectance values below $39.5 \%$. In other words, the negative going slope radiance is primarily controlled by the absorption of vis-nir solar radiation and temperature rise effect, while the positive going 
slope is primarily controlled by the higher concentration of the higher emissivity material in high reflectance areas.

TOA radiances from band $\mathrm{K}$ and $\mathrm{J}$ follow a similar response to the band $\mathrm{N}$ response. The TOA radiance values from band $\mathrm{J}$ cannot be trusted since the radiance measured is a combination of soil surface radiance and solar reflected radiance.

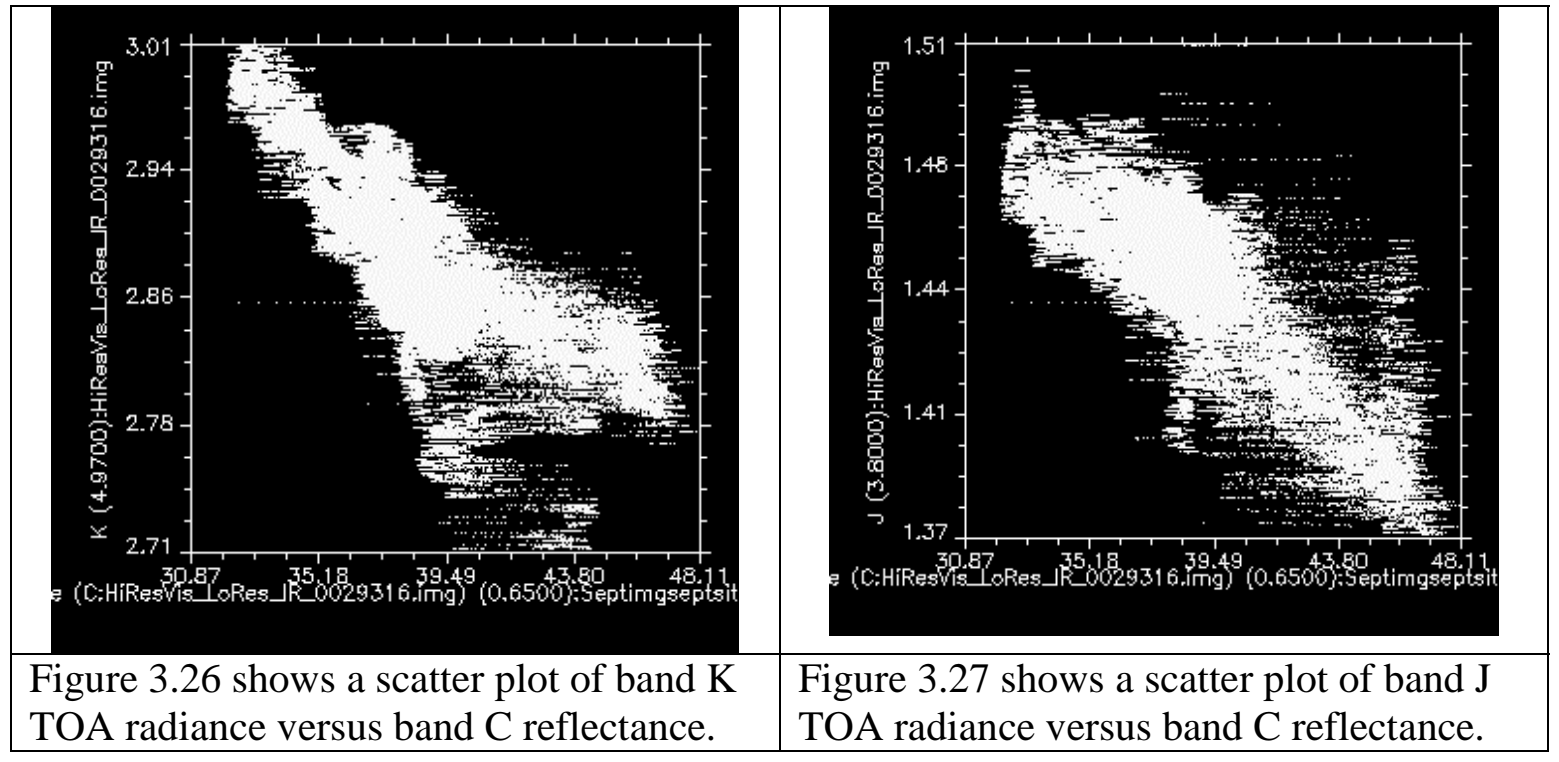

The correlation between bands $\mathrm{L}$ and $\mathrm{M}$ is shown in figure 3.28 2-d scatter plot. The linearity behavior suggests that these two bands are observing the same spectral feature on the soil surface.

Figure 3.29 shows a 2-d scatter plot of TOA radiances of bands $\mathrm{N}$ and $\mathrm{K}$. Once again, the linearity and their correlation are evident in the figure.

Figure 3.30 shows a 2-d scatter plot of TOA radiances of bands $\mathrm{N}$ and $\mathrm{J}$. The plot shows a two-slope line. Since band $\mathrm{J}$ radiance has a solar contribution, the first slope suggests the influence of solar reflectance while the second component

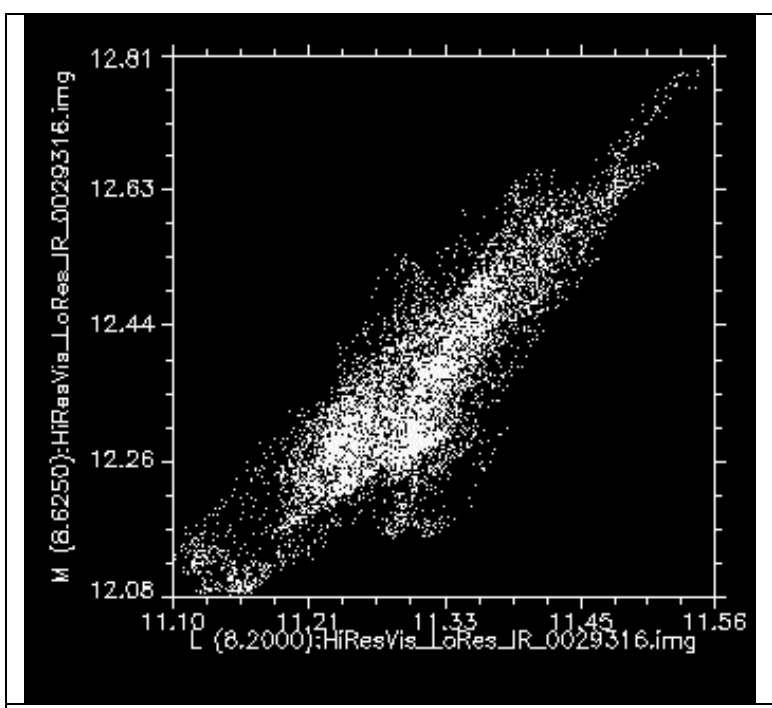

Figure 3.28 shows band $\mathrm{M}$ versus band $\mathrm{L}$ 2-d scatter plot. suggests primarily soil radiance from its temperature. 


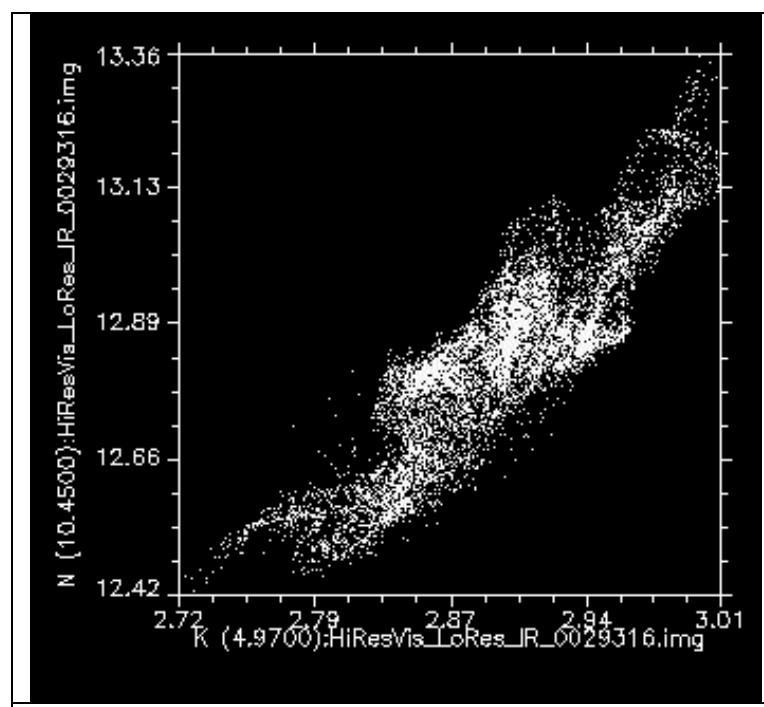

Figure 3.29 shows band $\mathrm{N}$ versus band $\mathrm{K}$ 2-d scatter plot.

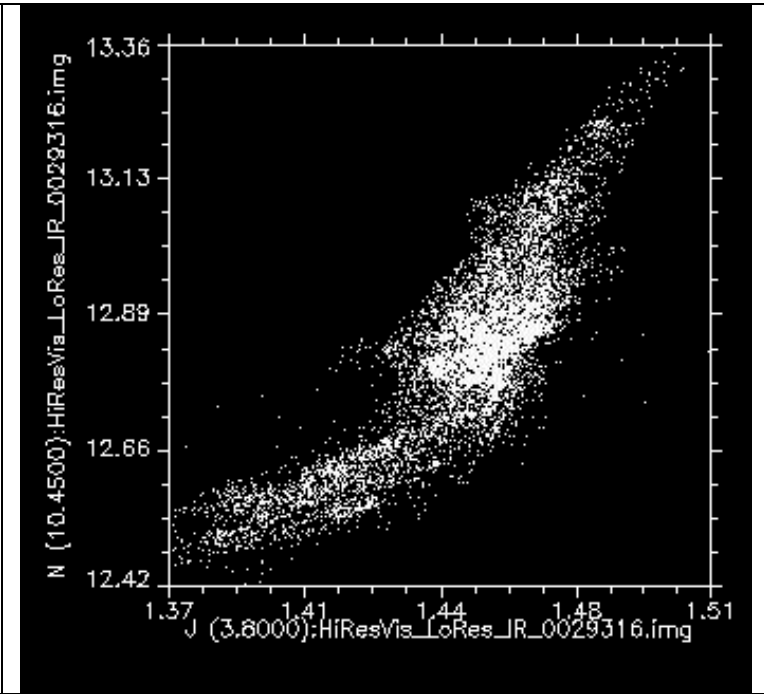

Figure 3.30 shows band $\mathrm{N}$ versus band $\mathrm{K}$ 2-d scatter plot.

\section{Experimental Emissivities}

The different campaigns conducted at Ivanpah Playa have shown that the playa's surface emissivity is not constant. The emissivity spectra measured with the FTIR spectrometer suggest that quartz like material and desert varnish are the main contributors to the emissivity spectra measured at the calibration sites. Figure 3.31 shows the three locations used by SRTC during the calibration campaigns. The campaigns from top to bottom are May 2001, September and July 2000 (one location) and March 2002. Figure 3.32 shows a comparison of the different emissivities measured at

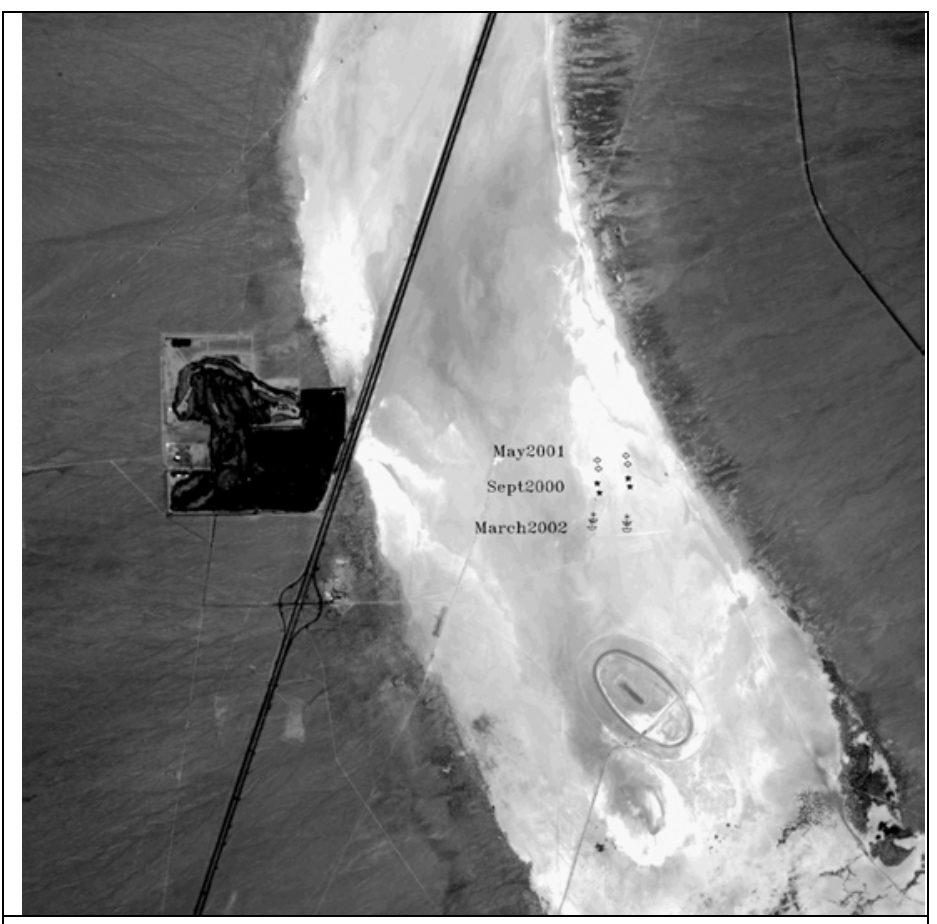

Figure 3.31 shows the multi-year location of the calibration sites at Ivanpah Playa.

Ivanpah Playa. The

emissivities at $8.5 \mu \mathrm{m}$ from top to bottom are May 2001, September 2000, July 2000, March 6, 2002 and March 5, 2002. Cloud coverage can affect the measurement of the emissivity. Two emissivities under different cloud coverage are shown for the March campaign. Water vapor lines were not successfully removed from the emissivity spectrum on March 5. 
The spectral region between 9.5 and $11.5 \mu \mathrm{m}$ has a low spectral variability. In contrast, the $8.00-9.5 \mu \mathrm{m}$ spectral range is characterized by high variability. The MTI bands, L $(8.2 \mu \mathrm{m}), \mathrm{M}(8.625 \mu \mathrm{m})$ and $\mathrm{N}(10.45 \mu \mathrm{m})$ fall in this spectral feature of the playa. The most dramatic change in the spectral emissivities of bands L, M, and $\mathrm{N}$ occurred between May 2001 and the other campaigns.

The emissivity values for the July and September 2000 campaigns (same calibration site) are very close. The shape is also similar to the March 2002 campaign (different calibration site). The emissivity measured on May 2001 (different calibration site) differed dramatically from the other campaigns. Figure 3.33 shows small variability in the location of band $\mathrm{N}$, while large variability in the location of bands $\mathrm{M}$ and $\mathrm{L}$. This is consistent with the 2-d scatter plots from the MTI images.

The May 2001 campaign emissivity resembles the emissivity spectrum of desert varnish. All campaigns suggest having this component in their spectral emissivity. In order to identify the spectral components in the emissivities measured during the several campaigns, the May 18, 2001 emissivity spectrum previously identified as desert varnish was removed from the July 4, 2000 emissivity spectrum. The resultant emissivity spectrum is the well-known quartz-like (silicate) spectrum shown in figure 3.34. Figure 3.35 shows the quartz-like emissivity spectrum measured at Ivanpah Playa and the quartz spectrum from a commercial library. The similarity between the spectra is clearly evident in the figure stating the fact of quartz present at the playa.

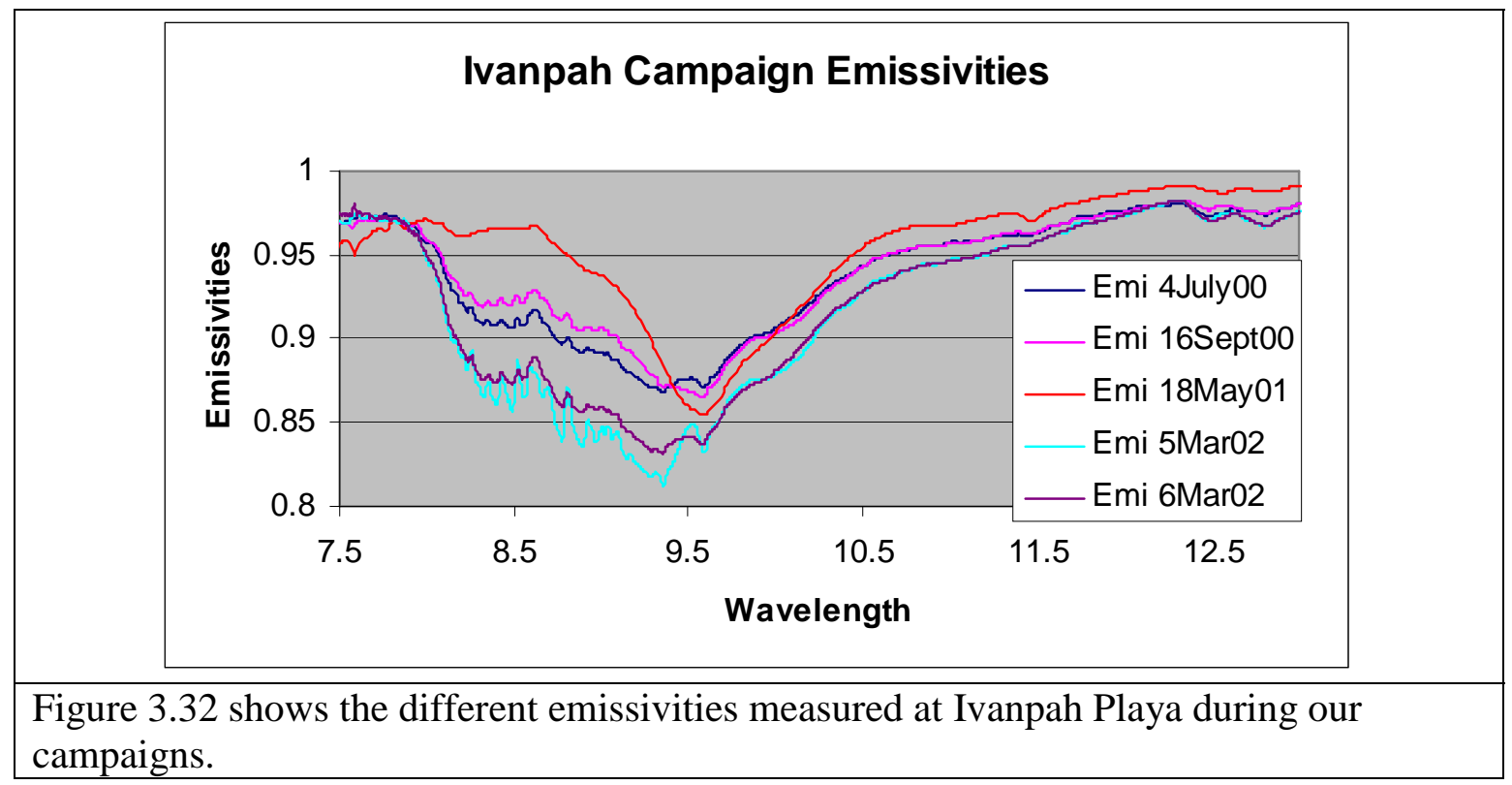




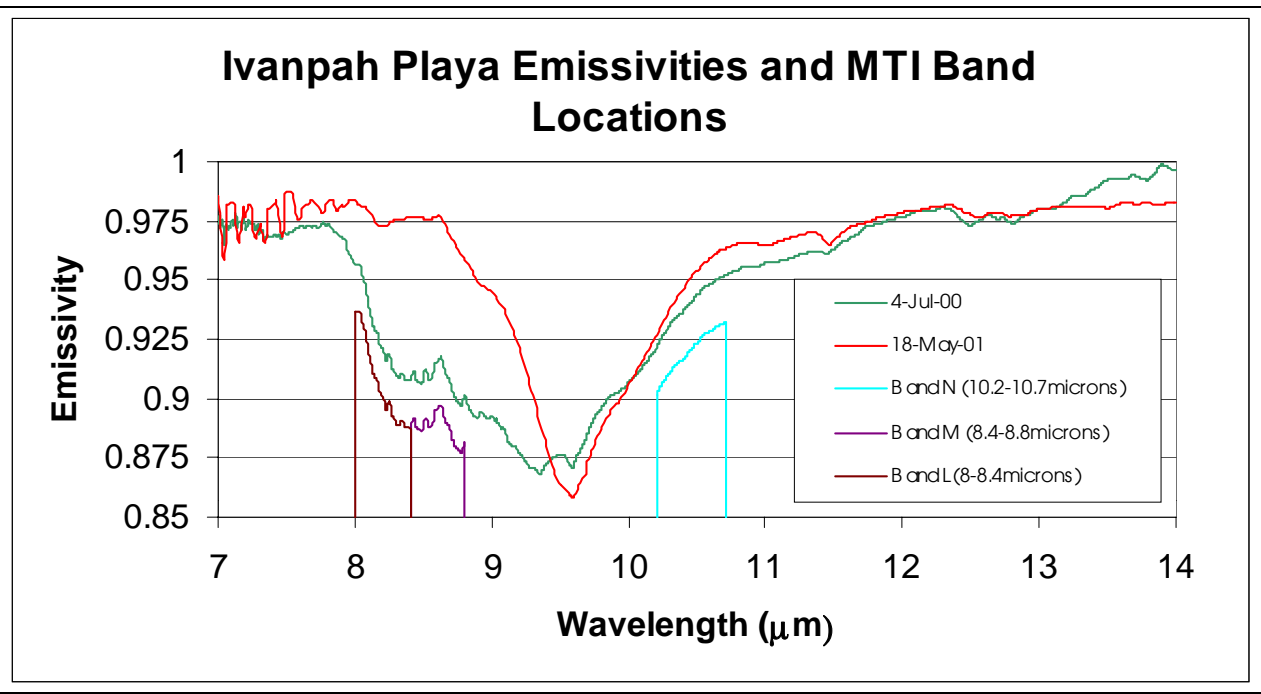

Figure 3.33 shows the emissivities measured on July 2000 and May 2001 campaigns. The location of the N, M, and L bands are shown for clarification. The shape of the bands was selected as a better indicator of location.

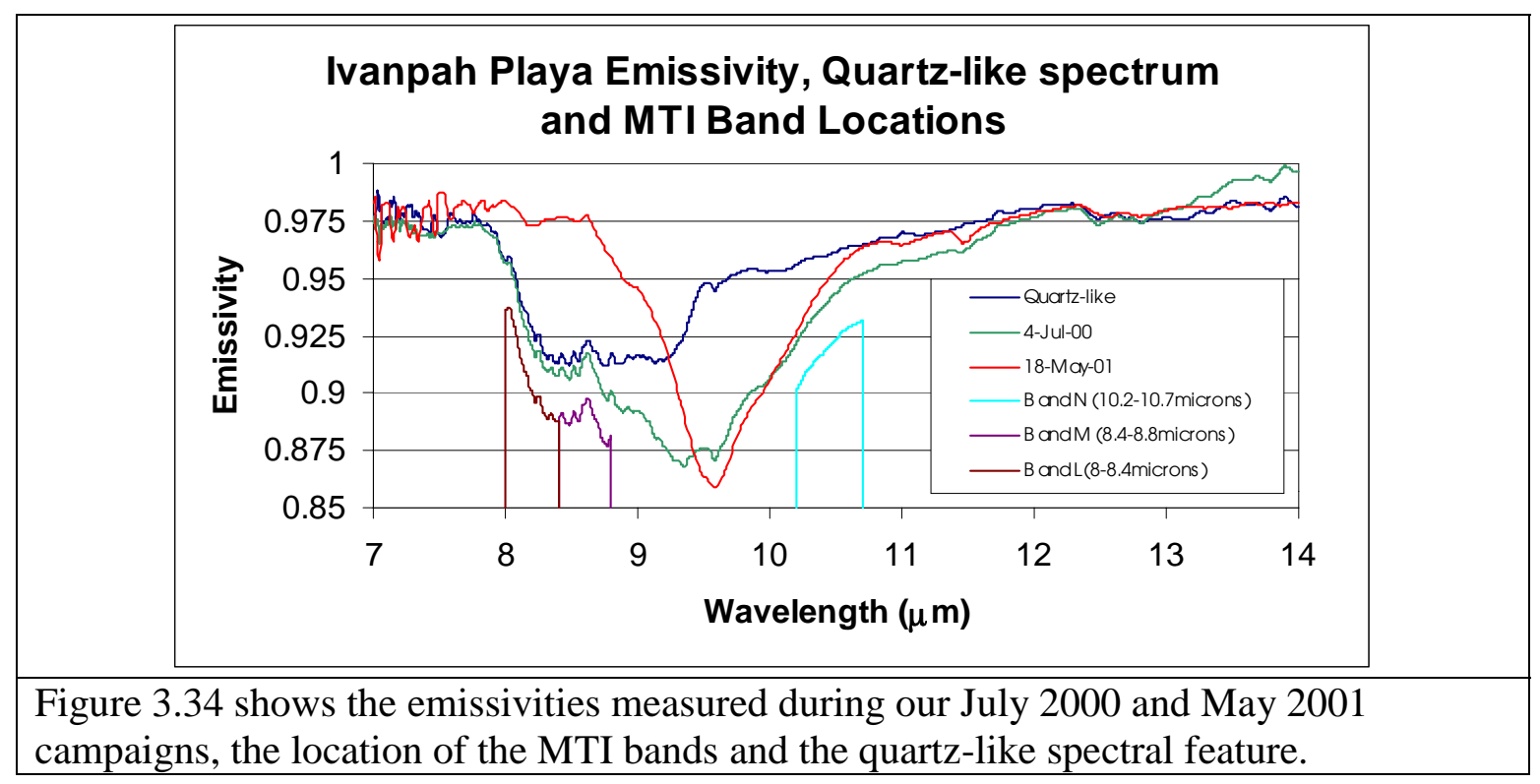




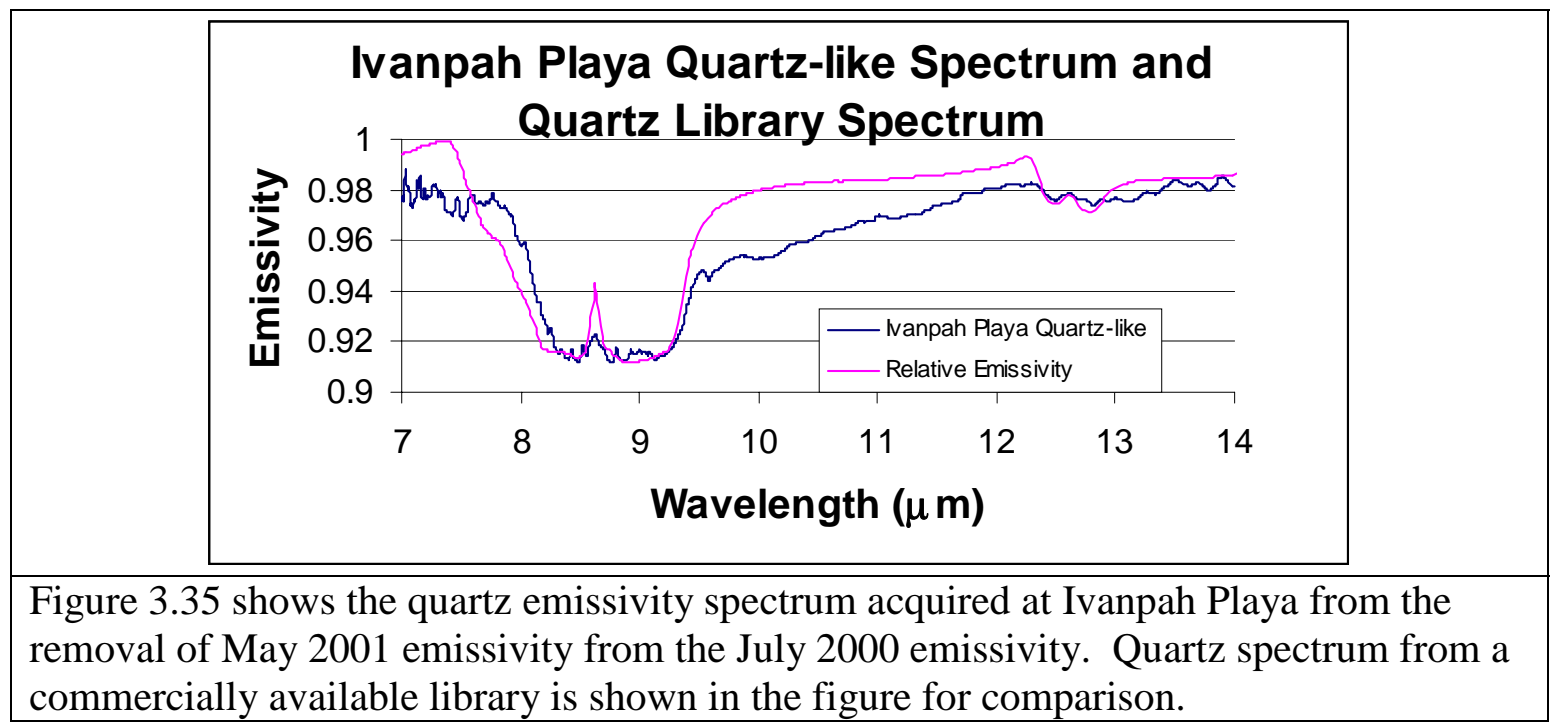

\section{Temperature and Emissivity Analysis from MTI Imagery}

The 2-d scatter plot of band $\mathrm{N}$ versus band $\mathrm{C}$ (figure 3.23) shows that the radiance emitted is inversely proportional to the reflectance of the playa. The ground truth emissivities measured at the playa shows little variation in the band $\mathrm{N}$ region. The experimental data from all the campaigns show an integrated emissivity in the band $\mathrm{N}$ region of $0.93 \pm 0.01$. Temperature images were calculated using band $\mathrm{N}$ as a reference with an emissivity of 0.93 . The variability of the emissivity in band $\mathrm{N}$ can be larger based on the satellite image. Work continues in order to define the bounds on the emissivity variability for band $\mathrm{N}$.

\section{September 2000 Campaign}

During the September campaign, the atmospheric conditions (humidity, air temperature, and pressure) were measured by releasing a balloon with a radiosonde. The atmosphere transmission was calculated using radiative code (MODTRAN 3.3). The TOA band $\mathrm{N}$ radiance was corrected to ground level radiance using the atmosphere transmission from MODTRAN(transmission 0.96). The new band $\mathrm{N}$ radiance image was used with ENVI 3.2 software to calculate the temperatures across the playa and to produce emissivities at the other MTI thermal bands. Figure 3.36 shows the result of the temperature image calculated with the MTI satellite. The temperature

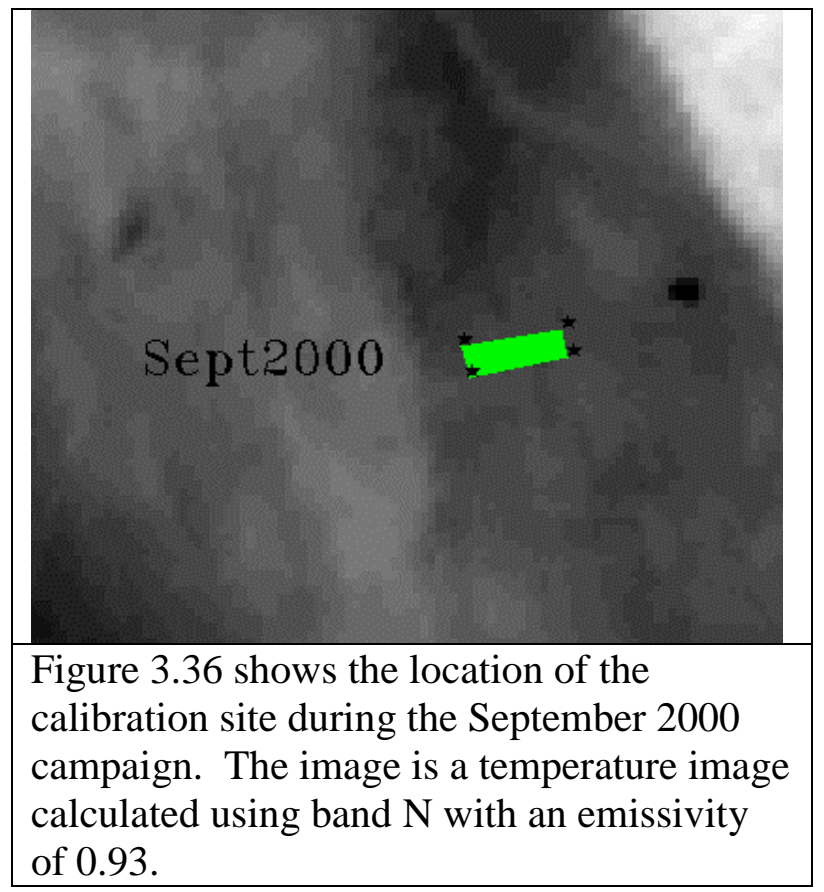


Retrieved with the MTI satellite using band N for the September calibration site was $326.08 \pm 0.12 \mathrm{~K}$. The temperature measured with the FTIR at the calibration site was $325.3 \pm 1.1 \mathrm{~K}$. The agreement between the satellite retrieved temperature and the FTIR retrieved temperature follows the 1 sigma accuracy of water temperature retrievals of $\pm 1 \mathrm{~K}$.

Figures 3.37 through 3.39 show emissivity images for the bands K, L, and N, respectively. Variations in emissivity are largest in the $\mathrm{L}$ and $\mathrm{M}$ images.

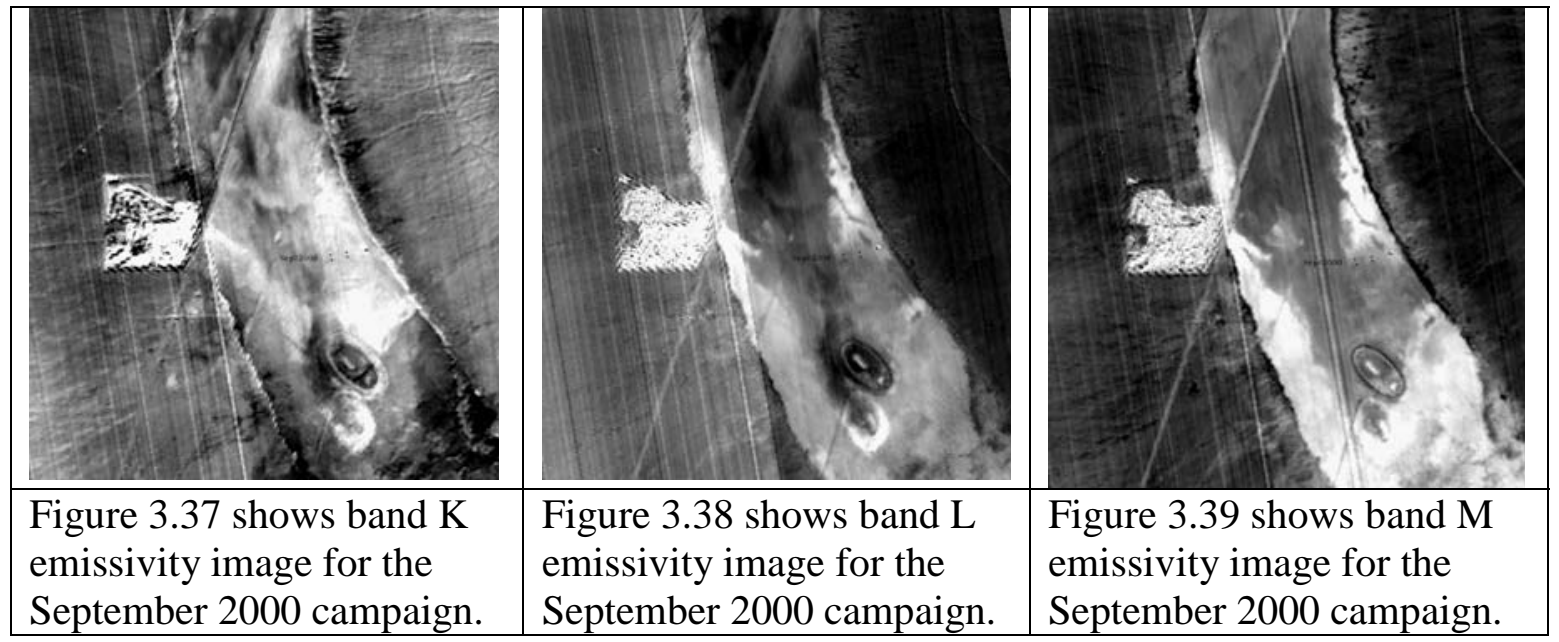

Figures 3.40 through 3.42 shows the images of the K, L, and M bands at the calibration site. Variations in emissivity for all bands at the calibration site were less than 0.005 . Once again, the $\mathrm{L}$ and $\mathrm{M}$ bands emissivity variations were much larger than the corresponding emissivity in the $\mathrm{K}$ band.

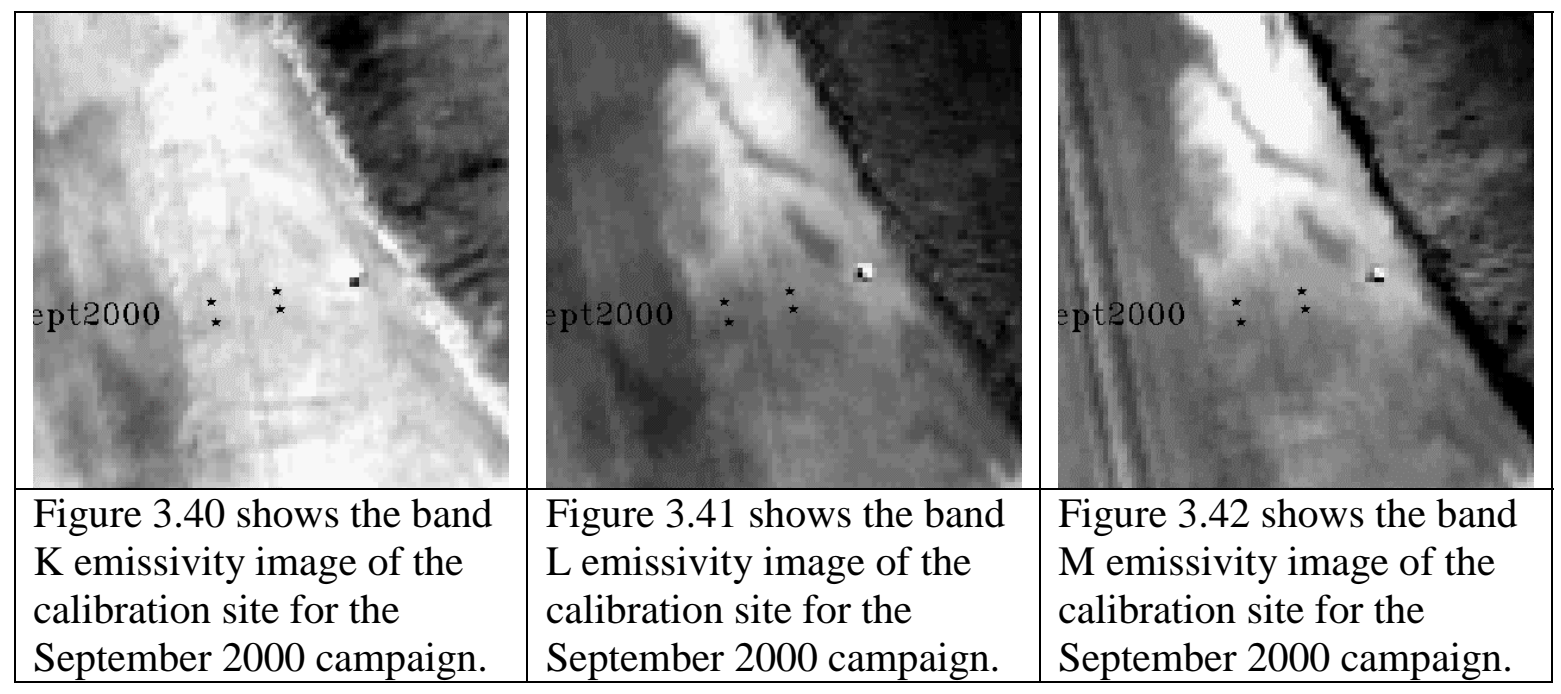

Table 3.1 shows the emissivity statistics calculated for all bands in the scatter region shown in figure 3.22. The emissivity of band $\mathbf{J}$ clearly shows the solar contribution. The standard deviation is approximately the same for the $\mathrm{K}, \mathrm{J}, \mathrm{M}$, and $\mathrm{N}$ bands. 


\begin{tabular}{|l|l|l|l|l|}
\hline Band & Min & Max & Mean & Stdev \\
\hline J & 1.065191 & 1.212120 & 1.148414 & 0.025363 \\
\hline K & 0.665917 & 0.722860 & 0.698334 & 0.009362 \\
\hline L & 0.819622 & 0.882012 & 0.844276 & 0.011086 \\
\hline M & 0.859719 & 0.925937 & 0.881129 & 0.012244 \\
\hline N 0.930000 & & & & \\
\hline Table 3.1 & 0.930000 & 0.930000 & 0.000000 \\
\hline
\end{tabular}

Table 3.1 shows the emissivity values in the scatter region analysis in figure 3.22 for the September campaign. An emissivity of 0.93 was selected for band N.

\section{May 2001 Campaign}

Figures 3.43 through 3.45 shows the K, L, and M bands for the May campaign. In contrast to the September campaign, little variability is seen among the bands. It is believed that strong rains washed away most of the quart-like component of the emissivity. The emissivities of bands M and L during the May campaign are larger than the emissivities calculated during September campaign. Large changes were observed in the visible bands between the September 2000 and May 2001 campaigns. Figures 3.46 through 3.48 shows the calibration site of the May campaign. The emissivity at the calibration site was nearly constant. Table 3.2 shows the spectral emissivities calculated for the thermal bands at the calibration site. The average temperature of the calibration site retrieved with the FTIR was $324.5 \pm 1.1 \mathrm{~K}$. The average temperature of the calibration site measured by the MTI satellite with band N (emissivity 0.93) and with an atmospheric transmission of 0.96 was $323.4 \mathrm{~K}$, in excellent agreement with the satellite accuracy prediction.

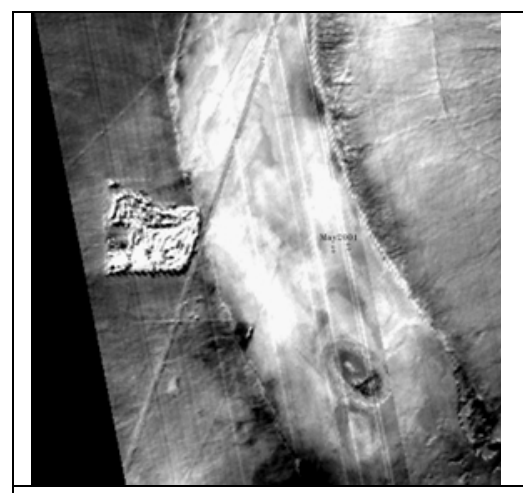

Figure 3.43 shows band $\mathrm{K}$ emissivity image for the May 2001 campaign.

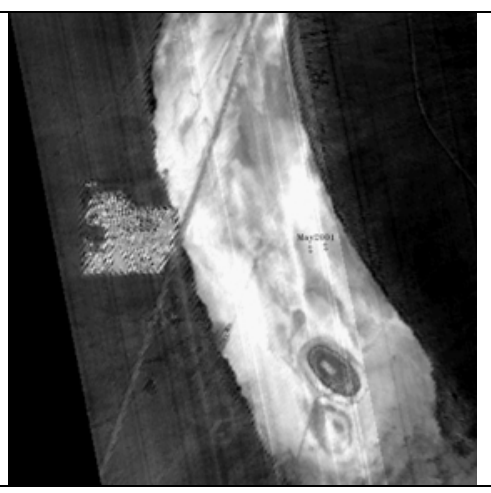

Figure 3.44 shows band L emissivity image for the May 2001 campaign.

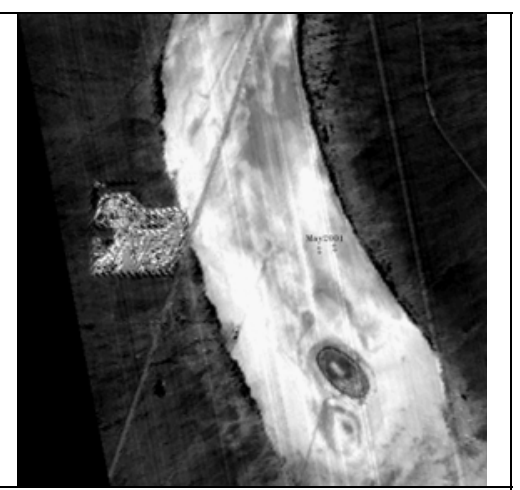

Figure 3.45 shows band $\mathrm{M}$ emissivity image for the May 2001 campaign. 


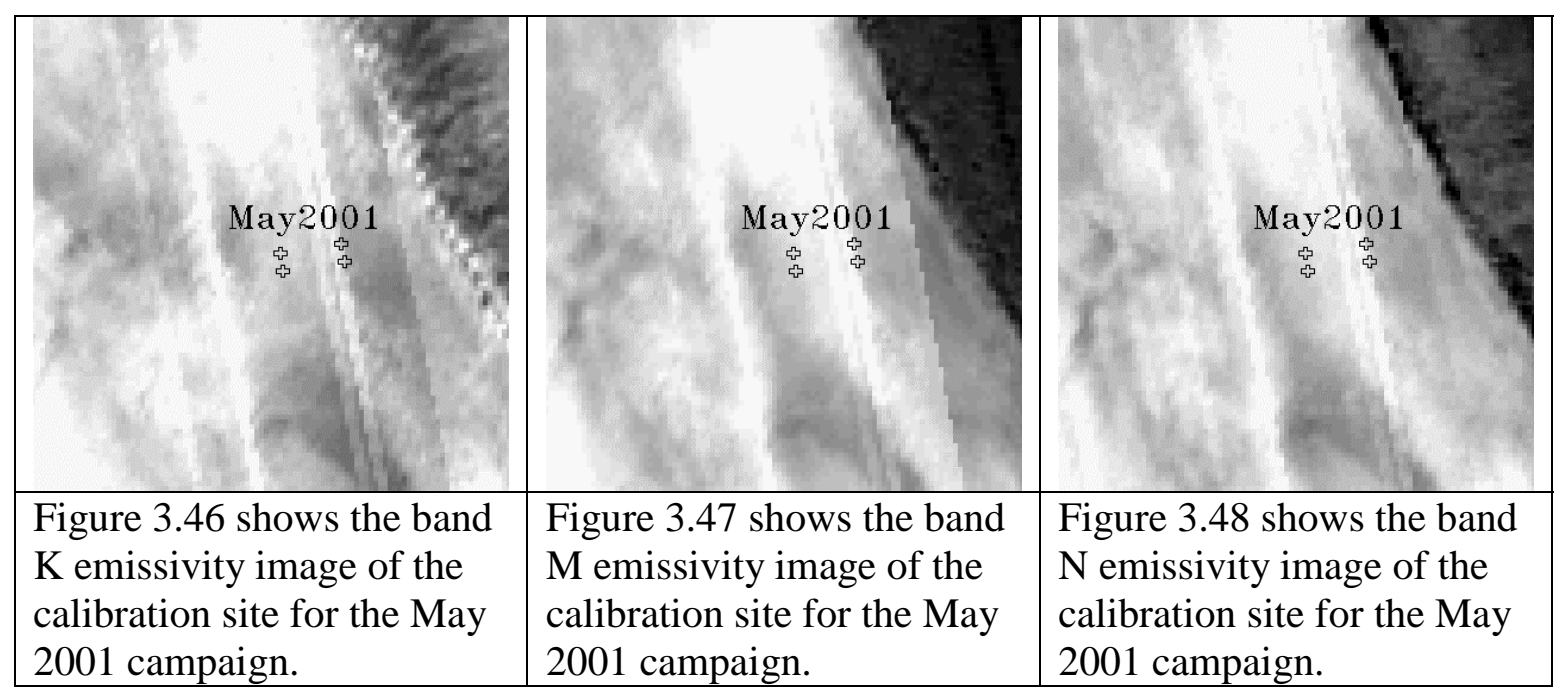

\begin{tabular}{|l|l|l|l|l|}
\hline Band & Min & Max & Mean & Stdev \\
\hline J & 1.112675 & 1.341814 & 1.211906 & 0.050960 \\
\hline K & 0.628207 & 0.673243 & 0.652000 & 0.007677 \\
\hline L & 0.844262 & 0.895125 & 0.869659 & 0.009470 \\
\hline M & 0.877628 & 0.926511 & 0.904740 & 0.008440 \\
\hline $\mathrm{N}$ & 0.930000 & 0.930000 & 0.930000 & 0.000000 \\
\hline
\end{tabular}

Table 3.2 shows the emissivity values in the scatter region analysis in figure 3.22 for the May campaign. An emissivity of 0.93 was selected for band N.

\section{March 2002 Campaign}

The ground truth campaign was conducted during the period of March 4-7, 2002. In this period, March 4 was used primarily for reflectance measurements. Unfortunately, March 4 was the only clear day in this period. Emissivity measurements and temperatures were conducted during March 5-6. Variable cloud coverage made it difficult to truly assess temperature retrievals at the calibration site with MTI imagery. On March 4, the temperature retrieved with band $\mathrm{N}$, and with an emissivity of 0.93 was $297.3 \mathrm{~K}$. The temperature measured on the ground on March 6 under variable cloud coverage was $292.5 \mathrm{~K}$.

The band N calculated average emissivity at the ground level with the FTIR on March 6 was 0.922 . The March emissivity value for band $\mathrm{N}$ is very close to the emissivity values measured on the other campaings. The shape of the emissivity measured at the March site is also very similar to the emissivities measured during the July and September 2000 campaigns. Figures 3.49 through 3.51 shows the emissivity images for bands K, L, and M, respectively. 


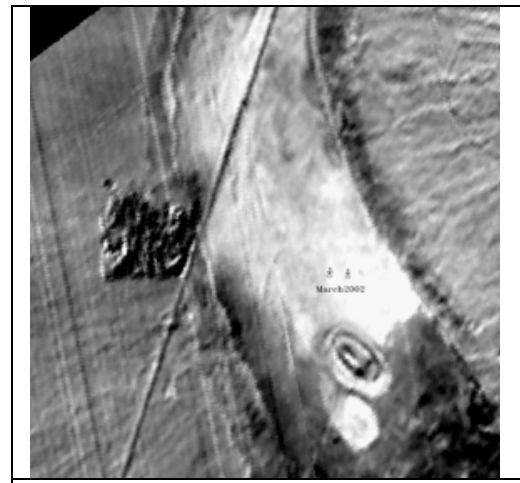

Figure 3.49 shows band K emissivity image for the March 2002 campaign.

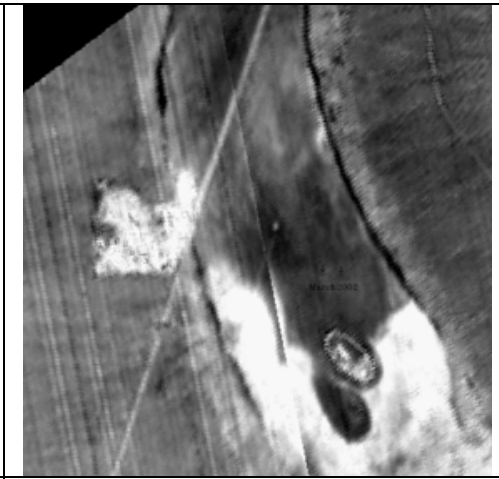

Figure 3.50 shows band L emissivity image for the March 2002 campaign.

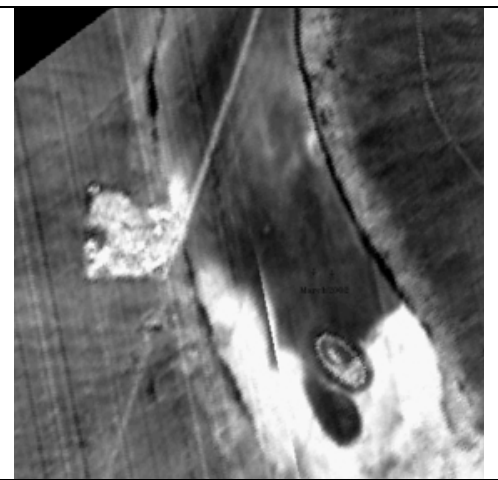

Figure 3.51 shows band $\mathrm{M}$ emissivity image for the March 2002 campaign.

\section{Thermal Campaigns Summary}

Four campaigns were conducted at Ivanpah Playa. The campaigns combined the visible, near-infrared and infrared regions of the electromagnetic spectrum. The Fourier transform infrared spectrometer was the primary instrument for the measurement of temperature and emissivity at the calibration sites. The mobile heated cone radiometer was used to confirm the soil surface temperature calculated with the FTIR. Spatial and temporal analysis of soil surface temperature was characterized with a variety of instruments that included infrared imaging radiometers, and point radiometers. The surface emissivity was identified to belong to desert varnish and quartz. The ratio of these two components was approximately the same for the July and September 2000 and March 2002. The quart component emissivity was missing from the emissivity measured during the May 2001 campaign. The data suggest that the quartz component was washed away with the winter rains prior to the May 2001 campaign. The emissivity in the spectral region of band $\mathrm{N}$ was almost constant during the campaigns. A constant emissivity of $0.93 \pm 0.01$ was used for temperature calculations from space.

Satellite imagery of Ivanpah Playa was reviewed and compared with ground truth temperatures and emissivity. Satellite data was available during the September 2000, May 2001 and March 2002 campaigns. Scatter plots were calculated from different reflectance bands and thermal bands. In contrast to bands $\mathrm{L}$ and $\mathrm{M}$, visible and TOA band $\mathrm{N}$ radiance show an inverse relationship. The bands $\mathrm{L}$ and $\mathrm{M}$ were shown to have two components in the playa. Band $\mathrm{N}$ with an average emissivity of 0.93 was used to calculate ground temperatures. The temperatures calculated from satellite imagery and with the FTIR agreed within 1K for the September 2000 and May 2001 campaigns. Ground truth temperature measurements were not conducted on the only clear day of the March campaign, therefore, temperature comparison between the satellite and ground truth was not available. 
Emissivity images for the different thermal bands were conducted for the different campaigns. The emissivities across the playa follow many of the changes observed in the visible images. A large change in the visible and infrared images was observed during the September 2000 and May 2001 campaigns. A small change was observed during the transition between May 2001 and March 2002 campaigns.

\section{$\underline{\text { References }}$}

1. Kurtis Thome, "Vicarious Calibration of the Multispectral Thermal Imager Proposal to Savannah River Technical Center", (1999).

2. Kurtis Thome, "Calibration of MTI at Ivanpah Playa, California on September 15 and 16, 2000", (2000).

3. B. Lance O'Steen, Eliel Villa-Aleman, "Measurement of Ivanpah Reflectivity in the Visible \& Near IR with ASD Spectroradiometer", Multispectral Thermal Imager Symposium, (2001).

4. Eliel Villa-Aleman, "Thermal Calibration of MTI at Ivanpah Playa", Multispectral Thermal Imager Symposium (2001).

5. Eliel Villa-Aleman, Alfred J. Garrett, Robert J. Kurzeja, Byron L. O'Steen, and Malcolm M. Pendergast, "Thermal targets for satellite calibration", in Thermosense XXIII, Proceedings of SPIE Vol. 4360, pp. 427-437, (2001).

6. Eliel Villa-Aleman, Robert J. Kurzeja, and Malcolm M. Pendergast, "MTI thermal bands calibration at Ivanpah Playa with a Fourier transform infrared spectrometer", in Imaging Spectrometry VII, Proceedings of SPIE Vol. 4480, pp. 295-306, (2002).

7. Eliel Villa-Aleman, "Performance analysis of conical cavities for surface temperature retrieval with a Fourier transform infrared spectrometer", in Thermosense XXIV, Proceedings of SPIE Vol. 4710, pp. 21-30, (2002).

\section{$\underline{\text { Author Contact Information: }}$}

Eliel Villa-Aleman
Nonproliferation Technologies Section
Savannah River Technology Center
Bldg. 735A, Rm. 116
Aiken, SC 29808
Phone: 803-725-0849
Email: eliel.villa-aleman@ srs.gov




\section{Distribution}

A.L. Boni, 773-A

A.J. Garrett, 773-A

J.E. Halverson, 735-A

R.J. Kurzeja, 773-A

Radiometric Group files (5), 735-A 